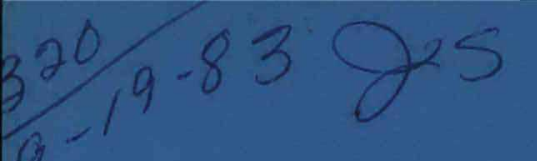

D. $.1771-x$

\title{
$I-11210$
}

RFP-3510

UC -60

\section{SEACC: THE SYSTEMS ENGINEERING AND ANALYSIS COMPUTER CODE FOR SMALL WIND SYSTEMS}

March 1983

\author{
P.K.C. Tu \\ V. Kertesz
}

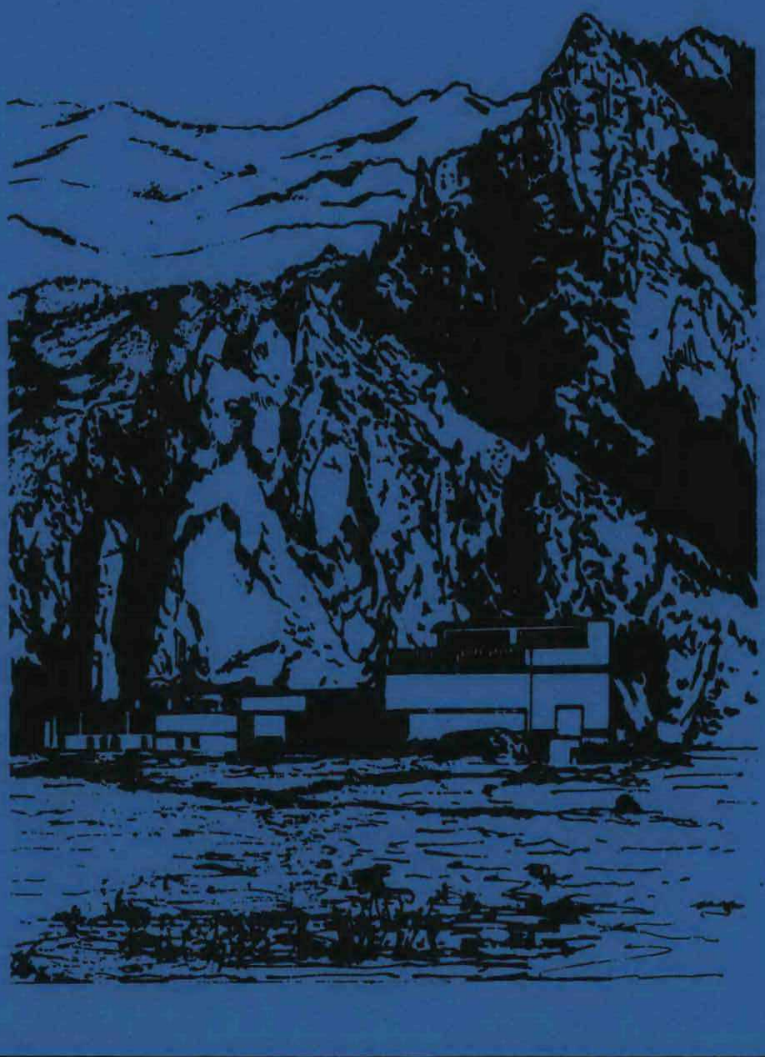

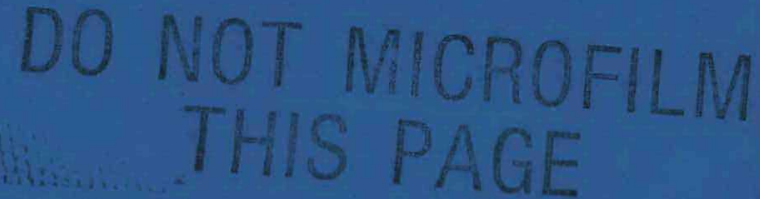

Prepared by

Rockwell International Corporation Energy Systems Group

Rocky Flats Plant

Wind Energy Research Center

Golden, Colorado 80402

As a part of the

UNITED STATES DEPARTMENT OF ENERGY

WIND ENERGY TECHNOLOGY DIVISION

FEDERAL WIND ENERGY PROGRAM

Contract No. DE-AC04-76DP03533

MASTER 


\section{DISCLAIMER}

This report was prepared as an account of work sponsored by an agency of the United States Government. Neither the United States Government nor any agency Thereof, nor any of their employees, makes any warranty, express or implied, or assumes any legal liability or responsibility for the accuracy, completeness, or usefulness of any information, apparatus, product, or process disclosed, or represents that its use would not infringe privately owned rights. Reference herein to any specific commercial product, process, or service by trade name, trademark, manufacturer, or otherwise does not necessarily constitute or imply its endorsement, recommendation, or favoring by the United States Government or any agency thereof. The views and opinions of authors expressed herein do not necessarily state or reflect those of the United States Government or any agency thereof. 


\section{DISCLAIMER}

Portions of this document may be illegible in electronic image products. Images are produced from the best available original document. 


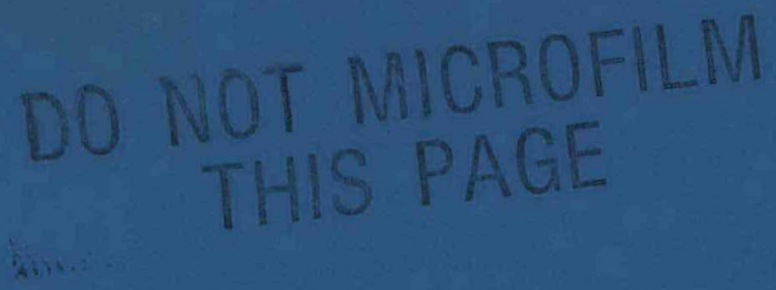

\section{DISCLAIMER}

This report was prepared as an account of work sponsored by the United States Government. Neither the United States nor the United States Department of Energy, nor any of their employees, makes any warranty, express or implied, or assumes any legal liability or responsibility for the accuracy, completeness, or usefulness of any information, apparatus, product, or process disclosed, or represents that its use would not infringe privately owned rights. Reference herein to any specific commercial product, process, or service by trade name, mark, manufacturer, or otherwise, does not necessarily constitute or imply its endorsement, recommendation, or favoring by the United States Government or any agency thereof. The views and opinions of authors expressed herein do not necessarily state or reflect those of the United States Government or any agency thereof.

Printed in the United States of America

Available from

National Technical Information Service

U.S. Department of Commerce

5285 Port Royal Road

Springfield, VA 22161

Printed Copy: A08 Microfiche: A01 
RFP -3510

DE83 017768

\title{
SEACC: THE SYSTEMS ENGINEERING \& ANALYSIS COMPUTER CODE FOR SMALL WIND SYSTEMS
}

\author{
August 1982 \\ P. K. C. Tu \\ V. Kertesz
}

\section{DISCLAIMER}

\begin{abstract}
This report was prepared as an account of work sponsored by an agency of the United States Government. Neither the United States Government nor any agency thereof, nor any of their employees, makes any warranty, express or implied, or assumes any legal liability or responsibility for the accuracy, completeness, or usefulness of any information, apparatus, product, or process disclosed, or represents that its use would not infringe privately owned rights. Reference herein to any specific commercial product, process, or service by trade name, trademark, manufacturer, or otherwise does not necessarily constitute or imply its endorsement, recommendation, or favoring by the United States Government or any agency thereof. The views and opinions of authors expressed herein do not necessarily state or reflect those of the United States Government or any agency thereof.
\end{abstract}

Prepared by

Rockwe 11 International Corporation Energy Systems Group

Rocky Flats Plant

Wind Energy Research Center

Golden, Colorado 80402

As a Part of the

UNITED STATES DEPARTMENT OF ENERGY OFFICE OF SOLAR POWER APPLICATIONS FEDERAL WIND ENERGY PROGRAM

DOE Contract No. DE-ACO4-76DP03533

$$
\text { Metrese }
$$

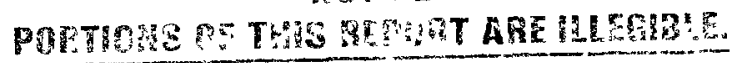

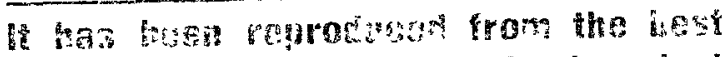

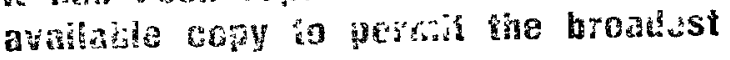


The systems engineering and analysis (SEA) computer program (code) evaluates complete horizontal-axis SWECS performance. Rotor power output as a function of wind speed and energy production at various wind regions are predicted by the code. Efficiencies of components such as gearbox, electric generators, rectifiers, electronic inverters, and batteries can be included in the evaluation process to reflect the complete system performance.

Parametric studies can be carried out for blade design characteristics such as airfoil series, taper rate, twist degrees and pitch setting; and for geometry such as rotor radius, hub radius, number of blades, coning angle, rotor rpm, etc. Design tradeoffs can also be performed to optimize system configurations for constant rpm, constant tip speed ratio and rpm-specific rotors. SWECS energy supply as compared to the load demand for each hour of the day and during each season of the year can be assessed by the code if the diurnal wind and load distributions are known. Also available during each run of the code is blade aerodynamic loading information. 
Page

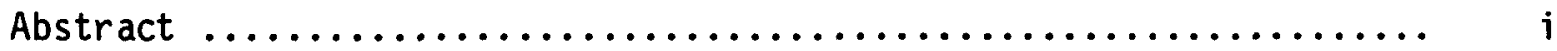

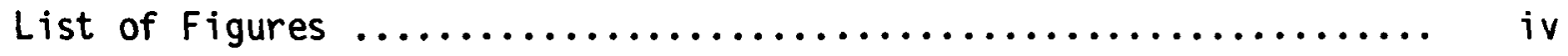

List of Tables $\ldots \ldots \ldots \ldots \ldots \ldots \ldots \ldots \ldots \ldots \ldots \ldots \ldots \ldots \ldots \ldots \ldots \ldots \ldots \ldots$

Nomencl ature $\ldots \ldots \ldots \ldots \ldots \ldots \ldots \ldots \ldots \ldots \ldots \ldots \ldots \ldots \ldots \ldots \ldots \ldots \ldots \ldots$

1. Introduction $\ldots \ldots \ldots \ldots \ldots \ldots \ldots \ldots \ldots \ldots \ldots \ldots \ldots \ldots \ldots \ldots \ldots$

2. Terminology and Equations $\ldots \ldots \ldots \ldots \ldots \ldots \ldots \ldots \ldots \ldots \ldots \ldots \ldots \ldots \ldots \ldots \ldots$

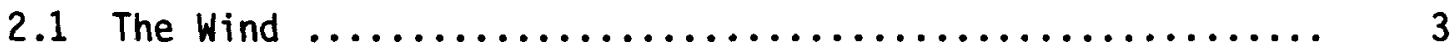

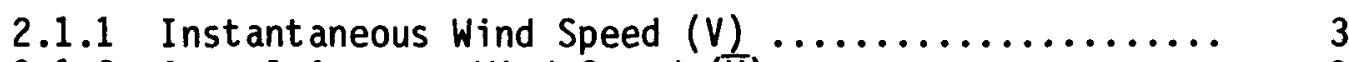

2.1.2 Annual Average Wind Speed $(\bar{V}) \ldots \ldots \ldots \ldots \ldots \ldots \ldots . \ldots \ldots$

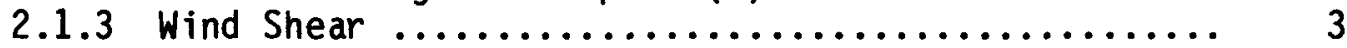

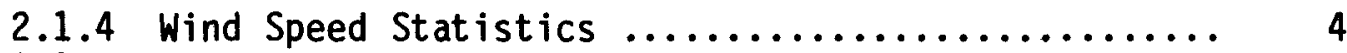

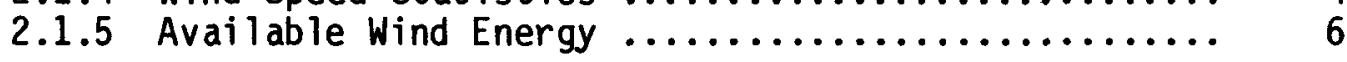

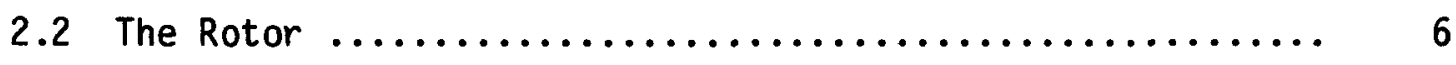

2.2 .1 Blades $\ldots \ldots \ldots \ldots \ldots \ldots \ldots \ldots \ldots \ldots \ldots \ldots \ldots \ldots \ldots \ldots \ldots \ldots \ldots$

2.2.1.1 Airfoil Design ................... 8

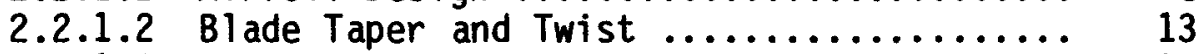

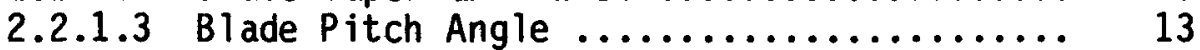

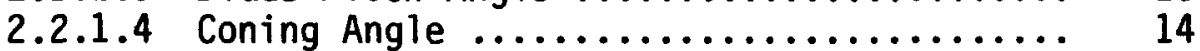

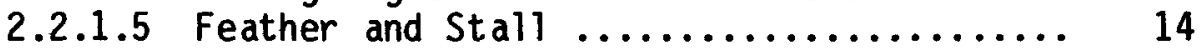

2.2.2 Rotor Force and Velocity ................. 14

2.2.3 Rotor Power Coefficient and Tip Speed Ratio ...... 16

2.3 The Power Train Subsystems ..................... 17

3. Computer Program Description and Flow Charts ............ 20

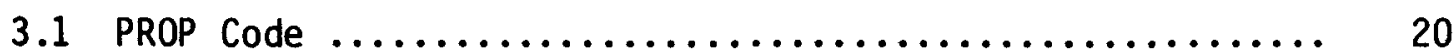

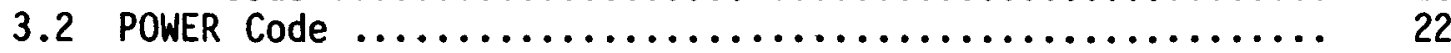

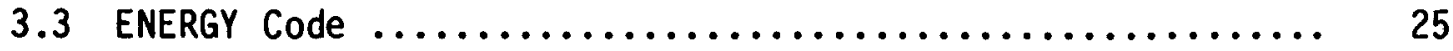




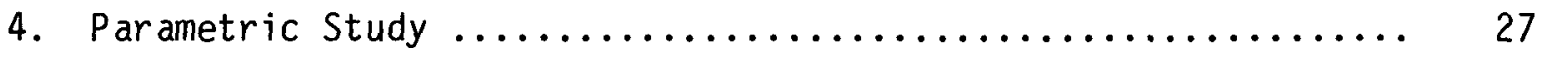

4.1 Case 1 - Blade Pitch Effects ....................... 31

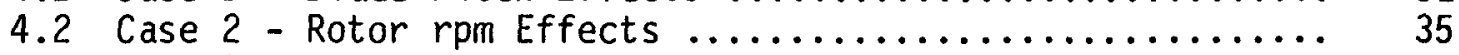

4.3 Case 3 - Constant $\lambda$ Rotor vs. Constant rpm Rotor ........ 35

4.4 Cases 4 and 5 - Power Train Efficiency Effects .......... 38

5. Conclusions and Recommendations $\ldots \ldots \ldots \ldots \ldots \ldots \ldots \ldots, 42$

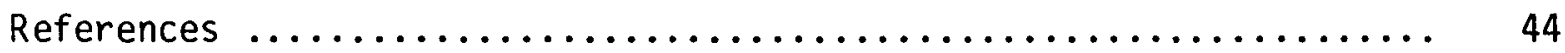

Appendices

Appendix A - User's Manual $\ldots \ldots \ldots \ldots \ldots \ldots \ldots \ldots \ldots \ldots . . . \ldots \ldots$

Appendix B - Establishing Computer Code on Eclipse ......... 78

Appendix C - Computer Code Listing ................... 81 
FIGURES

Figure

Page

1 Typical Measured Diurnal Wind Speed Distributions

by Seasons, (Ref. 9) $\ldots \ldots \ldots \ldots \ldots \ldots \ldots \ldots \ldots \ldots \ldots \ldots \ldots \ldots \ldots \ldots, 7$

2 Airfoil NACA 4415 Test Conditions and Profile Contour (Ref. 11) ..................................... 9

3 Graphical Presentation of $C_{L}$ and $C_{D}$ as a Function of $a^{\circ}$ and Reynolds No. .............................. 11

4 Rotor Force and Velocity Diagram ................... 15

5 Power Train Efficiency of a Constant rpm Rotor SWECS ....... 18

6 Power Train Efficiency of a Constant $\lambda$ Rotor SWECS ........ 18

7 A Summary of the SEA Computer Program With Input and Output Information $. . \ldots \ldots \ldots \ldots \ldots \ldots \ldots \ldots \ldots \ldots \ldots \ldots, 21$

8 The Computer Flow Chart of POWER Code $\ldots . . \ldots \ldots \ldots \ldots . . . .23$

9 The Computer Flow Chart of the ENERGY Code $\ldots \ldots \ldots \ldots \ldots . . .26$

10 Rotor Power Coefficient Characteristics as Affected by Variation of Pitch Angle Ranging from $+15^{\circ}$ to $3^{\circ} \ldots \ldots . \quad 32$

11 Rotor Power Coefficient Characteristics as Affected by Variation of Pitch Angle Ranging from $2^{\circ}$ to $-2^{\circ} \ldots \ldots \ldots .32$

12 Pitch Angle Effects on Rotor Power for $\angle \theta^{\circ}=15^{\circ}$ to $3^{\circ} \ldots .33$

13 Pitch Angle Effects on Rotor Power for $\angle \theta^{\circ}=2^{\circ}$ to $-2^{\circ} \ldots . \quad 33$

14 Pitch Angle Effects on Rotor Energy Production for

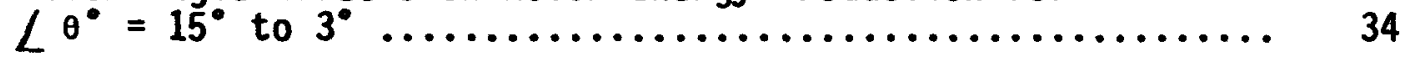

15 Pitch Angle Effects on Rotor Energy Production for

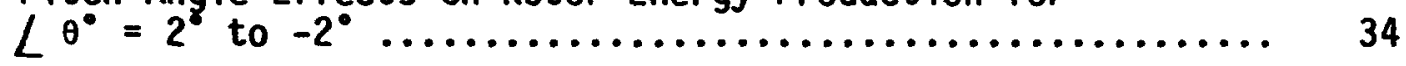

16 The Optimum $C_{p}$ Curve Used for a Constant rpm Rotor

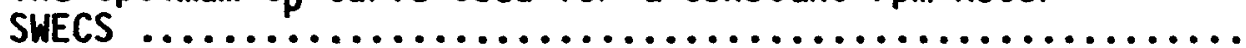




\section{FIGURES - contd.}

Figure $\quad \underline{\text { Page }}$

17 Rotor rpm Effect on the Power Output $\ldots \ldots \ldots \ldots \ldots \ldots \ldots . . . \ldots . .36$

18 Rotor Energy Production as a Function of $\bar{V}$ and $r p m \ldots \ldots .37$

19 Power Curve of a Constant rpm Rotor and a Constant $\lambda$

Rotor at Two Different Maximum Power Levels ............. 39

20 Rotor Energy Production Comparison Between a Constant rpm Rotor and a Constant $\lambda$ Rotor SWECS .................. 39

21 Final System Energy Production Comparison Between a Constant rpm Rotor and a Constant $\lambda$ Rotor SWECS ........... 41 


\section{TABLES}

Table

$\underline{\text { Page }}$

1 Airfoil NACA 4415 Section Coordinates (Reference 11) ..... 10

2 Tabulated Lift and Drag Coefficients as a Function of Angle of Attack and Reynolds Number (Ref. 11) ........... 12

3 Configuration of Model SWECS $\ldots \ldots \ldots \ldots \ldots \ldots \ldots \ldots \ldots \ldots$

4 A Summary of the Variables Used in the Parametric Study .... 29

5 Airfoil Data of Series NACA 0012 at a Reynolds Number

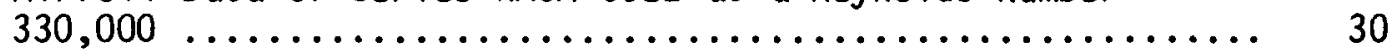




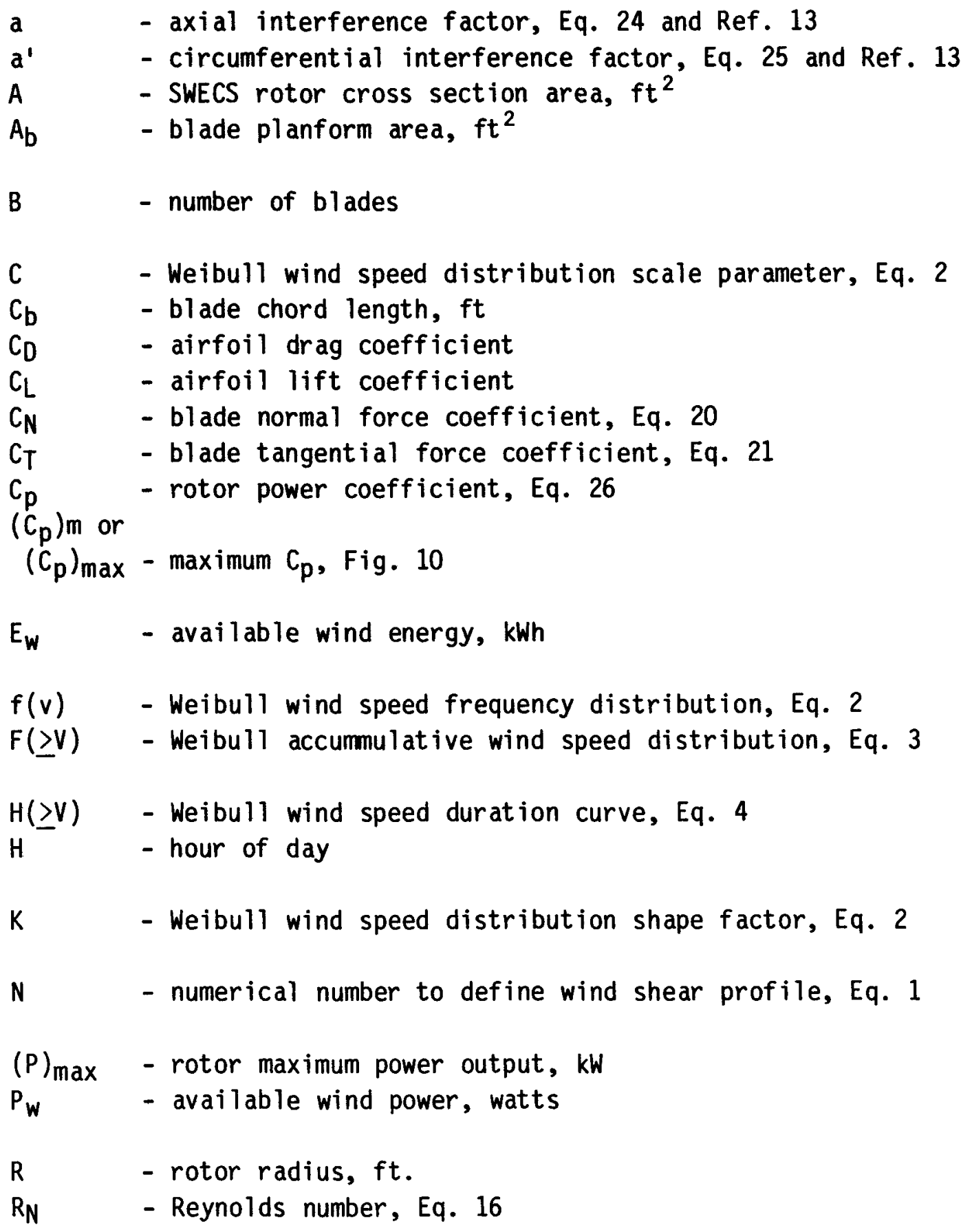


NOMENCLATURE - Contd.

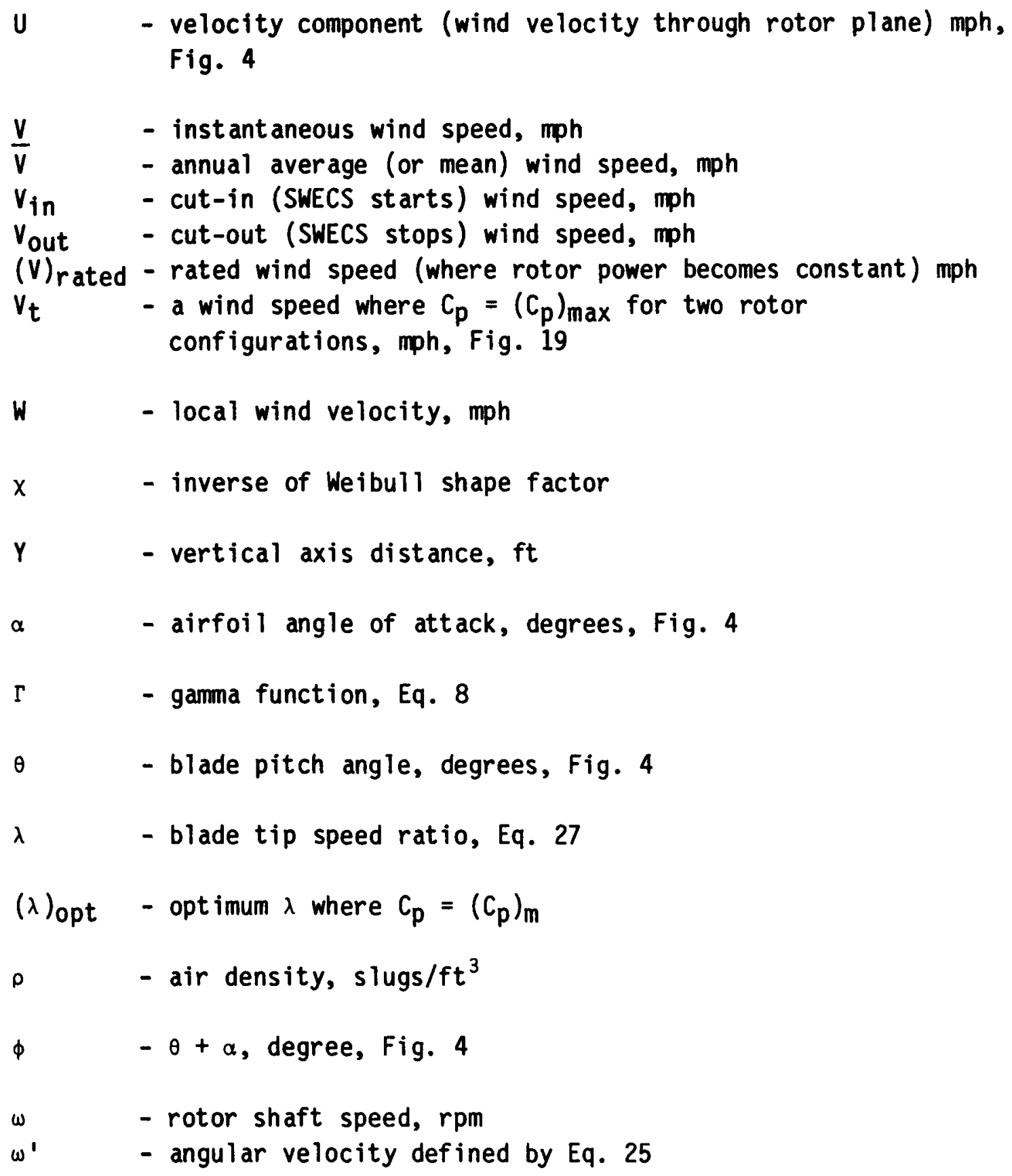

ix 


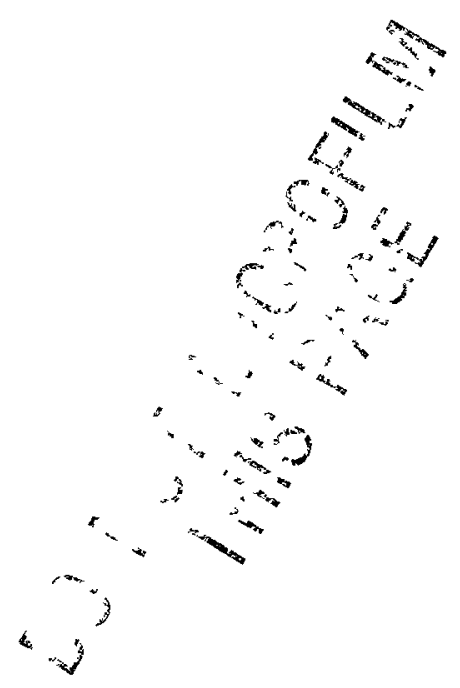




\section{INTRODUCTION}

Since 1976, the Rocky Flats Wind Systems Program, in its role of providing technical and management support to the Department of Energy, has established goals of assisting private industry through the research and development of small wind energy conversion systems (SWECS) and associated technologies. During the course of developing SWECS, it was found that system parametric tradeoffs and configuration optimization were necessary during preliminary system engineering and analysis, and that such a procedure was difficult and tedious without the aid of a computer. It was also felt that a SWECS performance model should be developed as a research tool for in-house R\&D projects. Therefore an effort to establish a system engineering and analysis computer code (SEACC) was put forward by the author with the following goals in mind:

1. Develop a viable SWECS performance model so that rotor/power and energy output can be accurately predicted from basic airfoil data and rotor geometry.

2. Include as many variables in configurations and wind characteristics as possible so that a thorough parametric study can be carried out.

3. Conduct system design tradeoff evaluations for such features as constant rpm, constant tip-speed ratio, and rpm-specific rotors (Ref. 1-5).

4. Carry out studies of power train efficiency influence on SWECS power and energy output, and the energy supply versus demand mismatch for potential applications.

The SEACC was first developed in Fortran on a CDC 720 computer. The code was later transferred to a Data General "Eclipse" computer. The two versions of code are not interchangable (i.e., one can not be run on the machine used for the other). The version utilizing the Data General machine is listed in Appendix A. 
This report is intended as a brief description and outline of basic terminology, theoretical equations, input and output files, and options for various design features. A limited parametric study is presented for illustration purposes. A user's manual and a complete listing of the program are included in the appendices. 


\section{TERMINOLOGY AND EQUATIONS}

The terminology and equations which are relevant and important to the SEA program are introduced in this section. Some theoretical material has been omitted because it can be found in the references listed.

\subsection{THE WIND}

\subsubsection{Instantaneous Wind Speed (V)}

This is the horizontal instantaneous wind speed measured by an anemometer and expressed in miles per hour (mph). The Rocky Flats data collection system samples the wind data every 15 seconds. Therefore, $V$ is defined as the average value of 15 seconds. However, this averaging method may vary with test systems or projects. Neither instantaneous wind turbulence nor wind gusting is considered in the analysis.

\subsubsection{Annual Average Wind Speed $(\bar{V})$}

This is the average value of $V$ for a year at an elevation of 10 meters (30 ft) from the ground. If $\bar{V}$ is measured at a height other than 10 meters, it should be interpolated (or extrapolated) by a power-law equation (see 2.1.3) to represent the wind site.

\subsubsection{Wind Shear}

A power-law equation is used to express the wind shear along the vertical axis, such as:

$$
\frac{V(\text { or } \bar{V})}{[V(\text { or } \bar{V})]_{\text {ref. }}}=\left(\frac{Y}{Y_{\text {ref }}}\right)^{1 / N}
$$


where:

$Y$ is the distance from the ground.

$N=7$ is used in the SEACC based on the classic velocity profile of a turbulent boundary layer in a smooth pipe. When the site wind shear profile is known, "N" should be derived from the profile and used in the analysis.

\subsubsection{Wind Speed Statistics}

The Weibull wind speed frequency distribution is used in SEA:

$$
f(v)=\frac{K}{c}\left(\frac{v}{c}\right)^{K-1} e^{-\left(\frac{v}{c}\right)^{K}}
$$

where:

$K$ is the distribution dispersion parameter, $C$ is the scale parameter of the annual average wind speed $(\bar{V})$.

$f(V)$ is also called the probability density function.

The accumulative wind speed distribution curve is given as:

$$
F(\underline{v V})=\int_{V}^{\infty} f(V) d V=\left[1-e^{-\left(\frac{V}{C}\right)^{K}}\right]_{y}^{\infty}=e^{-\left(\frac{V}{C}\right)^{K}}
$$

The wind speed duration curve is defined as when the $F(\geq V)$ is expressed in hours per year. That is:

$$
H(\geq V)=8766 \cdot F(\geq V)
$$




$$
V \text { or } H(\underline{V})=8766 \cdot e^{-\left(\frac{V}{C}\right)^{K}}
$$

The annual wind speed $(\bar{V})$ and the Weibull scale parameter (C) are related as (Ref. 6):

$$
\bar{V}=\operatorname{C} \Gamma(1+1 / K)
$$

$\Gamma(1+1 / K)$ is a Gamma function (Ref. 7$)$ and $c$ an be expressed as:

$$
\Gamma(1+1 / K)=\Gamma(1+x)=x \Gamma(x)
$$

where $x=1 / K$, and

$$
\Gamma(x)=\int_{0}^{\infty} u^{(x-1)} e^{-u} d u, x>0
$$

An asymptotic series is used to express $\Gamma(x)$, such as:

$$
\Gamma(x) \approx x^{x} e^{-x} \frac{2 \pi}{x}\left(1+\frac{1}{12 x}+\frac{1}{288 x^{2}}-\frac{139}{51840 x^{3}} \ldots .\right)
$$

It was pointed out in Reference 6 that $C$ and $\bar{V}$ are very nearly proportional since for $1.5<K<3.2$ the $C / \bar{V}$ ratio varies only between 1.11 and 1.13. The reader can simplify the computation by using the relation:

$$
C=1.12 \bar{V}
$$

The computer program provided an option in choosing a wind speed distribution curve used by the NASA-Lewis Research Center, which defined $K=2.27$ (Ref. 8). This is very close to the Rayleigh Distribution which defines $K=2.0$. 
Diurnal (hourly) wind distribution data on the American continent was published in Reference 9. A typical distribution is shown in Figure 1 in which seasonal changes in the distribution are indicated. This kind of data is needed in the energy supply/demand mismatch estimate.

\subsubsection{Available Wind Energy}

The power produced by wind speed $V$ across an area $A$ is given as the following:

$$
P_{W}=\frac{1}{2} \rho V^{3} A \text {, watts }
$$

where:

$\rho$ is the air density, $\mathrm{kg} / \mathrm{m}^{3}$
$V$ is the wind speed, $\mathrm{m} / \mathrm{sec}$
$A$ is the cross section area, $\mathrm{m}^{2}$

The available wind energy is defined as:

$$
E_{W}=\frac{1}{1000} \int_{0}^{\infty} P_{W} \cdot f(V) d V, k W h \text { (kilowatt-hour) }
$$

For British units, where $\rho$ is in slugs $/ \mathrm{ft}^{3}, V$ is in $\mathrm{ft} / \mathrm{sec}$ and $A$ is in $f t^{2}$, Equation 11 becomes:

$$
P_{W}=0.678 \rho V^{3} A \text {, watts }
$$

\subsection{THE ROTOR}

The rotor commonly consists of blades, hub, and blade pitch control devices. There are downwind rotors and upwind rotors. A downwind rotor is defined as a rotor that operates behind the tower with respect to the 

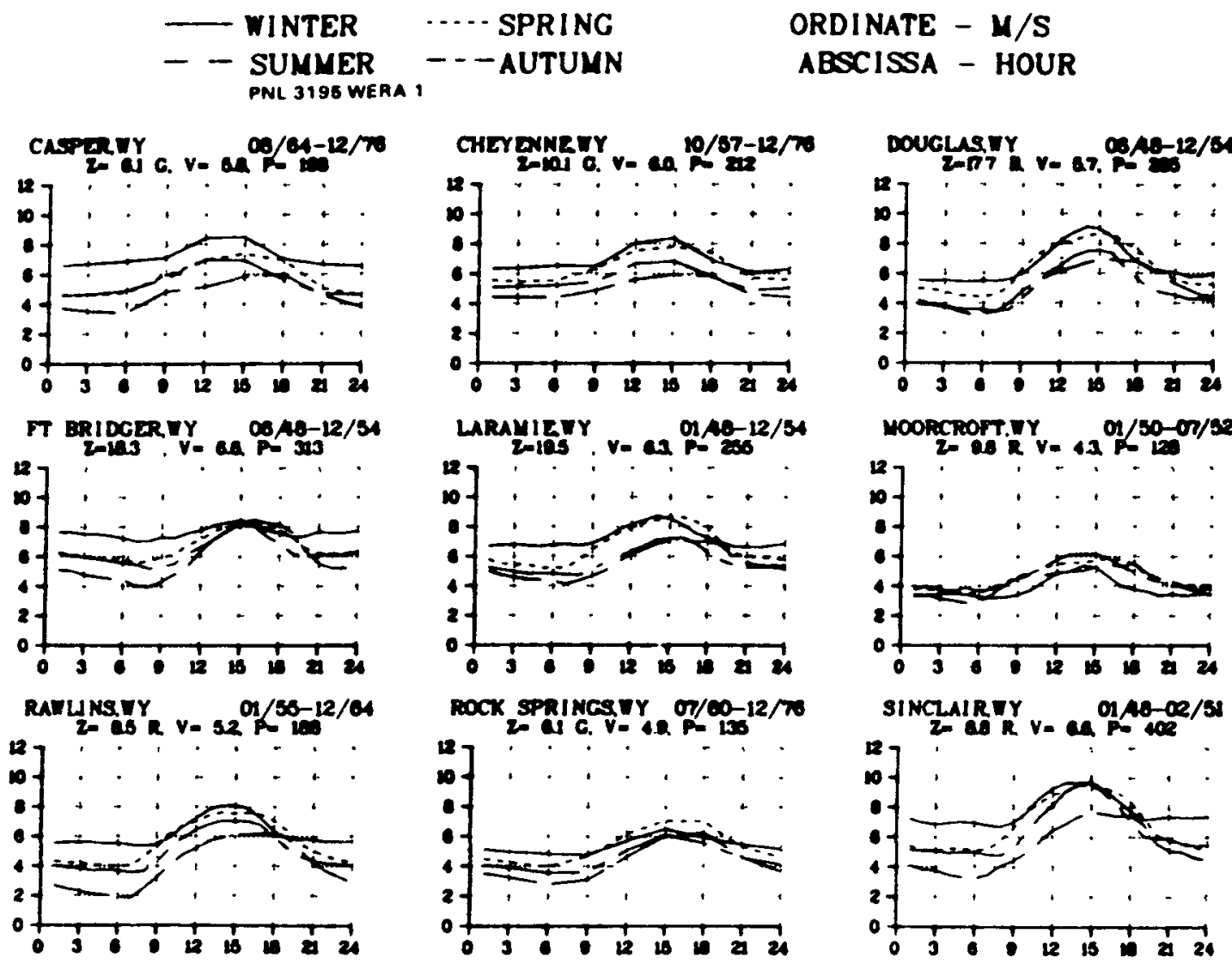

Figure 1

Typical Measured Diurnal Wind Speed Distributions by Season (Ref. 9) 
incoming wind. This section offers a brief explanation of how rotor elements are represented in the SEACC.

\subsubsection{Blades}

Blade configurations being considered by this analys is include airfoil design, taper and twist, pitch angle, coning angle, and feather and stall.

\subsubsection{Airfoil Design}

Various performance characteristics data of airfoil design can be found in References 10 and 11. As an example, airfoil series NACA 4415 (Ref. 11) is shown in Figure 2 and Table 1 and its aerodynamic lift and drag coefficients $\left(C_{L}\right.$ and $\left.C_{D}\right)$ as a function of angles of attack $\left(\alpha^{\circ}\right)$ is shown in Figure 3 . The lift and drag coefficients are defined as:

$$
\begin{aligned}
& C_{L}=1 \text { ift force } /\left(1 / 2 \rho V^{2} A_{b}\right) \\
& C_{D}=\operatorname{drag} \text { force } /\left(1 / 2 \rho V^{2} A_{b}\right)
\end{aligned}
$$

where:

$A_{b}$ is defined as the blade planform area which is the product of the chord length and the lateral span of the blade (Ref. 11).

The angle of attack $\left(\alpha^{\circ}\right)$ is defined as the angle between the direction of the wind and the airfoil chord line.

Reference 11 also tabulated the $C_{L}$ and $C_{D}$ as a function of $\alpha^{\circ}$ and Reynolds number as shown in Table 2 for the NACA 4415 series. Values listed in Table 2 can be used directly as an input file data for SEACC.

The Reynolds number $\left(R_{N}\right)$ of the rotor blade at .75R should be calculated and used to determine appropriate airfoil data values. In general terms $R_{N}$ is defined as: 
NACA 4415

Reference: (A2)

Wind Tunnel: NACA VDT

Date: 1937

Type of Test: Three-Dimensional

Wind Tunnel Turbulence: 2.0\%

Airfoil Surface: Smooth

Reynolds Number: $4.2 \times 10^{4}-3.0 \times 10^{6}$

Reference: (A3)

Wind Tunnel: NACA LTT

Date: 1945

Type of Test: Two-Dimensional

Wind Tunnel Turbulence: $0.03 \%$

Airfoil Surface: Smooth

Reynolds Number: $7.0 \times 10^{5}-3.0 \times 10^{6}$

Airfoil Surface: Rough

Reynolds Number: $7.0 \times 10^{5}-2.0 \times 10^{6}$

Reference: (A4)

Wind Tunnel: IAG Stuttgart \#1

Date: 1962-1972

Type of Test: Two-Dimensional

Wind Tunnel Turbulence: $0.02 \%$

Airfoil Surface: Smooth

Reynolds Number: $7.0 \times 10^{5}-3.0 \times 10^{6}$

Figure 2

Airfoil NACA 4415 Test Conditions and Profile Contour (Ref. 11) 
TABLE 1

AIRFOIL NACA 4415 SECTION COORDINATES (Reference 11)

NACA 4415

$\begin{array}{cc}\text { X(upper) } & Y \text { (upper) } \\ .00000 & .00000 \\ .01250 & .03070 \\ .02500 & .04170 \\ .05000 & .05740 \\ .07500 & .06910 \\ .10000 & .07840 \\ .15000 & .09270 \\ .20000 & .10250 \\ .25000 & .10920 \\ .30000 & .11250 \\ .40000 & .11250 \\ .50000 & .10530 \\ .60000 & .09300 \\ .70000 & .07630 \\ .80000 & .05550 \\ .90000 & .03080 \\ .95000 & .01670 \\ 1.00000 & .00000\end{array}$

$X, Y$ Coordinates

$\begin{array}{cc}X \text { (lower) } & \text { Y( lower) } \\ .00000 & .00000 \\ .01250 & -.01790 \\ .02500 & -.02480 \\ .05000 & -.03270 \\ .07500 & -.03710 \\ .10000 & -.03980 \\ .15000 & -.04180 \\ .20000 & -.04150 \\ .25000 & -.03980 \\ .30000 & -.03750 \\ .40000 & -.03250 \\ .50000 & -.02720 \\ .60000 & -.02140 \\ .70000 & -.01550 \\ .80000 & -.01030 \\ .90000 & -.00570 \\ .95000 & -.00360 \\ 1.00000 & .00000\end{array}$

leading edge radius $=2.48$

slope of radius $\quad=0.20$ 
NACA 4415 Airfoil

Reynolds Number

$4.2 \times 10^{4}$

$8.3 \times 10^{4}$

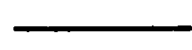

$1.6 \times 10^{5}$

.

$3.3 \times 10^{5}$

Test:

3-D

Test Conditions

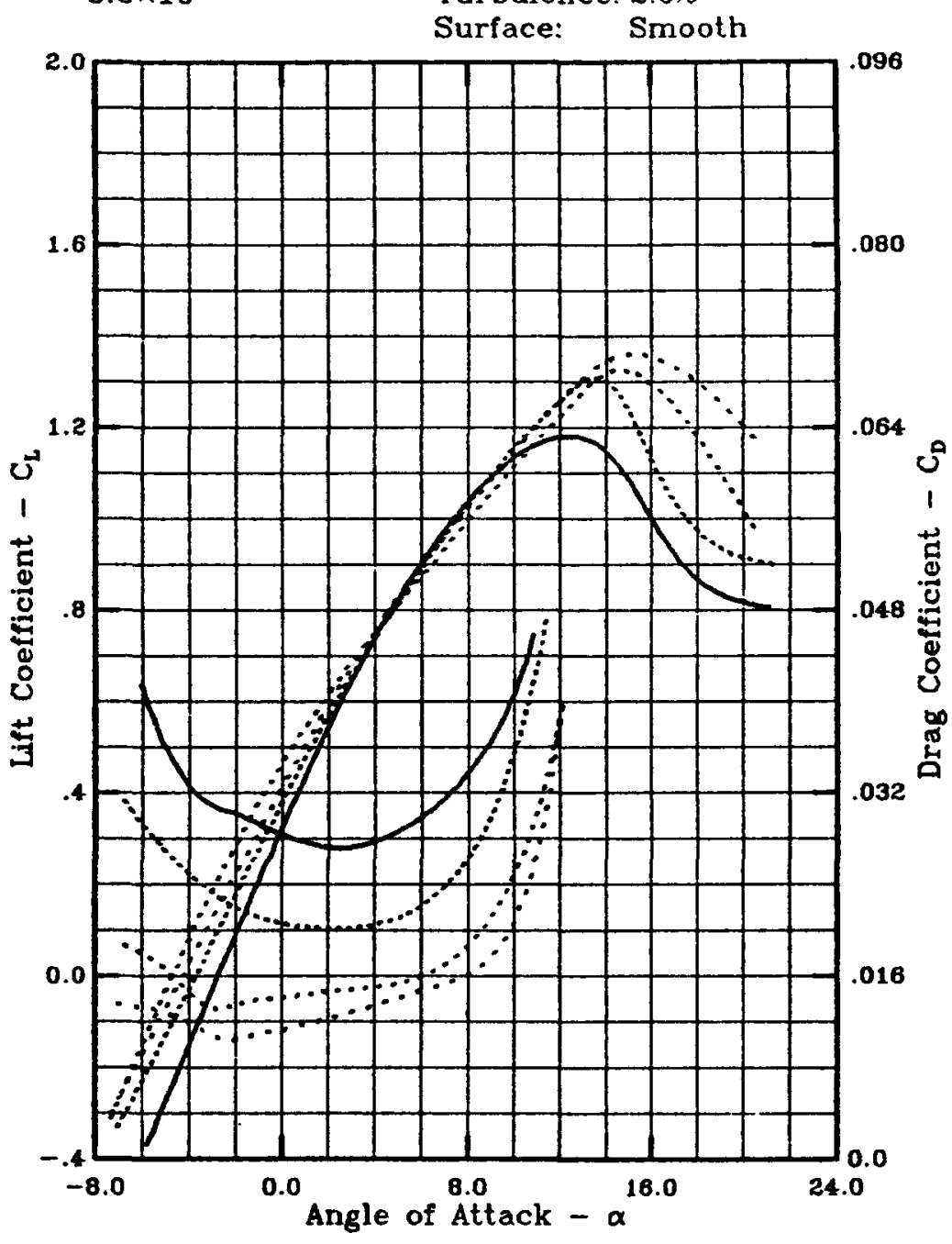

Figure 3

Graphical Presentation of $C_{L}$ and $C_{D}$ as a Function of $\alpha^{\circ}$ and Reynolds No. 
TABLE 2

TABULATED LIFT AND DRAG COEFFICIENTS AS A FUNCTION OF ANGLE OF ATTACK AND REYNOLDS NUMBER (REF. 11)

NACA 4415

Tunnel: NACA VDT / Date: 1937 / Test: 3-D / Turbulence: 2.0\% / Surface: Smooth

\begin{tabular}{|c|c|c|c|c|c|c|c|c|c|c|c|c|}
\hline RN & \multicolumn{2}{|c|}{$4.2 \times 10^{4}$} & \multicolumn{2}{|c|}{$8.3 \times 10^{4}$} & \multicolumn{2}{|c|}{$1.6 \times 10^{5}$} & \multicolumn{3}{|c|}{$3.3 \times 10^{5}$} & \multicolumn{3}{|c|}{$6.5 \times 10^{5}$} \\
\hline$A O A$ & $\mathrm{CL}$ & $C D$ & $\mathrm{CL}$ & $C D$ & $\mathrm{CL}$ & CD & $\mathrm{CL}$ & $C D$ & $C M$ & $\mathrm{CL}$ & CD & $C M$ \\
\hline-7.0 & 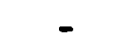 & 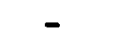 & -.33 & - & -.28 & 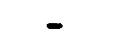 & -.27 & .0160 & & -.31 & - & 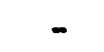 \\
\hline-6.0 & -.40 & .0485 & -.23 & .0346 & -.15 & .0213 & -.17 & .0157 & -.10 & -.20 & .0143 & 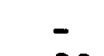 \\
\hline-5.0 & -.27 & .0425 & -.13 & .0318 & -.03 & .0196 & -.07 & .0151 & -.10 & -.09 & .0134 & -.09 \\
\hline-4.0 & -.15 & .0385 & -.03 & .0295 & .08 & .0172 & .03 & .0141 & -.10 & .02 & .0128 & -.09 \\
\hline-3.0 & -.03 & .0364 & .07 & .0275 & .19 & .0155 & .13 & .0128 & -.10 & .13 & .0125 & -.09 \\
\hline & .09 & .0356 & .18 & .0259 & .29 & .0159 & .22 & .0124 & -.10 & .24 & .0123 & -.10 \\
\hline 1. & .21 & .0345 & .28 & .0250 & .38 & .0164 & .32 & .0129 & -.10 & .35 & .0121 & -.09 \\
\hline 1 & .32 & $\begin{array}{r}.0335 \\
0327\end{array}$ & .38 & .0244 & .47 & .0166 & .41 & $\begin{array}{r}.0134 \\
\end{array}$ & -.10 & .4 & .0119 & $\begin{array}{r}-.09 \\
00\end{array}$ \\
\hline 2. & $\begin{array}{r}.44 \\
.54\end{array}$ & $\begin{array}{l}.0321 \\
.0322\end{array}$ & $\begin{array}{l}.48 \\
.57\end{array}$ & $\begin{array}{l}.0240 \\
.0239\end{array}$ & .62 & $\begin{array}{l}.0170 \\
.0173\end{array}$ & 59 & .0 & $\begin{array}{l}-.10 \\
-.10\end{array}$ & .66 & .0 & $\begin{array}{r}.09 \\
.09\end{array}$ \\
\hline 3.0 & .64 & .0322 & .66 & .0239 & .68 & .0175 & .68 & .0152 & -.1 & .75 & .0120 & -.09 \\
\hline 4.0 & .74 & .0328 & .74 & .0242 & .7 & .0177 & .7 & .0159 & -.10 & .8 & .0125 & -.09 \\
\hline 5.0 & .82 & .0338 & .82 & .0249 & .81 & .0181 & .8 & .0166 & -.10 & .91 & .0135 & -.09 \\
\hline 6. & $\begin{array}{r}90 \\
07\end{array}$ & $\begin{array}{r}.0352 \\
0372\end{array}$ & .89 & .0262 & .8 & .01 & 90 & .0 & - & & .0 & -.10 \\
\hline & $\begin{array}{l}.91 \\
.04\end{array}$ & .03 & $\begin{array}{r}.96 \\
1.03\end{array}$ & $\begin{array}{l}.0281 \\
.0311\end{array}$ & $\begin{array}{r}.94 \\
1.00\end{array}$ & $\begin{array}{l}.0201 \\
.0221\end{array}$ & 03 & .0181 & -1 & $\begin{array}{l}1.05 \\
1.11\end{array}$ & .0166 & $\begin{array}{l}10 \\
10\end{array}$ \\
\hline 9. & 1.09 & .0431 & 1.09 & .0354 & 1.06 & .0250 & 1.09 & .0209 & -.10 & 1.16 & .0221 & -.11 \\
\hline 10 & 1.13 & .0479 & 1.15 & .0417 & 1.11 & .0293 & 1.1 & .0245 & -.10 & 1.21 & .0262 & -.11 \\
\hline 11 & 1.16 & .0552 & 1.21 & .0507 & 1.17 & .0356 & 1.20 & .0316 & -.11 & 1.26 & .0317 & -.12 \\
\hline & 1.18 & - & 1.26 & - & 1.22 & .0450 & & .0452 & -.12 & 1.30 & .0394 & -.12 \\
\hline 13 & 1.18 & - & 1.30 & - & 1.28 & - & & - & -.12 & 1.3 & - & -.12 \\
\hline 14 & 1.15 & - & 1.30 & - & 1.32 & - & 1.35 & - &.- & 1.37 & - & -.13 \\
\hline 15 & 1.09 & - & 1.24 & - & 1.32 & - & 1.36 & - & -.14 & 1.40 & - & -.13 \\
\hline 16 & 1.00 & - & 1.13 & - & 1.30 & - & 1.35 & - & -.18 & 1.41 & - & -.14 \\
\hline 17 & .92 & - & 1.04 & - & 1.25 & - & 1.33 & - & -.19 & 1.40 & - & -.14 \\
\hline 18 & .87 & - & .97 & - & 1.18 & - & 1.3 & - & -.20 & 1.37 & - & -.14 \\
\hline & .83 & - & .9 & - & 1.10 & - & $?$ & 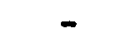 & -.19 & 1.34 & - & .15 \\
\hline & .8 & - & .9 & - & 1.02 & - & 1.21 & _ & 17 & 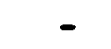 & 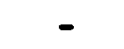 & - \\
\hline 21 & .81 & - & .90 & - & - & - & 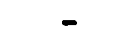 & - & - & - & - & 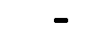 \\
\hline
\end{tabular}




$$
R_{N}=\frac{\text { (velocity) (density) (length) }}{\text { (viscosity) }}
$$

For small wind systems, the following relationships are used to calculate $\mathrm{R}_{\mathrm{N}}$ :

$$
\begin{aligned}
\text { Velocity } & =(.75 \mathrm{R}) \cdot \omega \cdot 2 \pi / 60, \mathrm{ft} / \mathrm{sec} \\
\text { Length } & =\text { chord length at } 75 \% \text { of rotor radius }
\end{aligned}
$$

where:

$$
\begin{aligned}
& R=\text { rotor radius, } \mathrm{ft} \\
& \omega=\text { rotor rotating speed, } \mathrm{rpm}
\end{aligned}
$$

For most small wind systems, $R_{N}$ is below a conventional aircraft's $R_{N}$ by an order of magnitude (see Ref. 11). Since airfoil data is often affected by the Reynolds number, the input data file should include airfoil data measured under those Reynolds numbers which cover the expected operating range.

\subsubsection{Blade Taper and Twist}

The blade taper is defined as the chord length change from blade root to tip. Constant chord (zero taper) blades would reduce manufacturing cost but also give poorer performance than tapered ones. This is also true for untwisted blades. The blade twist is defined as the angular change of the airfoil chord line from root to tip. Theories for optimum blade taper and twist $c$ an be found in Reference 12 .

\subsubsection{Blade Pitch Angle}

This is the angle between the airfoil chord line and the plane of rotation at 75 percent rotor radius section. Positive value is defined as the pitch angles measured towards the wind speed direction. 


\subsubsection{Coning Angle}

This is the angle between the blade span center line and the plane of rotation. Positive value indicates the blades are coned downwind.

\subsubsection{Feather and Stall}

A blade is feathered when the airfoil is parallel to the free wind speed (or the pitch angle is approaching $(+) 90^{\circ}$ ). The opposite of the feathering is defined as stalling (i.e., the pitch angle is greater than the airfoil stall angle).

\subsubsection{Rotor Force and Velocity}

A diagram of rotor force and velocity is shown in Figure 4. Lift force coefficient $\left(C_{L}\right)$ and drag force coefficient $\left(C_{D}\right)$ are produced by the airfoil in a stream $(W)$ at an angle of attack $\alpha^{\circ}$. The pitch angle of the blade is $\theta^{\circ}$. Therefore:

$$
\phi^{\circ}=\theta^{\circ}+\alpha^{\circ}
$$

Normal and tangential force coefficients assuming no coning angle, therefore are defined as:

$$
\begin{aligned}
& C_{N}=C_{L} \cos \phi+C_{D} \sin \phi \\
& C_{T}=C_{L} \sin \phi-C_{D} \cos \phi
\end{aligned}
$$

Rotor torque and thrust are the integral of $C_{N}$ and $C_{T}$ along the blade, respectively:

$$
\text { Thrust }=\int_{0}^{R}\left(B \times C_{b}\right) \times C_{N}\left(1 / 2 \rho W^{2}\right) \times d r
$$


-

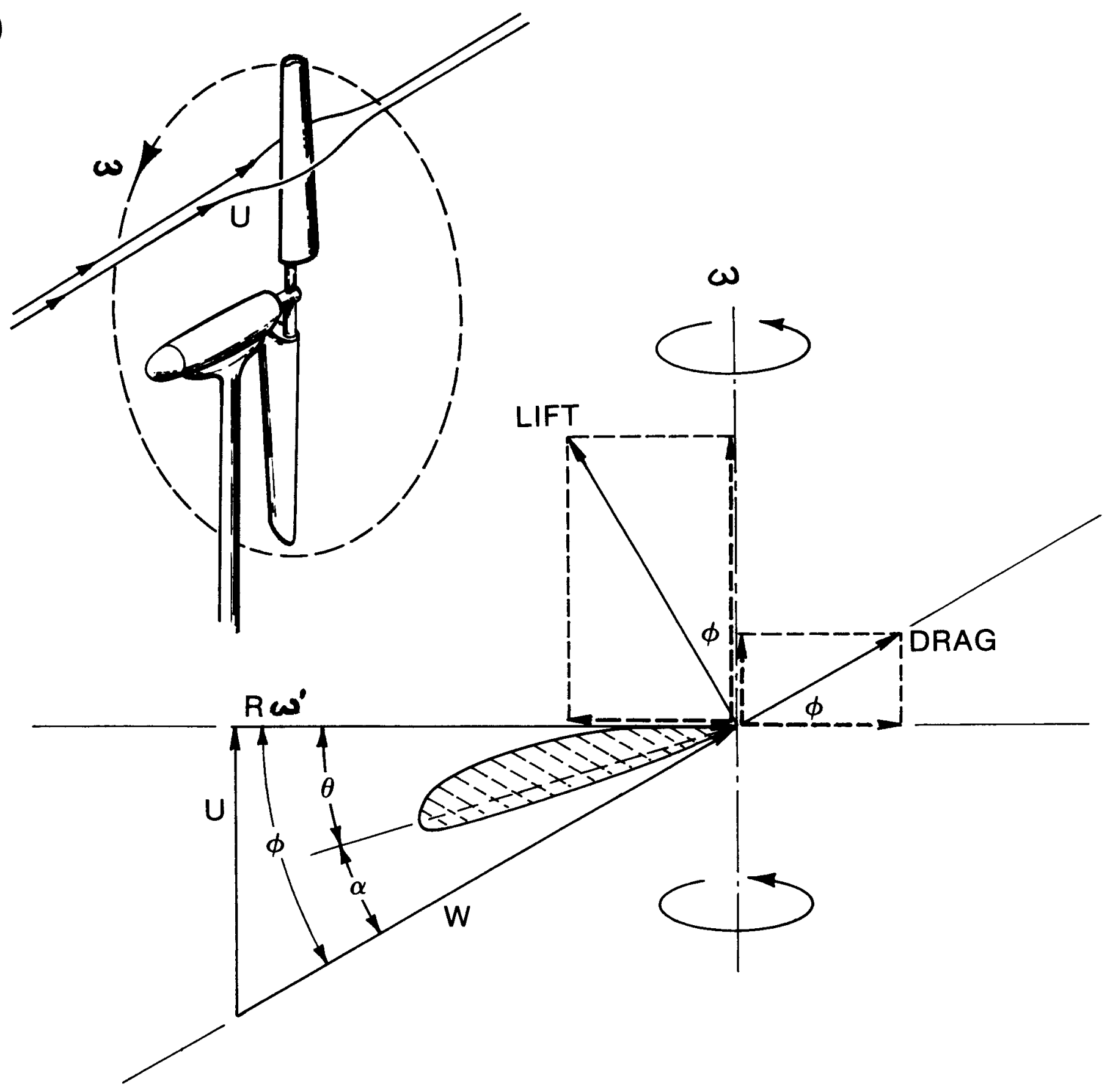

Figure 4

Rotor Force and Velocity Diagram 


$$
\text { Torque }=\int_{0}^{R}\left(B \times C_{b}\right) \cdot C_{T}\left(1 / 2 \rho W^{2}\right) \cdot r d r
$$

where:

$B$ is the number of blades

$C_{b}$ is the blade chord length, $f t$

$W$ is the resultant velocity, $\mathrm{ft} / \mathrm{sec}$

$R$ is the rotor radius, $f t$

$\rho$ is the air density, slugs $/ \mathrm{ft}^{3}$

Velocity component $u$ and $r \omega^{\prime}$ are defined as (Ref. 13):

$$
\begin{aligned}
u & =v(1-a) \\
r \omega^{\prime} & =r \omega\left(1+a^{\prime}\right)
\end{aligned}
$$

where:

$V$ is the free air (wind) speed, $\mathrm{ft} / \mathrm{sec}$

$\omega$ is the rotor shaft speed, rpm

$a$ is the axial interference factor (or axial induction factor) at the plane of the rotor

$a^{\prime}$ is the circumferential interference factor (or angular induction factor) at the rotor $\mathrm{pl}$ ane.

In the SEACC, $a$ and $a^{\prime}$ are solved based on the propeller theory from the PROP computer code (see Section 3.1 for a discussion of this code).

\subsubsection{Rotor Power Coefficient and Tip Speed Ratio}

Rotor power coefficient and rotor tip-speed ratio are defined as:

$$
\begin{aligned}
C_{p} & =\frac{\text { Rotor Power }}{1 / 2 \rho V^{3} A}=\frac{\text { Torque } x \text { (Rotor Speed) }}{1 / 2 \rho V^{3} A} \\
\lambda & =\frac{R \omega}{V}
\end{aligned}
$$

where $\omega$ is in radians/sec., $R$ in $\mathrm{ft}$, and $V$ in $\mathrm{ft} / \mathrm{sec}$. 
$C_{p}$ can be predicted by knowing "Torque" from Equation 23.

The rotor performance curve, $C_{p}$ vs. $\lambda$, is the data base for the rest of the calculations in this systems analysis.

\subsection{THE POWER TRAIN SUBSYSTEMS}

The power train subsystems have a significant influence on power output and annual energy production. A machine with a constant rpm rotor may have a power train consisting of a gearbox and induction generator, whereas one with a variable rpm rotor may have a direct drive ac alternator, a rectifier, and an electronic inverter. Small wind systems analysts and designers are often confronted with the task of estimating the subsystem efficiency as a function of power ratio. Efficiencies in the manufacturer's specifications are often not sufficiently accurate for wind system applications. More reliable data can be obtained from dynamometer tests, but this method is often too expensive for preliminary wind system design and analysis.

Typical power train subsystem efficiency curves for a constant rpm rotor and a variable rpm rotor are shown in Figures 5 and 6 , respectively.

Figure 5 indicates a two-dimensional efficiency curve where power train efficiencies are expressed as a function of power ratio, which is defined as:

$$
\text { Power Ratio }=\frac{\text { Output Power }}{\text { Generator Rated Power }}
$$

Figure 6 shows a three-dimensional efficiency curve where power train efficiencies are expressed as a function of power ratio and rpm ratio. The rpm ratio is defined as: 


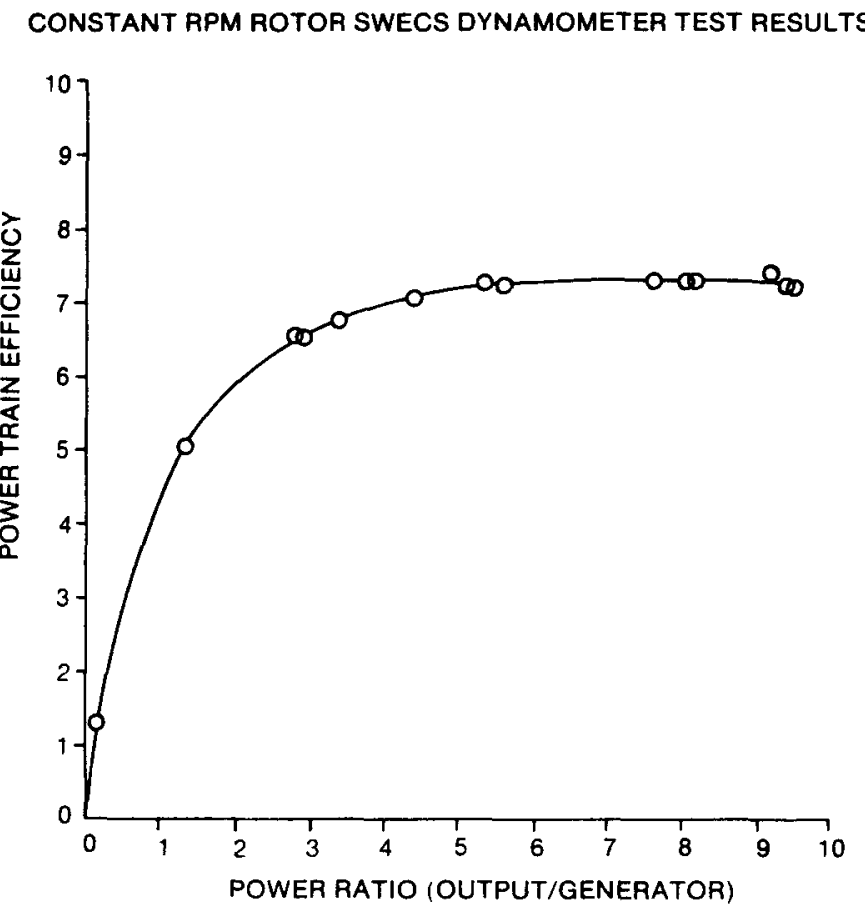

Figure 5

Power Train Efficiency of a Constant rpm Rotor SWECS

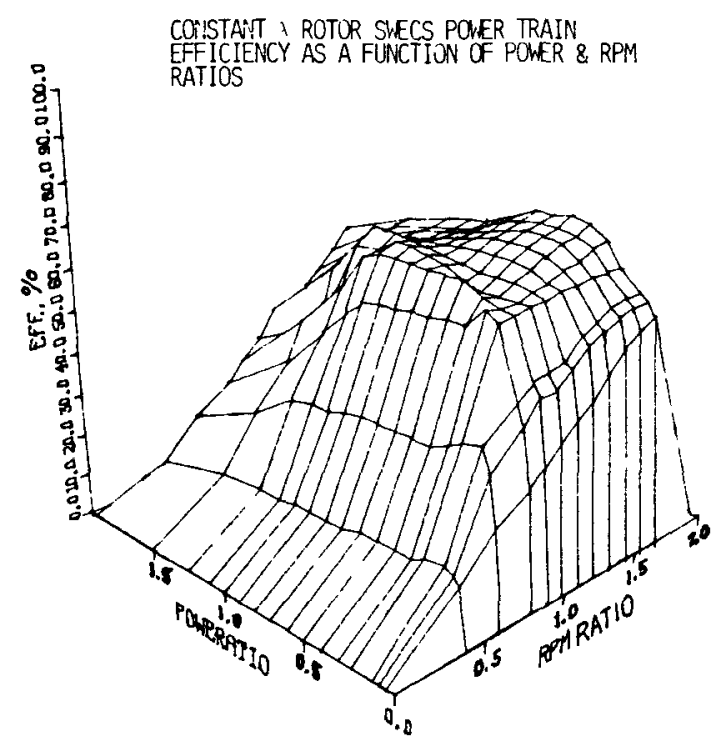

Figure 6

Power Train Efficiency of a Constant $\lambda$ Rotor SWECS 


$$
\text { rpm Ratio }=\frac{\text { Generator rpm }}{\text { Generator rpm at Rated Power }}
$$

The subsystem efficiency curves are applied to the rotor performance curve to obtain final power and energy output. 


\section{COMPUTER PROGRAM DESCRIPTION AND FLOW CHARTS}

The SEACC consists of three major subprograms: 1) the PROP code, 2) the POWER code, and 3) the ENERGY code. Rotor power coefficient as a function of blade tip-speed ratio is the major output of the "PROP" code. Likewise, the power output (kW) as function of wind speed (V) and annual energy production ( $k W h)$ as a function of annual average wind speed $(\bar{V})$ are the major outputs of the "POWER" and "ENERGY" codes, respectively.

A summary of the SEACC is shown in Figure 7, which also indicates input and output information required for each subprogram.

\subsection{THE PROP CODE}

The PROP computer program (Ref. 13) utilizes blade element and momentum theory to compute $a$ and $a^{\prime}$. By equating the thrust force from blade element theory to the change in axial momentum, the unknown a can be determined through an iterative process. Likewise, by equating the torque force from blade element theory to the change in angular momentum, the unknown a' can be iteratively calculated. In addition, the PROP code utilizes several tip loss options to account for the three-dimensional flow near the blade tip.

The PROP code has been widely used by the wind energy industry since its publication in June 1976. However, several modifications have been made in the code by the Rocky Flats Wind Systems Program, as follows:

1. The inclusion of Glauert's empirical formula describing the windmill brake and vortex ring state performance; i.e., the flow field at high tip speed ratios (Ref. 14). Although this idea was suggested by Reference 13 it was not implemented in that version.

2. The inclusion of a subroutine which synthesizes post-stall airfoil data based on an empirical formulation (Ref. 15). 


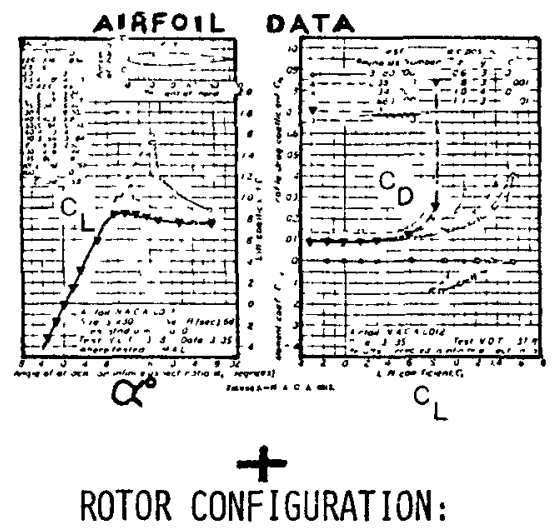

$R, H B, N O, B, \quad$ CONING ${ }^{\circ}$,

TAPER, TWIST, HUB $H, R P M \ldots \ldots \ldots$

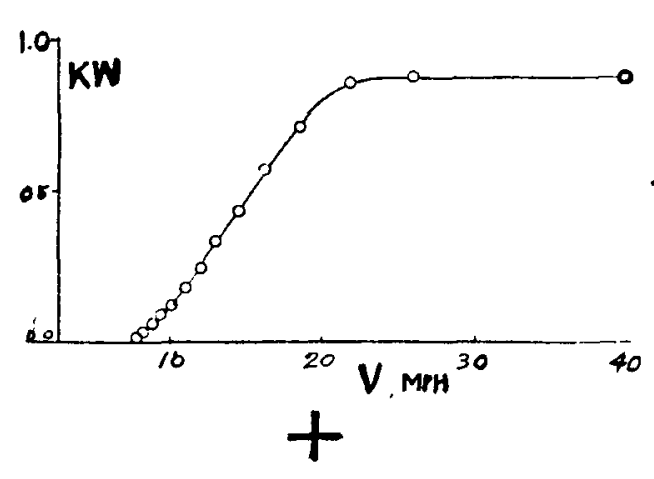

WEIBULL WIND DISTRIBUTION

\section{SWECS SYSTEMS ENGIINEERING \& ANALLYSIS}
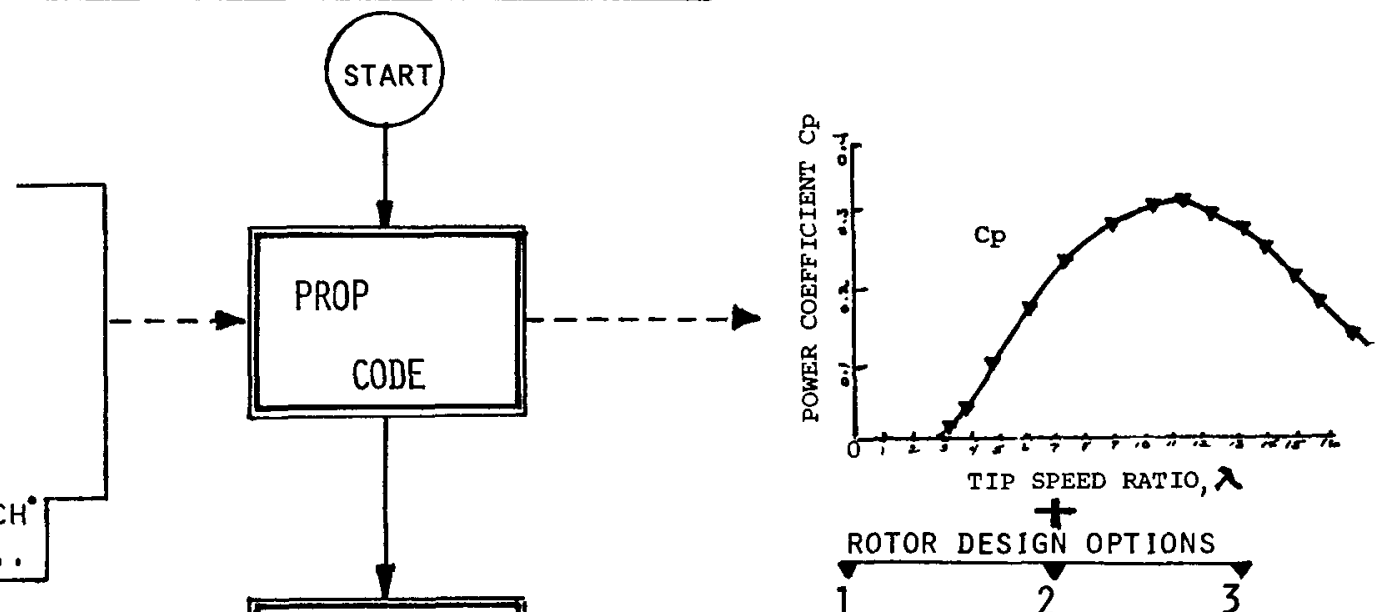
ROTOR DESIGN OPTIONS
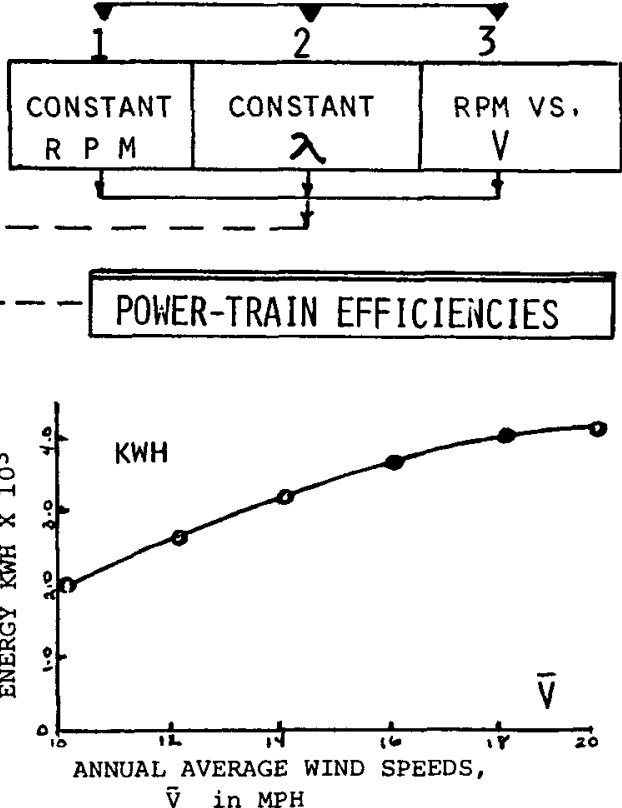

$\overline{\mathrm{V}}$ in $\mathrm{MPH}$

Figure 7

A Summary of the SEA Computer Program with Input and Output Information 
3. The inclusion of a method to interpolate between aerodynamic data input at various Reynolds numbers for each radial blade station.

4. An improvement on the code so that the hub losses can be calculated simultaneousiy with any of the tip loss models.

The input parameters required by the PROP code are the following:

1. Rotor configuration - rotor radius, hub radius, coning angle, rotor rpm, number of blades, etc.

2. Blade configuration - airfoil data $\left(C_{L}\right.$ and $C_{D}$ vs. $\left.\alpha^{\circ}\right)$, rates of taper and twist, pitch angle, etc.

3. Systems and site information - hub height, site altitude, wind shear power law exponent, etc.

The major output data of the PROP code used in the analysis is the rotor power coefficient curve (i.e., $C_{p}$ vs. $\lambda$ ). However other computational results contained in PROP are readily available at the user's command when each run is made. Users who are interested in those results should consult Reference 13 for details.

\subsection{POWER CODE}

The POWER code is so defined because this subprogram calculates rotor power output as a function of wind speed from the power coefficient curve given by PROP code.

The POWER code contains three major options in choosing rotor rpm design. The flow chart (Figure 8 ) indicates that after taking in $C_{p}$ vs. $\lambda$ table from the PROP code three options, numbered as 1,2 , and 3 , are offered: 


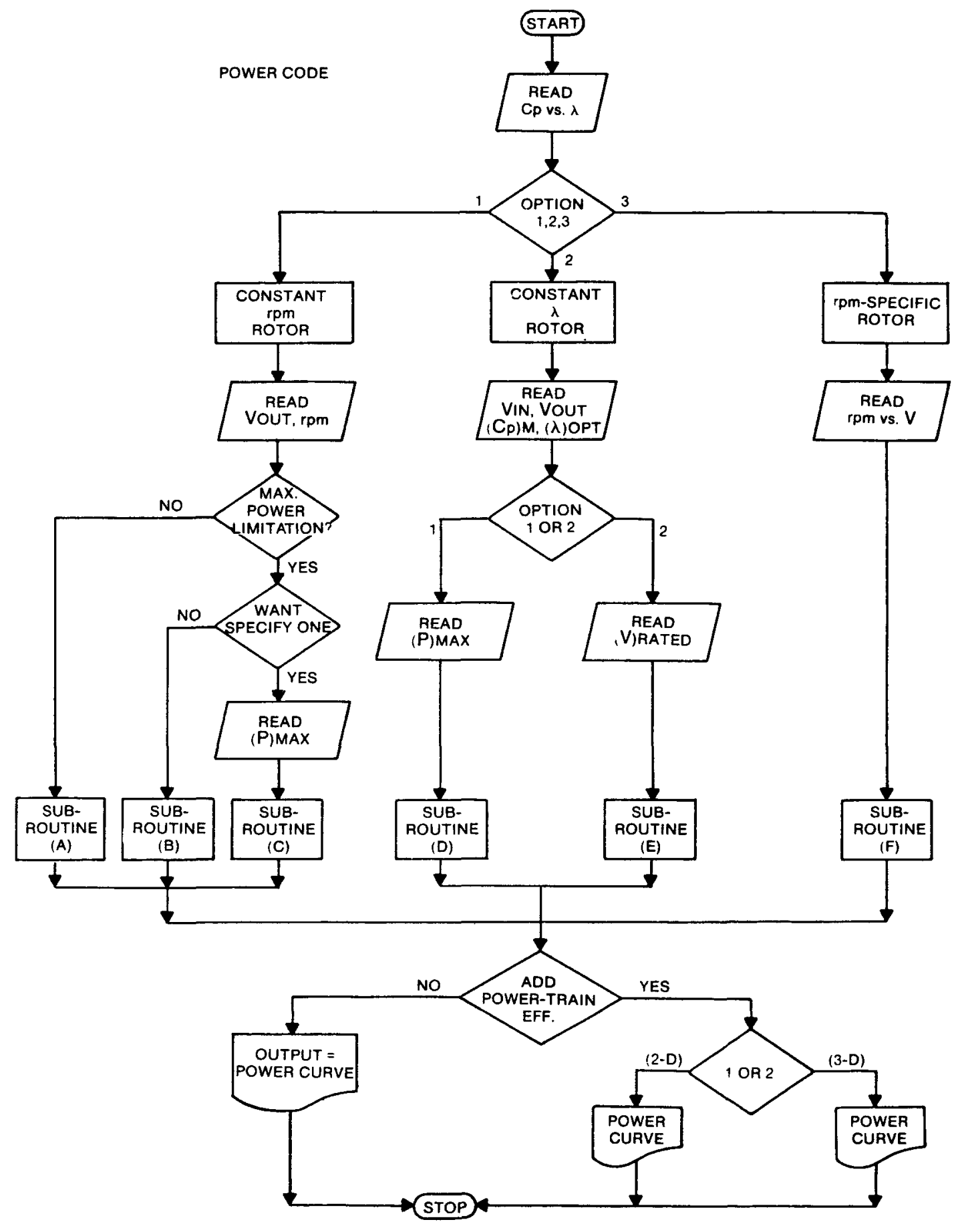

Figure 8. The Computer Flow Chart of POWER Code 
1. Choose 1 for a constant rpm rotor design. This design requires the rotor to maintain a constant shaft speed for all wind speeds up to the cut-out condition. The user must specify an rpm for the rotor and the cut-out wind speed. In this subrout ine the computer will ask the user to decide whether a maximum power limitation should be imposed on the rotor. If the answer is YES, the user has the option to specify a power limitation or let the computer seek and maintain a maximum power. A constant rpm rotor is often used for an induction generator or a synchronous generator which produces constant frequency and voltage ac electricity at $1800 \mathrm{rpm}$, with a maximum rpm fluctuation of $+10 \%$.

2. Choose 2 for a constant $\lambda$ (or variable rpm) rotor design. This design requires the rotor rpm to vary with wind speed so that an optimum $\lambda$ (where $C_{p}$ is maximum) can be maintained in all wind speeds. The user needs to specify cut-in and cut-out wind speeds, the maximum $C_{p}$ and the corresponding $\lambda$. A rotor maximum power limitation option, as described above, is also provided here. Furthermore, the user is given an additional choice of using the rated wind speed to limit the maximum rotor power output. This design is often used with a power train subsystem consisting of an ac alternator and a rectifier (for a dc current application) or an ac alternator, a rectifier, and an inverter (for an ac house current application).

3. Choose 3 for a rotor rpm-specific design. This design requires the rotor rpm to follow a certain rpm schedule specified by the user. The user needs to create an input file for this particular design. The input file should contain an rpm vs. wind speed table to cover operating conditions between cut-in and cut-out wind speeds.

When one of the above-mentioned options is selected, the computer will pose the following questions before the final power curve is calculated:

1. Should the subsystem's efficiency be applied to the rotor power curve?

2. If the answer is yes, then which efficiency table should be used? A 2-D or 3-D table? The user should be aware that a 2-D table is selected for a constant rpm rotor design only. Whereas a 3-D table is for the constant $\lambda$ rotor design. 


\subsection{ENERGY CODE}

In this subprogram, SWECS annual energy production will be calculated based on the power curve produced by the previous code (Figure 9). The user is required to specify a hub height and make a choice on the wind speed distribution - a Weibull distribution or a NASA distribution. When a Weibul1 distribution is selected, the shape factor $(K)$ is requested by the computer. The computer sets $K=2.27$ for a NASA distribution. Options for a quick summary report or a detailed energy report are also provided. The quick summary report lists energy yield in $\mathrm{kWh}$ as a function of annual average wind speed ranging from 5 to $18 \mathrm{mph}$ at an interval of $1 \mathrm{mph}$. The detailed report will list, in addition to the energy kWh, the most probable wind speed, most probable power output and wind speed for maximum energy density for each annual average wind speed.

Energy supply/demand mismatch can be estimated by the ENERGY code. To accomplish the mismatch estimate the user is required to prepare diurnal wind speed and load distributions for four seasons (winter, spring, summer, and fall). The code will then combine the diurnal distribution and the power curve to summarize the net or total energy mismatch for the four seasons separately and for the entire year. Diurnal SWECS power output superimposed on the load profile can be plotted by the code. Choices for constructing a diurnal wind distribution are also provided by the code. 


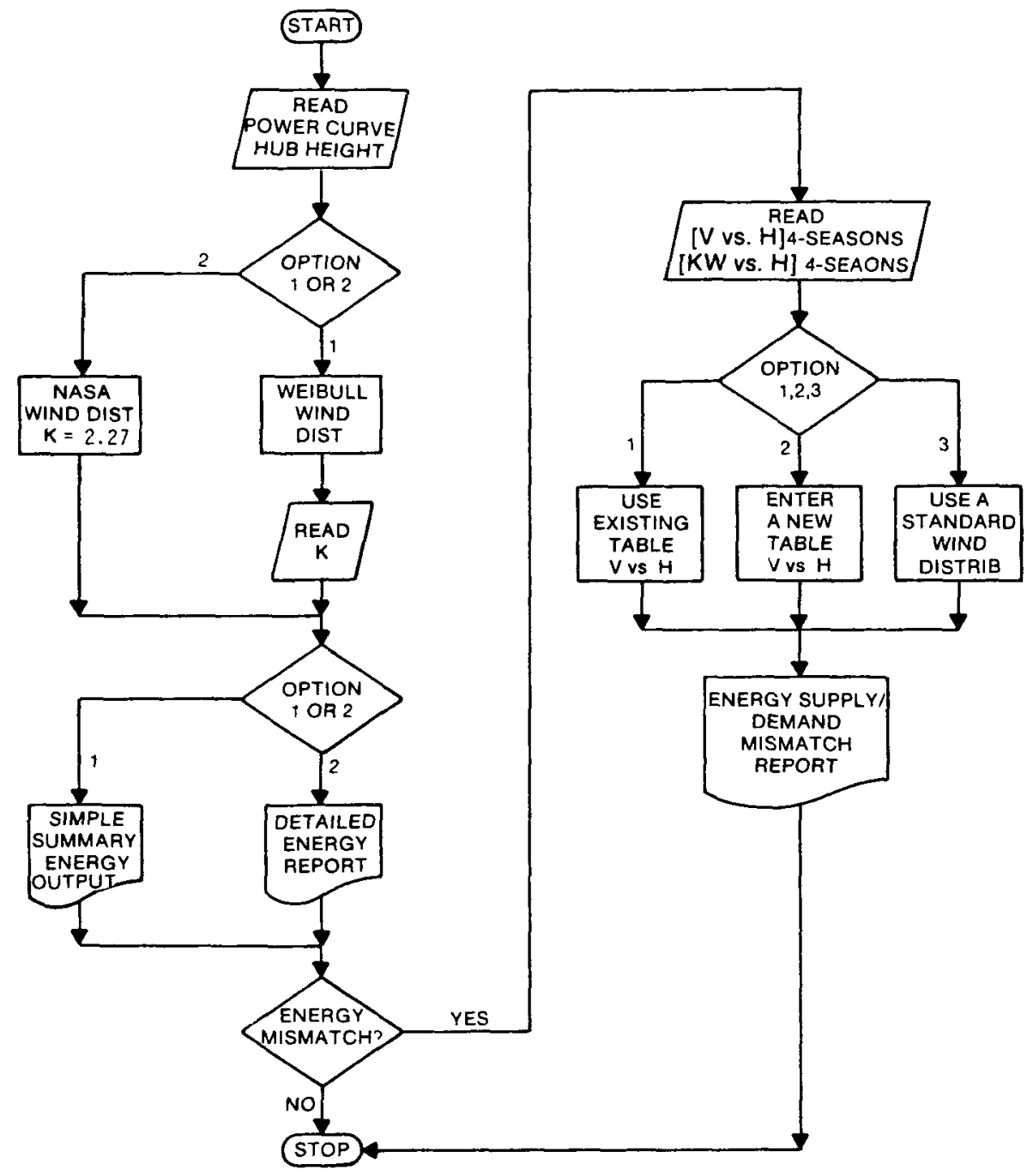

Figure 9. The Computer Flow Chart of the ENERGY Code 


\section{PARAMETRIC STUDY}

The effect of SWECS configuration parameters on rotor and system performance can be evaluated with the SEACC. If enough runs are carried out, optimum conditions can be pinpointed. A case study was carried out to demonstrate the effectiveness of the code (Ref. 16).

A model SWECS for the case study is selected and listed as shown in Table 3 .

The design parameters under study are pitch angle setting for a fixed-pitch rotor and rotor rpm for a constant rpm rotor. In addition, comparisons were made between an optimized constant rpm rotor and constant $\lambda$ rotor systems. The effect of power train efficiency on such comparisons is also included.

A total of five cases have been studied. A sumary of the variables used in the case studies is shown in Table 4 and described in the following.

Case 1 - The purpose of this case study is to investigate the pitch angle effects on SWECS rotor performances. The pitch angle was varied from $15^{\circ}$ to $-2^{\circ}$. The rotor rpm option was selected as a constant shaft speed rotor at $346 \mathrm{rpm}$. No power train efficiency was used to discount the rotor power or energy output. Results of this case study are shown in Section 4.1.

Case 2 - The purpose of this case study is to investigate the rotor rpm effects on SWECS rotor performance. The rotor rpm was varied from 50 percent to 150 percent of $346 \mathrm{rpm}$, which was used as the target rpm in Case 1. The pitch angle was fixed at an optimum angle found in Case 1 . Results of the rpm effects are listed in Section 4.2.

Case 3 - The rotor rpm option was selected as a variable rpm rotor at an optimum $\lambda$ found in Case 2 and an optimum $\theta^{\circ}$ from Case 1. Rotor maximum power output was made to match the one calculated in Case 2 (in this case, five different power levels 
TABLE 3

CONFIGURATION OF MODEL SWECS

\begin{tabular}{|c|c|}
\hline Rotor configuration & - horizontal-axis and downwind \\
\hline Number of blades & -2 \\
\hline Rotor di ameter & $-10 \mathrm{ft}$ \\
\hline Blade pitch control desig & - Active controls with actuators \\
\hline Blade geometry & $\begin{array}{l}\text { - Airfoil series NACA } 0012 \text { (Ref. 11) whose lift } \\
\text { and drag coefficients are listed in Table } 2\end{array}$ \\
\hline Performance goals & $\begin{array}{l}\text { - The SWECS will produce } 1.5 \mathrm{~kW} \text { household elec- } \\
\text { tricity (120 volts, } 60 \mathrm{~Hz} \mathrm{ac)} \text { at } 25 \mathrm{mph} \text { wind } \\
\text { speed }\end{array}$ \\
\hline Rotor rpm options & $\begin{array}{l}\text { - 1) Constant rpm rotor with a target rpm at } 346 \\
\text { 2) Variable rpm rotor at an optimum tip speed } \\
\text { ratio }\end{array}$ \\
\hline Cut-out wind speed & $-40 \mathrm{mph}$ \\
\hline Tower height & $-50 \mathrm{ft}$ \\
\hline Site altitude & - At sea level \\
\hline Wind speed distribution & - NASA definition \\
\hline
\end{tabular}


TABLE 4

A SUMMARY OF THE VARIABLES USED IN THE PARAMETRIC STUDY

\begin{tabular}{|c|c|c|c|c|c|c|c|}
\hline $\begin{array}{l}\text { Case } \\
\text { Study } \\
\text { No. }\end{array}$ & $\begin{array}{l}\text { Power } \\
\text { Train } \\
\text { Effi- } \\
\text { ciency } \\
\text { Used }\end{array}$ & $\begin{array}{l}\text { Rotor } \\
\text { Design } \\
\text { Options }\end{array}$ & $\begin{array}{l}\text { Rotor } \text { rpm } \\
\text { or } \\
(\mathrm{rpm})^{\max .}\end{array}$ & $\lambda$ & $\begin{array}{c}\text { Pitch } \\
\text { Angle } \\
\theta^{\circ}\end{array}$ & $\begin{array}{c}\text { Wind Speed } \\
v \\
(\mathrm{mph})\end{array}$ & $\begin{array}{l}\text { Annual } \\
\text { Average } \\
\text { Wind } \\
\text { Speed } \\
\bar{V} \text { (mph) }\end{array}$ \\
\hline 1 & No & $\begin{array}{l}\text { constant } \\
\text { rpm } \\
\text { rotor }\end{array}$ & $\begin{array}{c}346 \\
\text { (design } \\
\text { value) }\end{array}$ & $\begin{array}{c}\text { calculated } \\
\text { by } \\
\text { code }\end{array}$ & $\begin{array}{l}15^{\circ}, 10^{\circ} \\
5^{\circ}, 3^{\circ}, \\
2^{\circ}, 1^{\circ}, \\
-1^{\circ},-2^{\circ}\end{array}$ & $\begin{array}{c}\text { (V) in by } \\
\text { code } \\
\text { (V) out } \\
=40\end{array}$ & $10-18$ \\
\hline 2 & No & $\begin{array}{l}\text { constant } \\
\text { rpm } \\
\text { rotor }\end{array}$ & $\begin{array}{l}50 \%, 75 \% \\
100 \%(=346) \\
125 \%, 150 \%\end{array}$ & $\begin{array}{c}\text { calculated } \\
\text { by } \\
\text { code }\end{array}$ & $\begin{array}{l}\text { opt imum } \theta^{\circ} \\
\text { from Case } \\
1 \quad\left(=2^{\circ}\right)\end{array}$ & $\begin{array}{c}\text { same } \\
\text { as } \\
\text { above }\end{array}$ & $\begin{array}{l}\text { same } \\
\text { as } \\
\text { above }\end{array}$ \\
\hline 3 & No & $\begin{array}{c}\text { Constant } \\
\lambda \\
\text { rotor }\end{array}$ & $\begin{array}{l}(r p m) \text { max. } \\
\text { calculated } \\
\text { by code }\end{array}$ & $\begin{array}{l}\text { opt imum } \\
\quad \lambda \\
(=10)\end{array}$ & $\begin{array}{c}\text { same } \\
\text { as } \\
\text { above }\end{array}$ & $\begin{array}{l}(V) \text { in }=7 \\
\text { (V) out } \\
=40\end{array}$ & $\begin{array}{l}\text { same } \\
\text { as } \\
\text { above }\end{array}$ \\
\hline 4 & Yes & & & SAME AS & CASE 2 & & \\
\hline 5 & Yes & & & SAME AS & CASE 3 & & \\
\hline
\end{tabular}




\section{TABLE 5}

AIRFOIL DATA OF SERIES NACA 0012 AT A REYNOLDS NUMBER 330,000

\begin{tabular}{|c|c|c|}
\hline$\alpha^{\circ}$ & $c_{L}$ & $C_{D}$ \\
\hline-4.0 & -.40 & .011 \\
\hline-3.0 & -.30 & .010 \\
\hline-2.0 & -.20 & .009 \\
\hline-1.0 & -.10 & .008 \\
\hline 0.0 & 0.00 & .008 \\
\hline 1.0 & .11 & .008 \\
\hline 2.0 & .21 & .009 \\
\hline 3.0 & .31 & .010 \\
\hline 4.0 & .41 & .011 \\
\hline 5.0 & .51 & .012 \\
\hline 6.0 & .60 & .013 \\
\hline 7.0 & .69 & .015 \\
\hline 8.0 & .77 & .019 \\
\hline 9.0 & .83 & .024 \\
\hline 10.0 & .84 & .025 \\
\hline 11.1 & .86 & .084 \\
\hline
\end{tabular}


were made according to the five rpm's used in Case 2). The $(\mathrm{rpm})_{\max }$ based on each maximum power output was calculated by the code. No power train efficiencies were used in this case. Results of this case as compared to Case 2 are shown in Section 4.3.

Case $4 \& 5$ - The purpose of these case studies was to show the effect of power train efficiency on rotor performance. Therefore, Cases 2 and 3 were repeated but with power train efficiencies applied to each output, respectively. Results of Case 4 and 5 are included in Section 4.4.

This section details the results of the case study.

\subsection{CASE 1 - BLADE PITCH ANGLE EFFECTS}

As shown in Figure $4, \phi^{\circ}$ is determined by the local wind velocity and the blade tangential velocity. The angle of attack, $\alpha^{\circ}$, a determinant of airfoil's $C_{L}$ and $C_{D}$, is the difference of $\phi^{\circ}$ and $\theta^{\circ}$, where $\theta^{\circ}$ is the blade pitch angle and a constant in the case of a fixed-pitch rotor. A proper choice of $\theta^{\circ}$ is necessary for a fixed-pitch rotor SWECS. Figures 10 through 15 show the effects of $\theta^{\circ}$ on rotor $C_{p}$, power output, and energy production, respectively. The $\theta^{\circ}$ was varied from $15^{\circ}$ to $-2^{\circ}$ and indicated an optimum $\theta^{\circ}$ of $2^{\circ}$ based on the energy production plots (Figure 15). This is the pitch angle a fixed pitch rotor SWECS should have during normal operation. The power curve plots (Figures 12 and 13) also indicate a trend that the maximum possible power output and the cut-in wind speed decrease at lower pitch angles. This family of power curves at various pitch angles can be used as the basic pitch control data for a variable pitch rotor SWECS. In the design of a constant $\lambda$ rotor machine, Figure 11 indicates the maximum $C_{p}$ and the corresponding $\lambda\left(\lambda_{\text {opt }}\right)$ to be used for achieving optimum performance. Detailed comparisons between the constant rpm rotors and the constant $\lambda$ rotors will be addressed later in the report. 


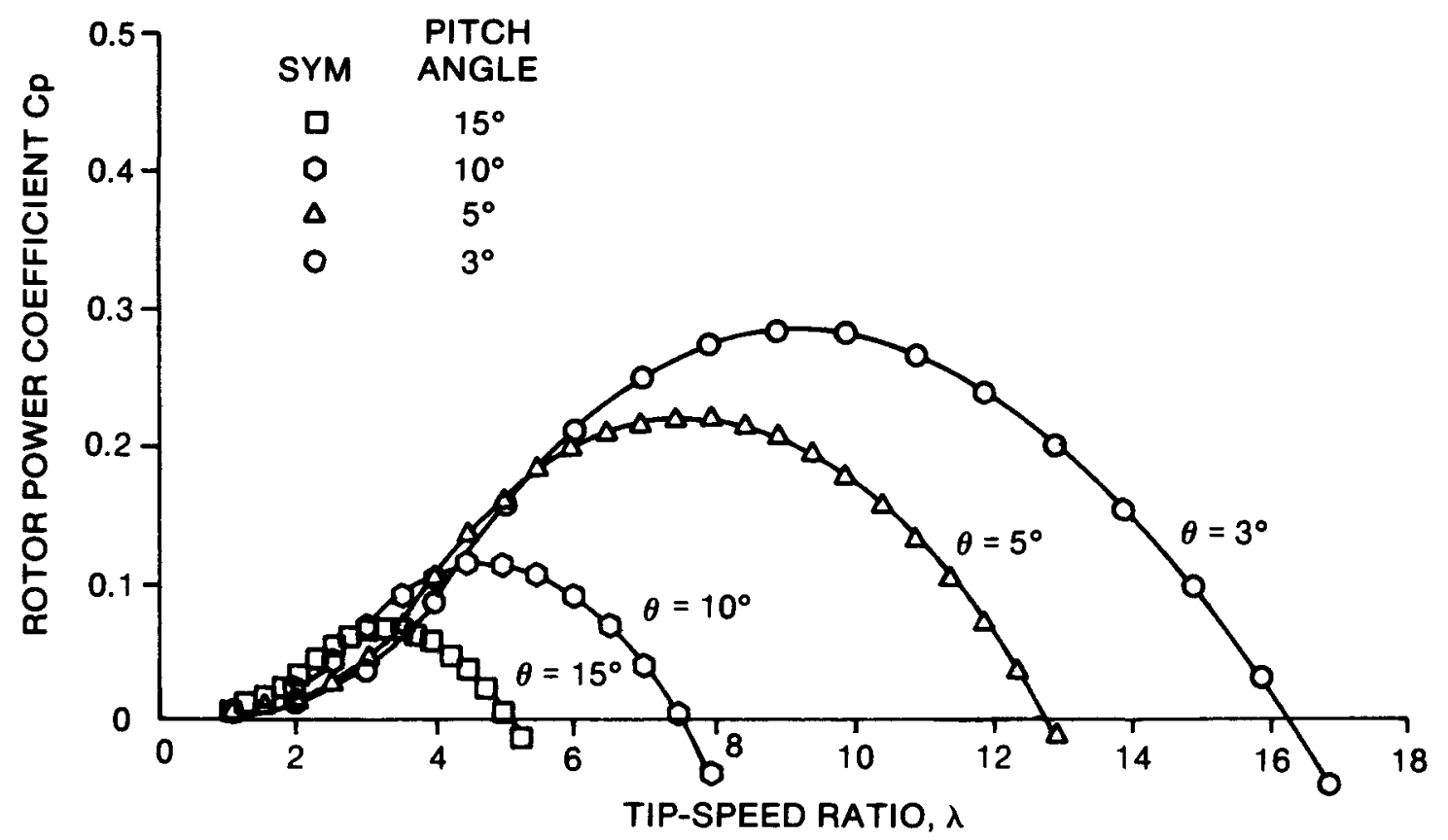

Figure 10. Rotor Power Coefficient Characteristics As Affected by Variation of Pitch Angle Ranging |From $+15^{\circ}$ to $3^{\circ}$

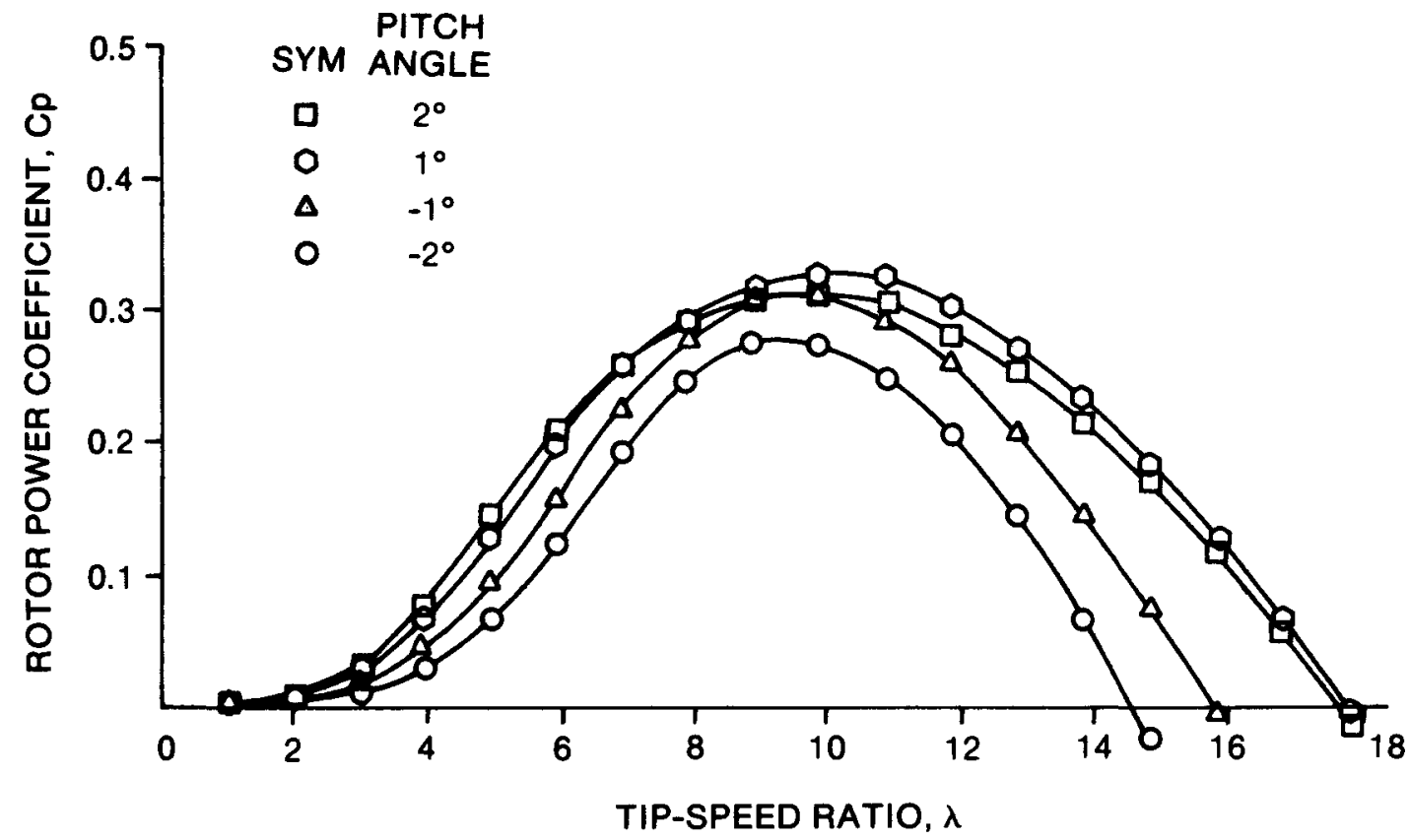

Figure 11. Rotor Power Coefficient Characteristics As Affected by Variation of Pitch Angle Ranging from $2^{\circ}$ to $-2^{\circ}$ 


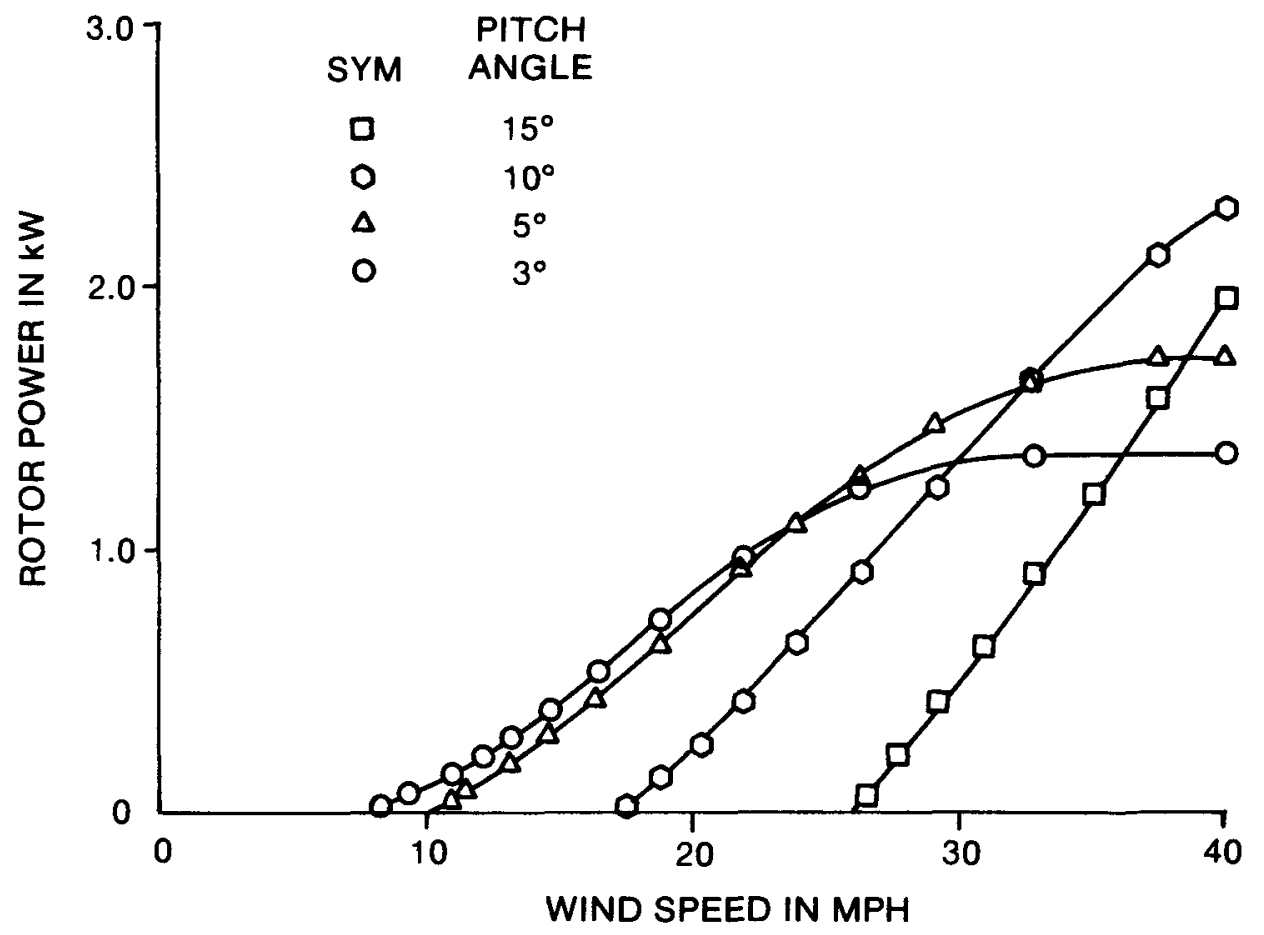

Figure 12. Pitch Angle Effect on Rotor Power for $\angle \theta=15^{\circ}$ to $3^{\circ}$

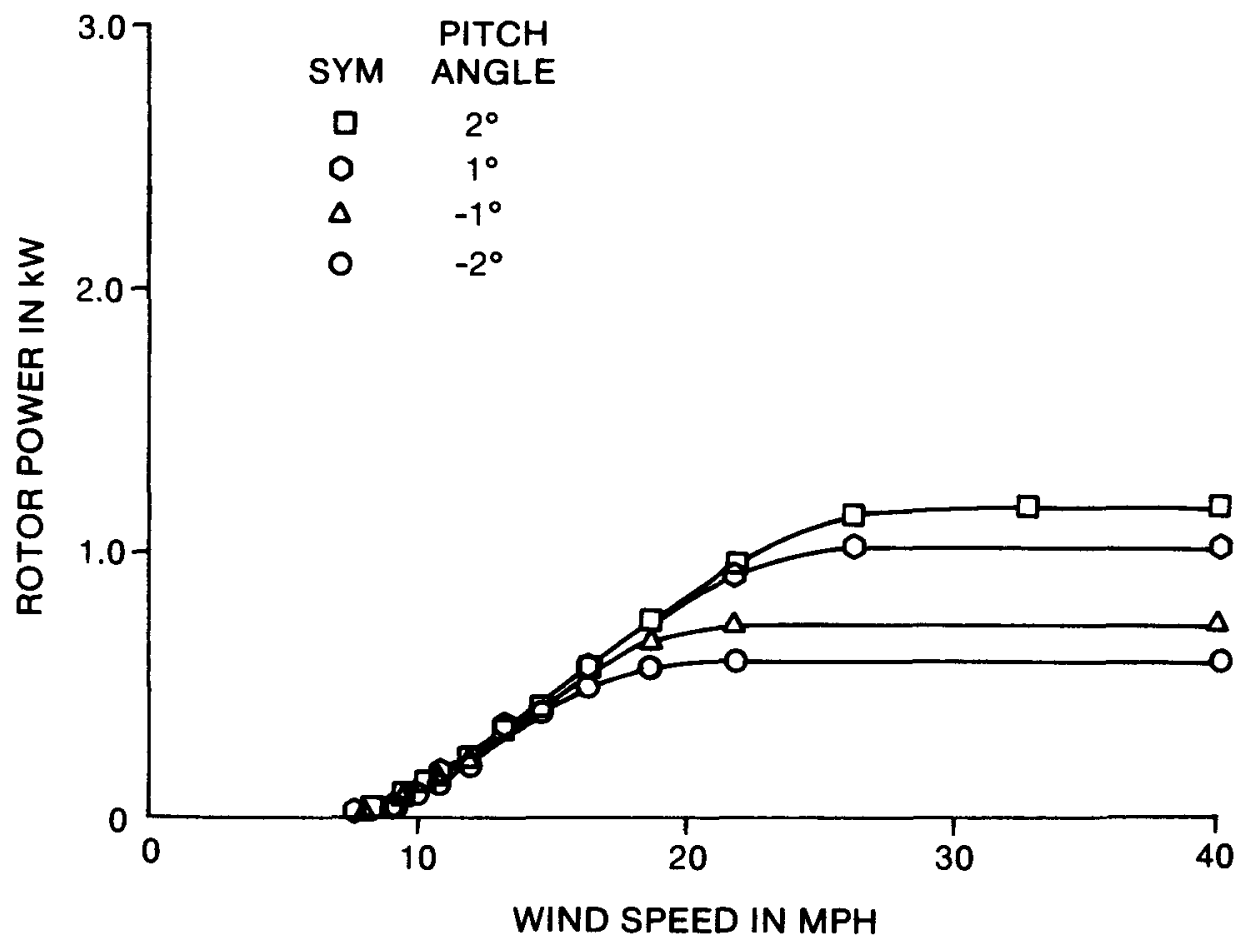

Figure 13. Pitch Angle Effect on Rotor Power for $\angle \theta=2^{\circ}$ to $-2^{\circ}$ 


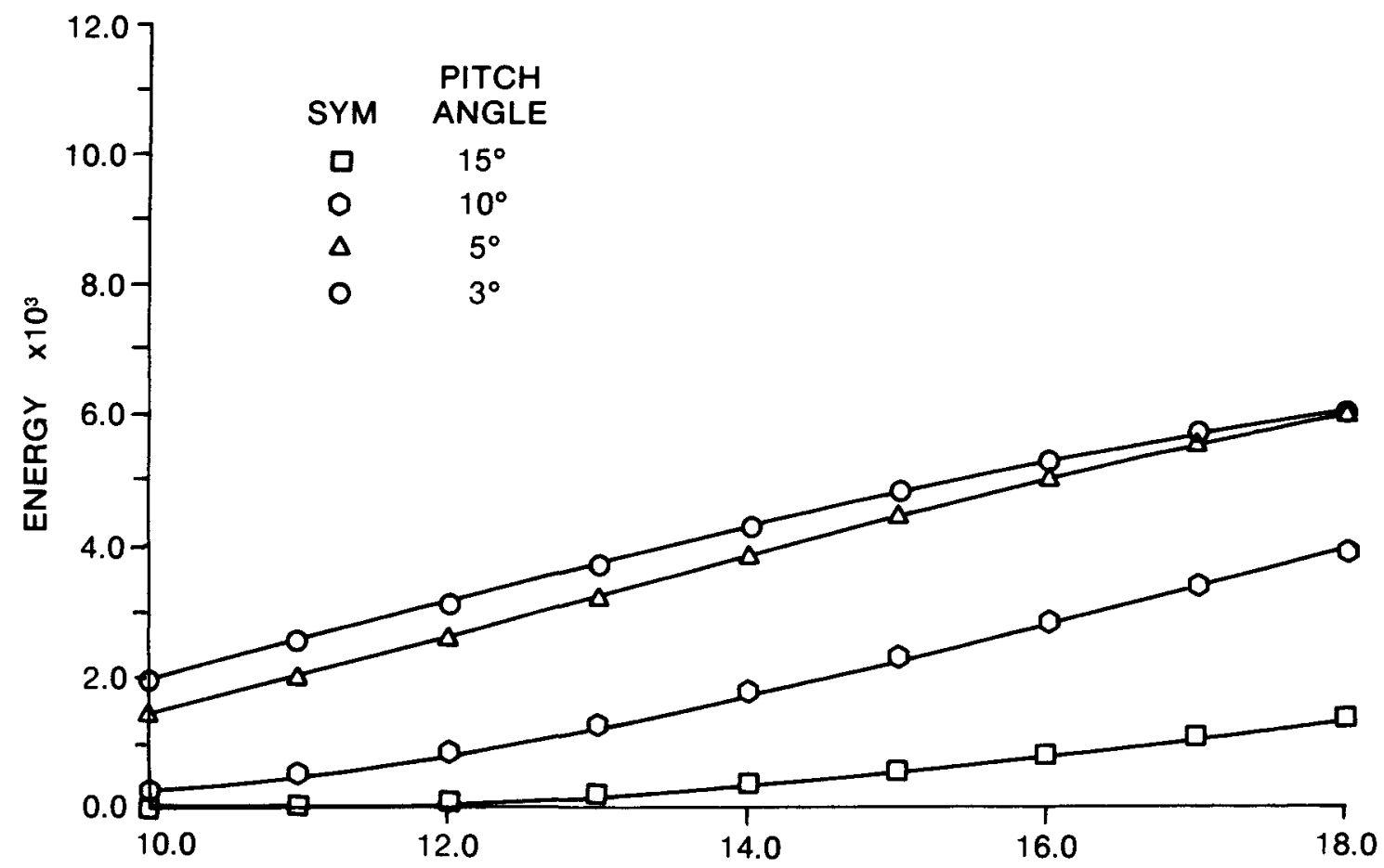

ANNUAL AVERAGE WIND SPEED IN MPH

Figure 14. Pitch Angle Effect on Rotor Energy Production for $\angle \theta=15^{\circ}$ to $3^{\circ}$

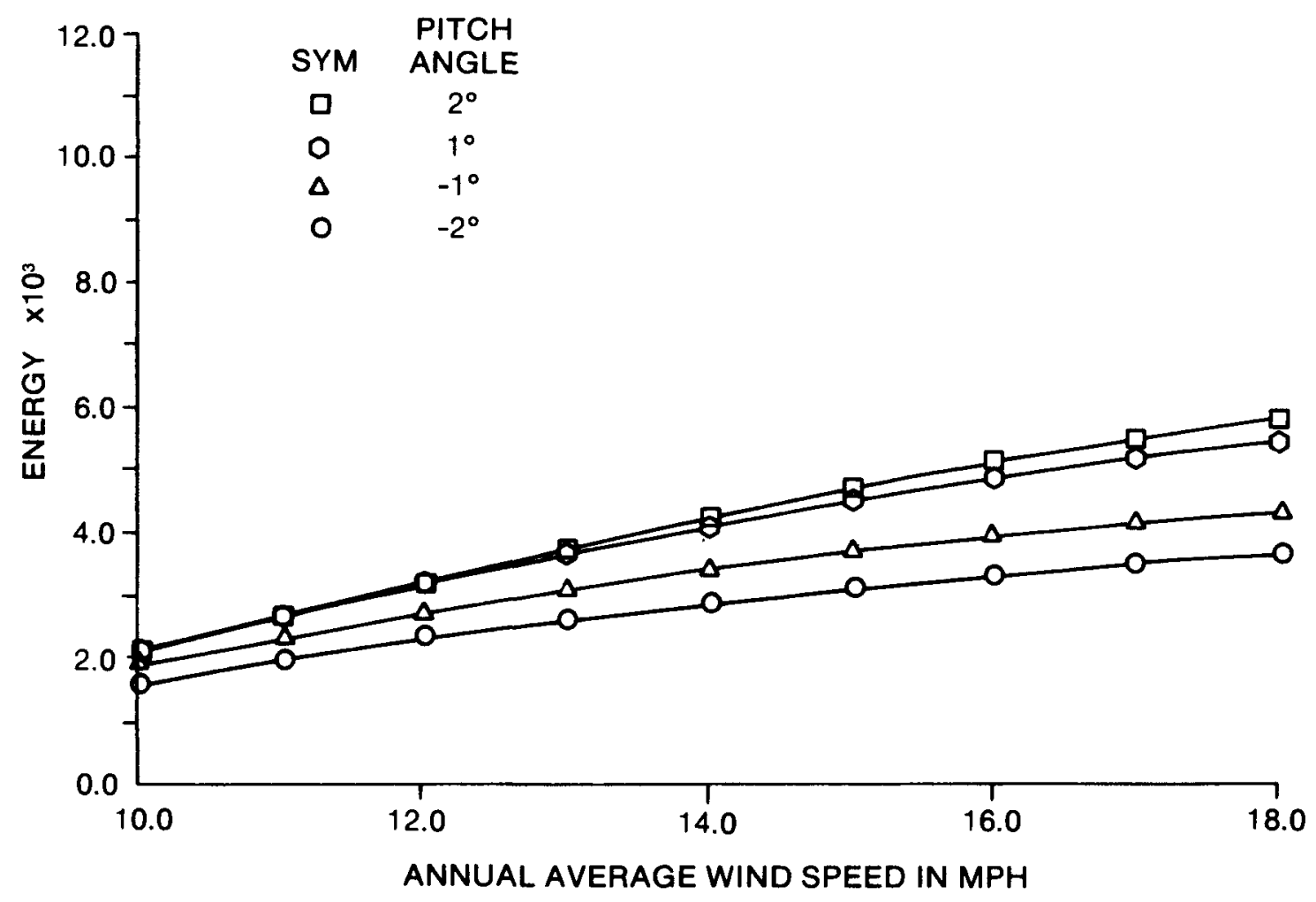

Figure 15. Pitch Angle Effect on Rotor Energy Production for $\angle \theta=2^{\circ}$ to $-2^{\circ}$ 


\subsection{CASE 2 - ROTOR RPM EFFECTS}

The model constant rpm rotor design will have a different $\lambda$ value whenever wind speed changes as, by definition,

$$
\lambda=(\text { rotor } \text { radius }) \cdot \omega /(\text { wind speed })
$$

The rotor $C_{p}$ will then vary accordingly, following the curve shown in Figure 16 from $(\lambda)$ cut-in to $(\lambda)$ cut-out as wind speed varies from $V_{\text {in }}$ to $V_{\text {out }}$. However, when the rotor has a different rpm value, $(\lambda)$ cut-in and $(\lambda)$ cut-out change accordingly. This will produce $C_{p}$ 's in a different range, and rotor power output and annual energy production will be greatly affected. Figure 17 shows that the maximum rotor power output and its corresponding wind speed increase with rotor rpm. However, in low wind speeds the rotor power decreases with rotor rpm. The cut-in wind speed also increases with rotor $\mathrm{rpm}$ as seen in the same figure. This demonstrates the fact that the rotor rpm has to be increased to obtain higher maximum rotor power output without changing rotor size. This may result in high blade root stress or high cut-in wind speed.

Rotor annual energy production, as shown in Figure 18, increases with rotor rpm, reaches a maximum and tapers off at high rpm's. The optimum rotor rpm increases with annual average wind speed. This indicates that it may be desirable for SWECS manufacturers to provide gearbox ratio options for various wind sites to optimize energy output.

\subsection{CASE 3 - CONSTANT $\lambda$ ROTORS VS. CONSTANT RPM ROTORS}

When rotor $C_{p}$ is maintained at maximum in all wind speeds, the rotor is considered most efficient because the rotor power, derived by

$$
P=1 / 2 \rho A V^{3} \cdot\left(C_{p}\right)_{\max },
$$




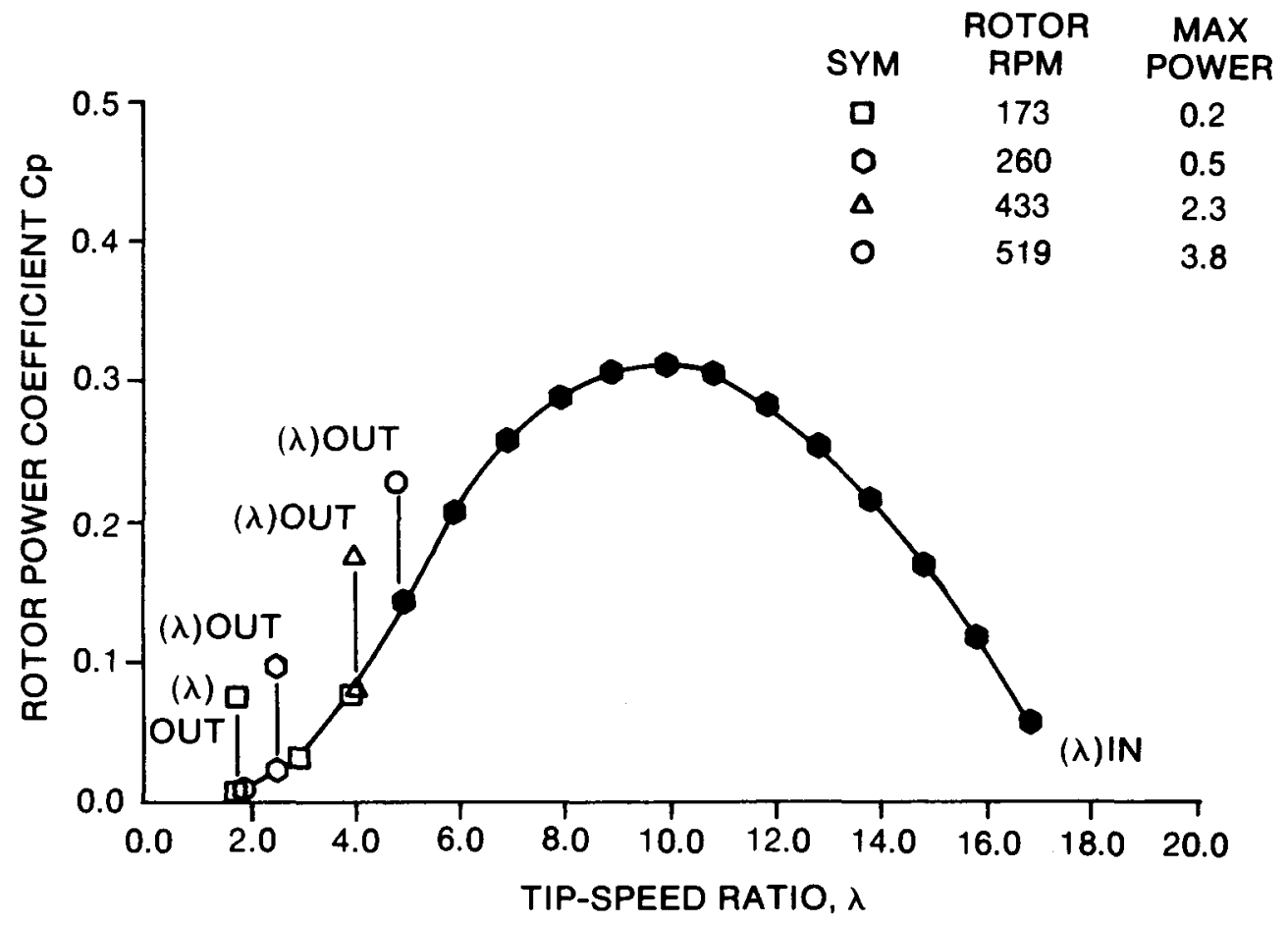

Figure 16. The Optimum Cp Curve Used for a Constant rpm Rotor SWECS

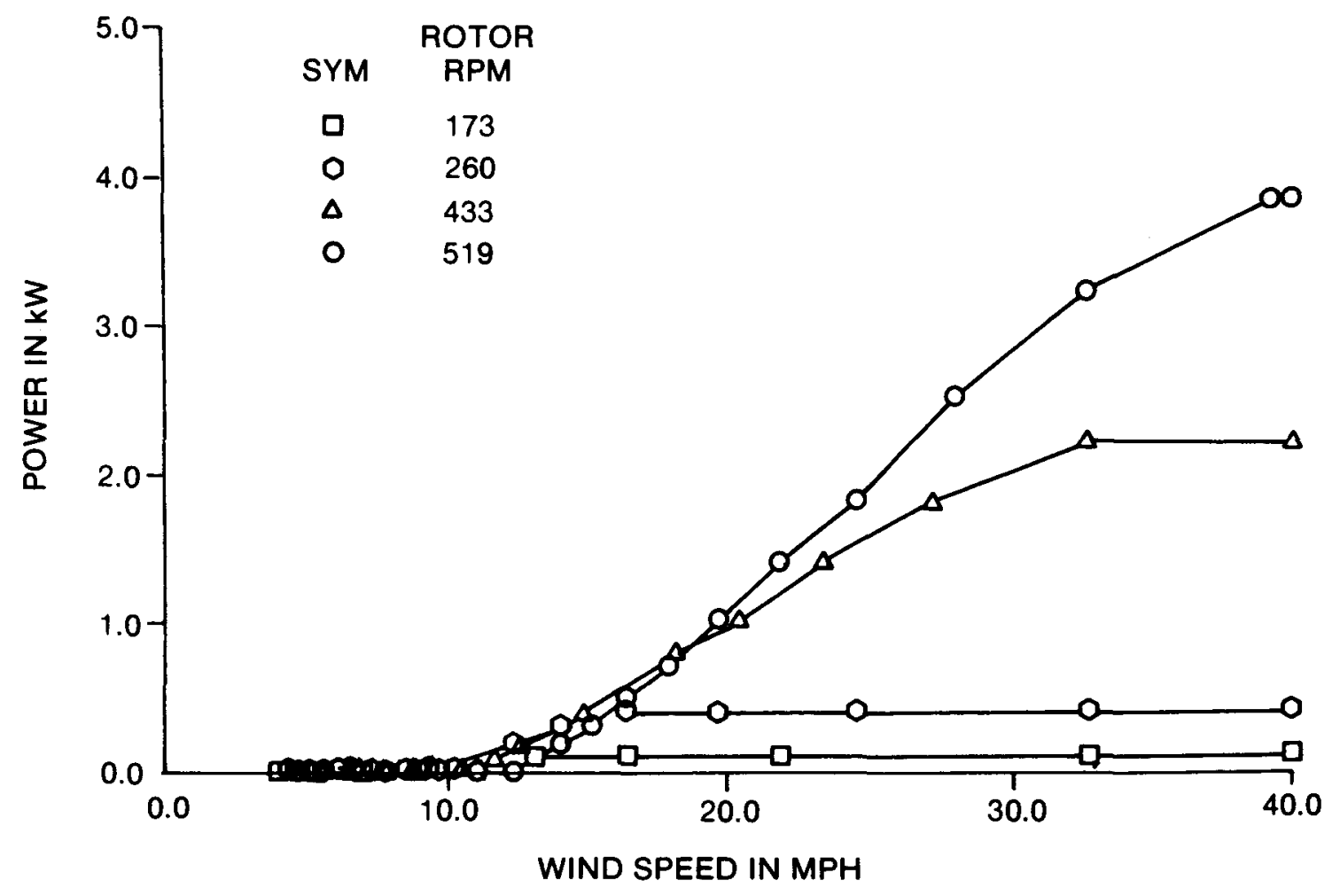

Figure 17. Rotor rpm Effect on the Power Output 


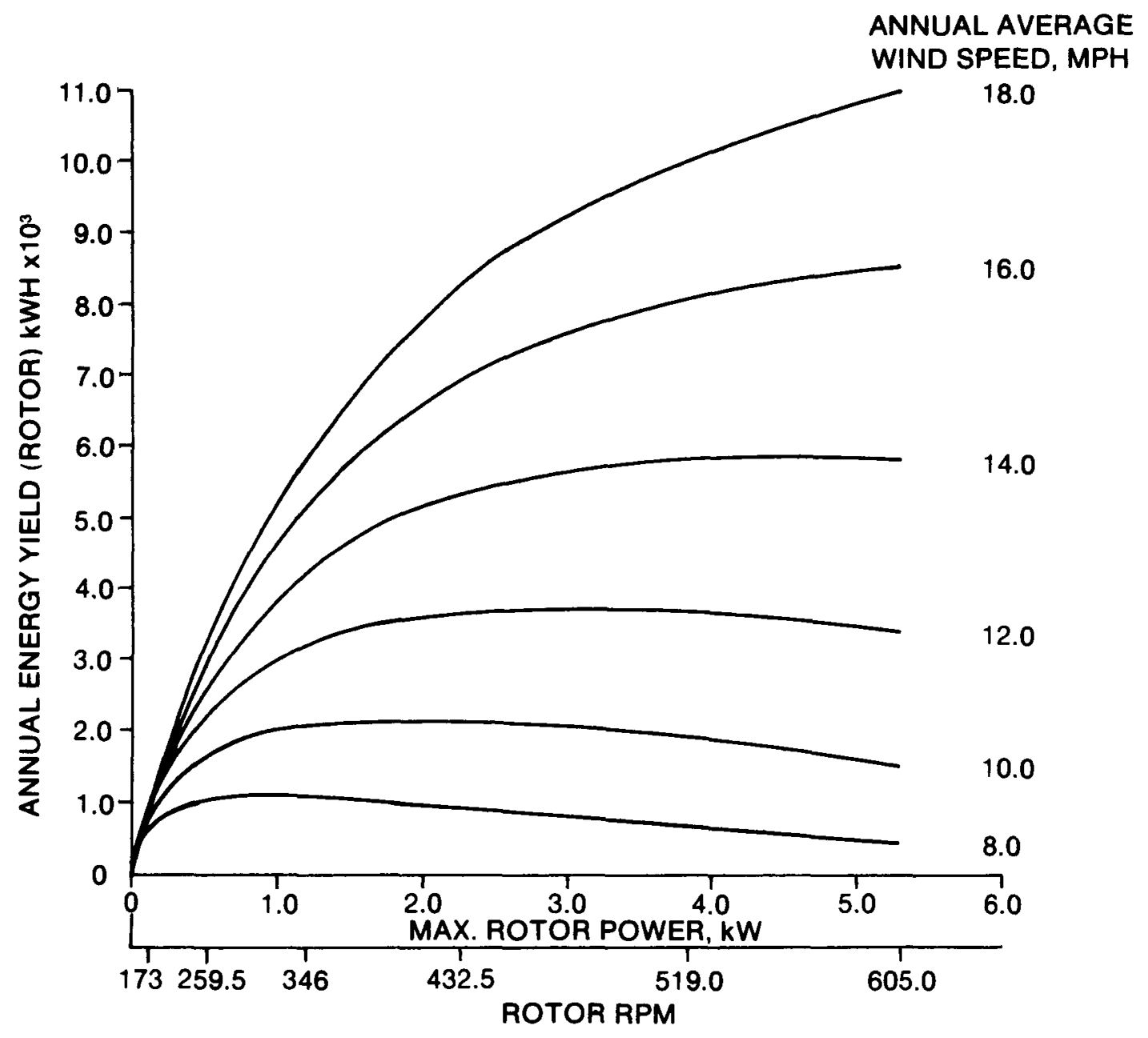

Figure 18

Rotor Energy Production as a Function of $\bar{V}$ and rpm 
is at optimum all the time. The rotor rpm has to vary with wind speed so that the optimum $\lambda$ and maximum $C_{p}$ can be maintained. As the rotor power increases with the cubic wind speed, a maximum power ceiling which is required by the generator size has to be imposed upon the rotor in high wind speeds.

When this constant $\lambda$ rotor is compared with a constant rpm rotor, a maximum generator capacity is used as the common point. Both rotors will reach a given maximum power and maintain that level until cut-out wind speed, $V_{\text {out }}$.

Higher power output of a constant $\lambda$ rotor than that of a constant rpm rotor is seen in the wind speeds below the rated wind speed (Figure 19). $V_{t}$ is the point where $C_{p}=\left(C_{p}\right)$ max for both rotors. Figure 19 also indicates that the power difference of two rotors increases with generator maximum power capacity.

The energy production difference of two rotors is expressed in annual percentage and as a function of annual average wind speed and generator maximum power capacity, Figure 20. The difference is very large in low wind speed regions but narrows as wind speed increases. Rotor configuration tradeoffs for a given wind site can now be carried out with both Figures 18 and 20 .

\subsection{CASES 4 AND 5 - POWER TRAIN EFFICIENCY EFFECT}

Components of power train subsystems may vary with rotor type. Constant rpm machines may have a gearbox and an induction generator, whereas constant $\lambda$ rotor machines may have a direct drive ac alternator, a rectifier, and an electronic inverter. Efficiencies of these power train subsystems are different and this has a decisive influence on annual energy production. 


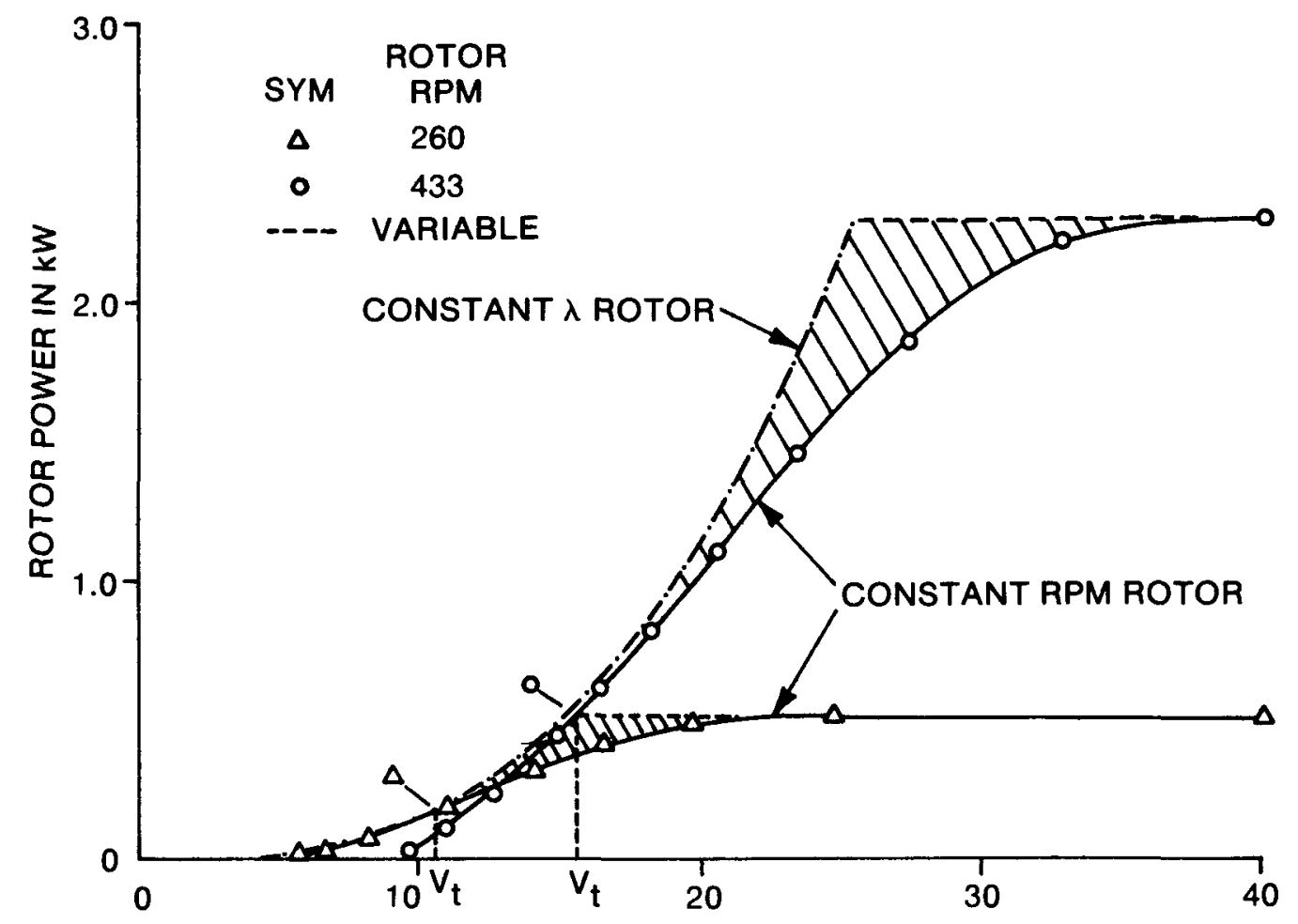

Figure 19. Power Curves of a Constant rpm Rotor and a Constant $\lambda$ Rotor at Two Different Maximum Power Levels

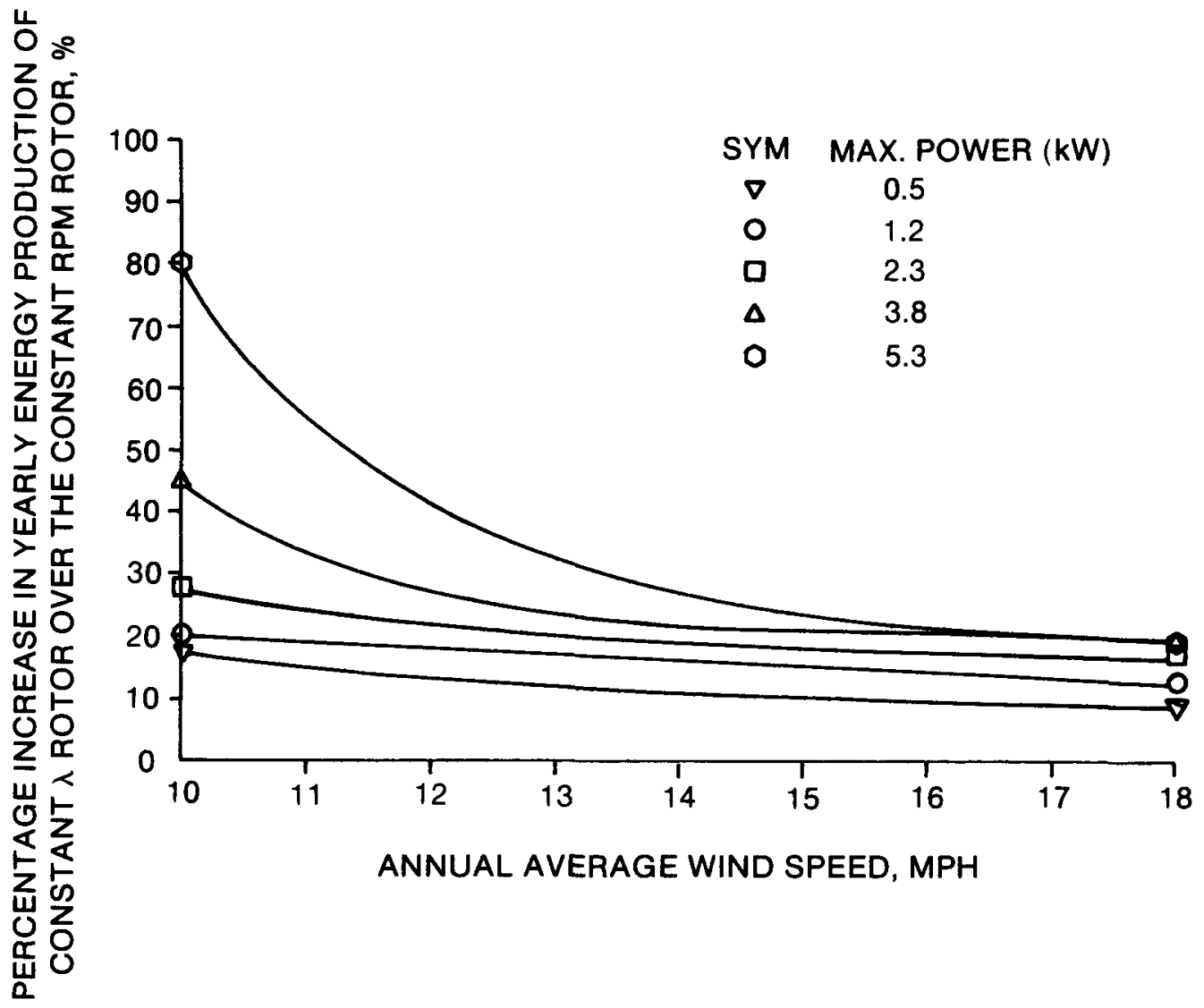

Figure 20. Rotor Energy Production Comparison Between a Constant rpm Rotor and a Constant $\lambda$ Rotor SWECS 
An illustration of this effect has been made by using efficiency curves taken from dynamometer tests carried out at Rocky Flats. The efficiency curve as a function of power ratio (two-dimensional) of a constant rpm rotor subsystem is plotted in Figure 5 . Figure 6 shows the efficiency curve of a constant $\lambda$ rotor subsystem as a function of power ratio and rpm ratio (three-dimensional). The performance comparison of the two rotor configuration systems is shown in Figure 21 . It is seen that the difference in energy production is greatly reduced and mostly diminished in high winds. This is due to much poorer power train efficiency given by a constant $\lambda$ rotor subsystem. Should a better subsystem be developed, of course, energy production would improve. 


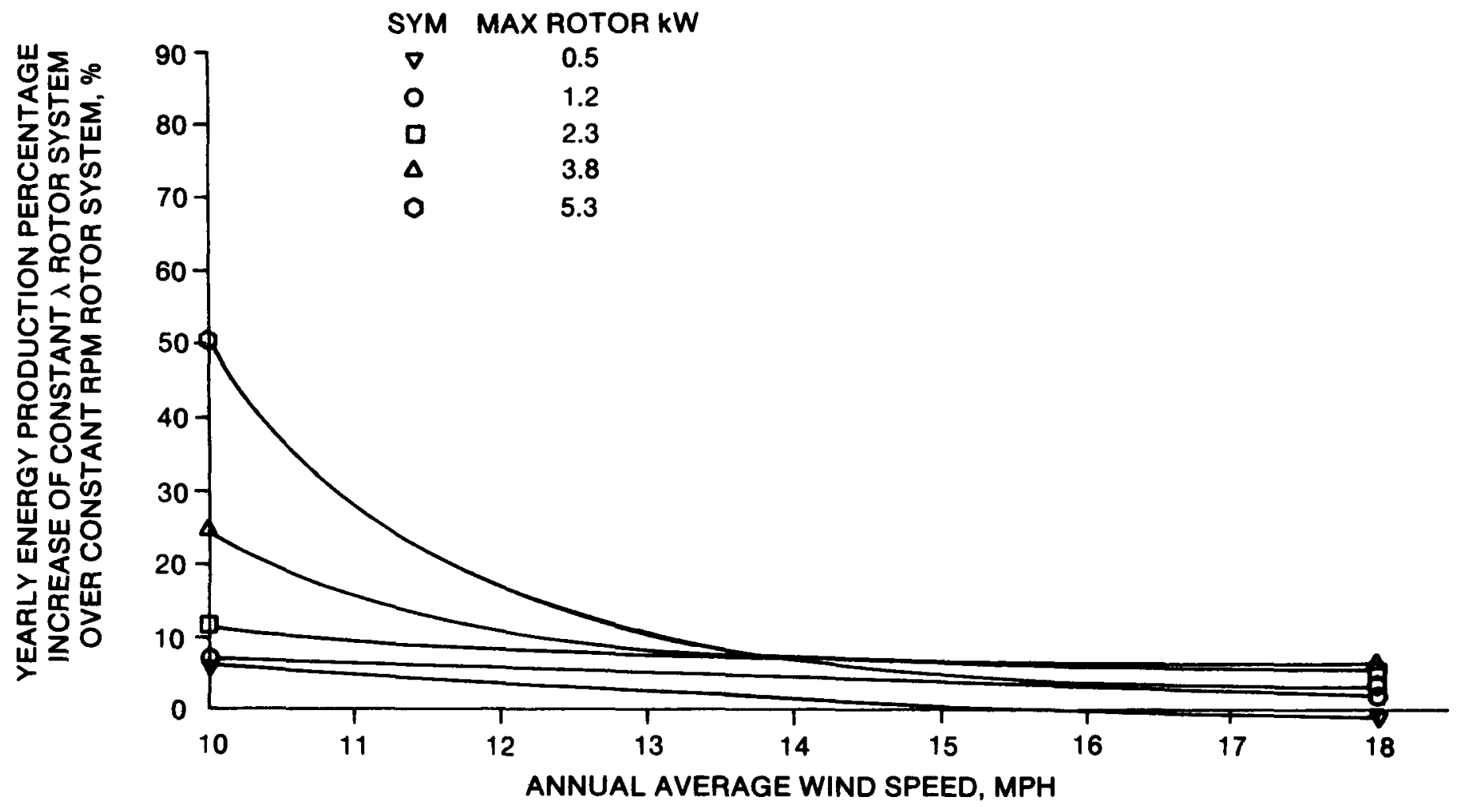

Figure 21

Final System Energy Production Comparison Between a

Constant rpm Rotor and a Constant $\lambda$ Rotor SWECS 


\section{CONCLUSIONS AND RECOMMENDATIONS}

The Systems Engineering Analysis Computer Code has proven to be an efficient SWECS research, development, and design tool. Preliminary configuration design trade-offs and parametric studies now can be carried out with minimum computer costs. With rotor geometry and blade airfoil aerodynamic data, major rotor performance can be calculated by the code. When subsystem efficiencies are known, SWECS system performance can be predicted. The energy matching/mismatching questions between SWECS supply and load demand can be answered when the local diurnal wind and load profiles are available.

The following conclusions regarding the general trends of wind system design parameters have been derived from case study results.

1. Rotor power coefficient curve $\left(C_{p}\right.$ vs. $\left.\lambda\right)$ is strongly affected by the blade pitch angle for a fixed pitch rotor and indicates that deviation of half a degree from the optimum pitch angle can result in noticeable performance degradation.

2. Rotor maximum power output and cut-in wind speed are a strong function of rotor $\mathrm{rpm}$ for a constant $\mathrm{rpm}$ rotor SWECS. In general, they increase with rotor $\mathrm{rpm}$.

3. The optimum rotor $\mathrm{rpm}$ for a constant $\mathrm{rpm}$ rotor SWECS increases with annual average wind speeds.

4. Annual rotor energy production of a constant $\lambda$ rotor SWECS is found much higher than that of a constant rpm rotor SWECS. The difference decreases with $\bar{v}$.

5. Overall system efficiency is vital to the final determination of SWECS energy yield. While a constant $\lambda$ rotor is more efficient than a constant rpm rotor, the rectifiers and inverters required to process constant $\lambda$ rotor output reduce their overall performance advantage. Development of more efficient power conversion equipment for constant $\lambda$ systems (or use of mechanical loads) would enhance their energy production edge. 
The following recommendations are appropriate for the continuation of SEACC work:

1. Component cost sensitivity can be included in the code to evaluate the effects of components on the cost of energy (COE).

2. A component sizing subroutine is needed to accomplish the COE sensitivity study.

3. A rotor and tower dynamics calculation subroutine should be included to ensure vibration-proof SWECS.

4. Economic issues such as life cycle costs, energy credit, insurance cost and tax benefits can be included.

5. The SEACC model can be expanded to allow analysis of wind farm applications. 
1. Banas, J. F. and Sullivan, W. N., "Engineering of Wind Energy Systems," Sandia Laboratories, Albuquerque, NM, SAND75-0530, January 1976 or Wind Technology Journal, Vol. 1, No. 1, Spring 1977.

2. Klıng, A., "Varıable Speed Wind Turbines for High Wind Energy Conversions," Wind Engineering, Vol. 1, No. 2, 1977.

3. Justus, C. G., Mikha11, A., "Generic Power Performance Estimates for Wind Turbines," Wind Technology Journal, Vol. 2, Nos. 1 and 2, Spring and Surmer 1978.

4. Moment, R. L., and Butterfield, C. P., "New Developments in Wind Systems Technology," Proceedings of the Second International Conference on Alternative Energy Sources, Miamı, Florida, December 1979.

5. Martin, C. W., "Annual Energy Production from Fixed-Pitch, ConstantSpeed Rotors," Proceedings of the 1981 Wind Energy Technology Conference, Engineering Extension, College of Engineering, University of Missouri-Columbia, Columbia, Missouri 65211.

6. Justus, C. G, Hargraves, W. R., and Mikhai T, A., Reference Wind Speed Distribution and Height Profiles for Wind Turbine Design and Performance Evaluations, 0R0/5108-7614, Department of Energy/Georg1a Institute of Technology, August 1976.

7. Hodgman, C. D., C.R.C. Standard Mathematical Tables, Chemral Rubber Publishing Co.

8. NASA-Lewis Research Center, Wind Power Office, Cleveland, Ohio.

9. Elliott, D. L., and Barchet, W. R., Wind Energy Resource Atlas, Volume 1-12, PNL-3195, WERA-1-12, UC-60 D0E/PaCif IC Northwest Laboratory, April 1980.

10. Jacobs, E. N. and Sherman, A., "Airfoll Section Characteristics as Affected by Variations of the Reynolds Number," NACA TR 586, 1937.

11. Miley, S. J., A Catalog of Low Reynolds Number Airfoll Data for Wind Turbine Applications, Rockwell International, Rocky Flats Wind Systems Program, RFP-3387, February 1982.

12. Miller, R. H., et al., Wind Energy Conversion Volume 2: Aerodynamics of Horizontal Axis Wind Turbine, C00-4131-T1 (Volume 2), MIT, September 1978.

13. Wilson, R. E., Lissaman, P. B. S., and Walker, S. N., Aerodynamic Performance of Wind Turbines, Oregon State University, June 1976.

14. Stoddard, F. S., "Momentum Theory and Flow States for Windmrlls," Wind Technology Journal, Vol. 1, No. 1, Spring 1977.

15. Viterna, L. A., Janetzke, D. C., "Theoretical and Experimental Power from Large Horizontal-Axis Wind Turbines," Fifth Biennial Wind Energy Conference and Workshop, Washington, D.C., October 1981.

16. Tu, P. K. C., "Small Wind Systems Performance Model Development and Some Parametric Study Results," Proceedings of the 1982 Wind and Solar Energy Technology Conference, the University of Missouri-Columbia, Columbia, Missour 1, Apr11 1982. 
APPENDIX A SEACC USER'S MANUAL 


\section{APPENDIX A \\ SEACC USER'S MANUAL}

\section{A.1 Introduction}

This manual is intended to help prospective users become familiar with the SWECS Systems Engineering \& Analysis Computer Code (SEACC), understand the options provided, and operate the program with minimum guesswork by presenting it with step-by-step illustrations.

A user with a basic knowledge in general engineering, perhaps with some understanding of wind energy terminology, and a little home work in the subject of airfoil characteristics and data tables (Refs. 10, and 11) should be able to use this computer program and perform parametric studies.

The present computer codes (Appendix $C$ ) were written for computer mode 1 "Eclipse" manufactured by Data General Corp. Users should seek assistance from computer experts in adapting this program to a computer which differs from "Eclipse."

Appendix $B$ shows the computer commands for compiling and integrating code subprograms and establishing a procedure file and output files. Again, these steps should be completed by persons who are familiar with the computer operation and its programming requirements.

Included in the following sections are the input files, program steps, and a sample calculation. Users should prepare their own input files based on the desired designs. However, a sample input file is included so that users can validate the code and become familiar with the options provided by the SEACC. 


\section{A.2 Input Files}

Before the execution of the computer program, a user needs to prepare input data files, such as: 1) rotor data file, 2) special rotor rpm schedule file, 3) power train efficiency file, either for a constant rpm rotor or for a variable rpm rotor SWECS, 4) data file for local diurnal wind speed distribution of four seasons, and 5) data file for load characteristics of four seasons. Data file 3 is required for the system performance. Those who are interested in the rotor performance only may skip file 3 and data files 4 and 5, which are for energy supply/demand matching investigations only.

\section{A.2.1 Rotor Data File}

As explained in the PROP code (Ref. 13), this file should describe blade aerodynamic characteristics $\left(C_{D}\right.$ and $\left.C_{L}\right)$, rotor geometry, tower height and wind site altitude, etc. Computer statements and names of variables are as follows:

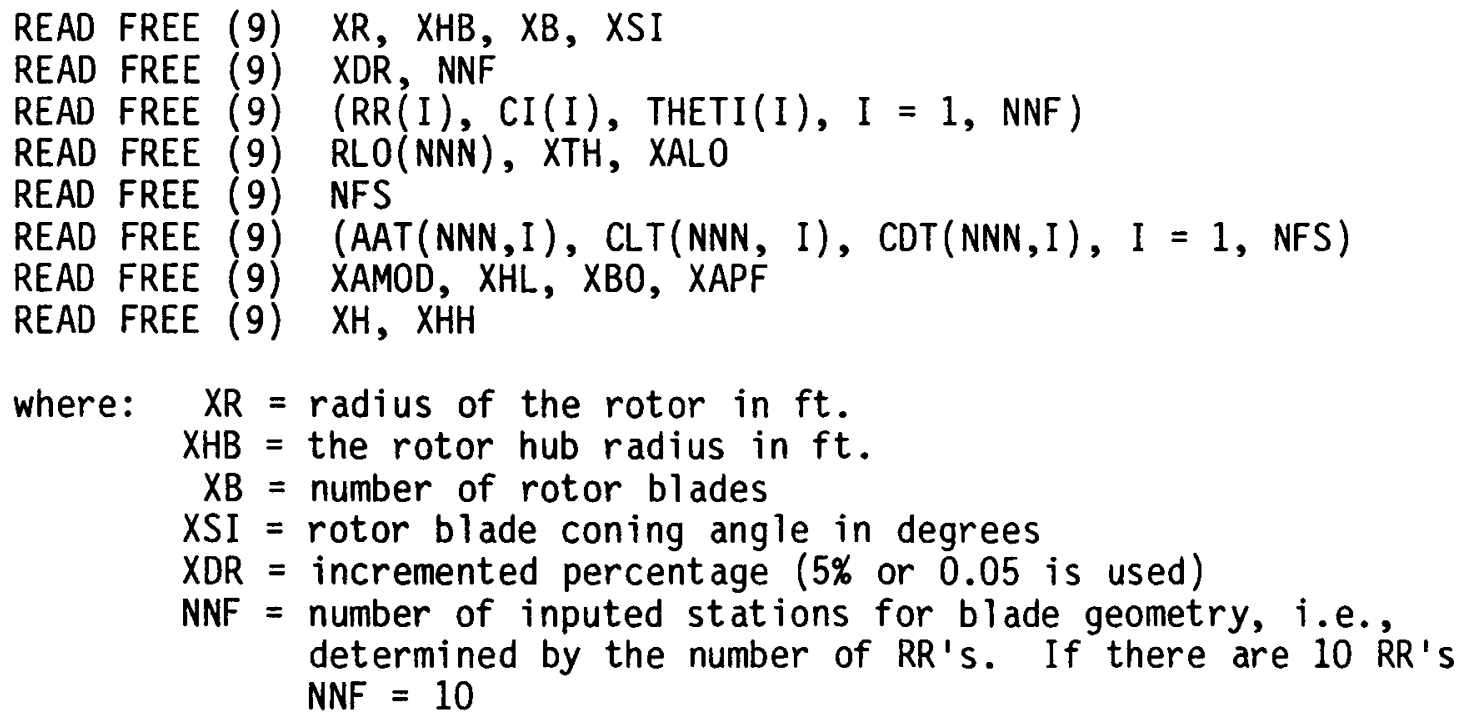




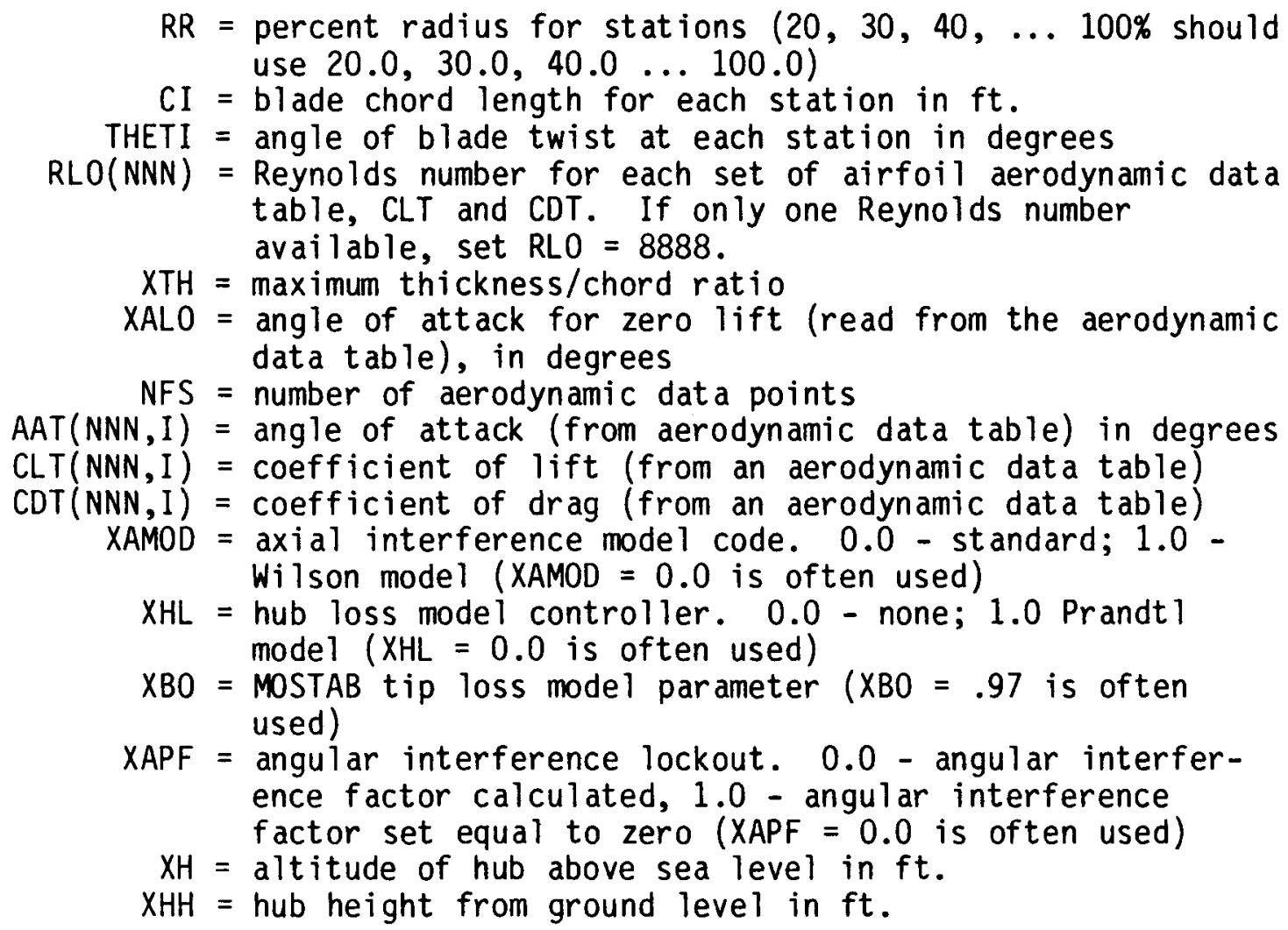

An example of a rotor data file, ROTORIN, is shown in Table A-1 for a rotor design (shown in Table 3) whose dimensions are:

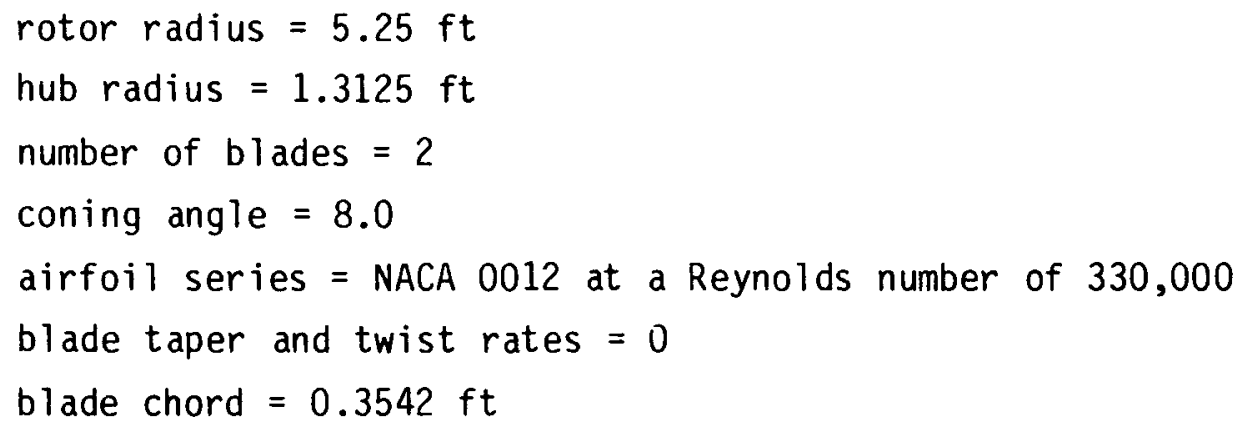

ROTORIN will be used in the sample calculation later in the text. 
PROP Code Rotor Input File - ROTORIN

$\begin{array}{llll}5.25 & 1.3125 & 2.0 & B .0 \\ 0.05 & 16 & \\ 100.0 & 0.3542 & 0.0 & \\ 95.0 & 0.3542 & 0.0 \\ 90.0 & 0.3542 & 0.0 \\ 85.0 & 0.3542 & 0.0 \\ 80.0 & 0.3542 & 0.0 \\ 75.0 & 0.3542 & 0.0 \\ 70.0 & 0.3542 & 0.0 \\ 65.0 & 0.3542 & 0.0 \\ 60.0 & 0.3542 & 0.0 \\ 55.0 & 0.3542 & 0.0 \\ 50.0 & 0.3542 & 0.0 \\ 45.0 & 0.3542 & 0.0 \\ 40.0 & 0.3542 & 0.0 \\ 35.0 & 0.3542 & 0.0 \\ 30.0 & 0.3542 & 0.0 \\ 25.0 & 0.3542 & 0.0 \\ 8388 & 0.12 & 0.0 \\ 16 & -.0 & \\ -4.0 & -.40 & .011 \\ -3.0 & -.30 & .010 \\ -2.0 & -.20 & .009 \\ -1.0 & -.10 & .008 \\ 0.0 & 0.00 & .008 \\ 1.0 & .11 & .008 \\ 2.0 & .21 & .009 \\ 3.0 & .31 & .010 \\ 4.0 & .41 & .011 \\ 5.0 & .51 & .012 \\ 6.0 & .60 & .013 \\ 7.0 & .69 & .015 \\ 8.0 & .77 & .019 \\ 9.0 & .83 & .024 \\ 10.0 & .84 & .026 \\ 11.0 & .86 & .084 \\ 0.0 & 1.0 & 0.97 \\ 0.0 & 9.0 & & \\ & & \\ & & \end{array}$




\section{A.2.2 Special Rotor rpm Schedule File}

This file determines the rotor rpm as a function of wind speed. It is used for a special rotor rpm schedule design. Computer statements for read-in of the file are as follows:

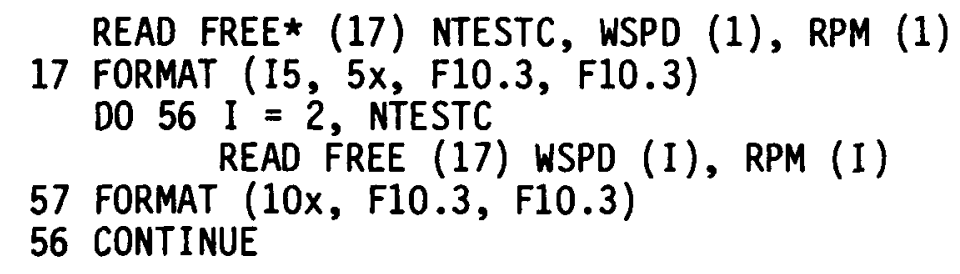

where: NTESTC $=$ number of points in the table (maximum of 26) WSPD $(I)=$ wind speeds $R P M(I)=$ rotor $r p m$ 's

* An optional format is provided for those who wish a formatted read.

The file name of this input file should be "RPMFIL." No other file name will be recognized by the computer. An example is shown in Table A-2.

\section{A.2.3 Power Train Efficiency File}

This file includes efficiencies of SWECS components such as gearboxes, electric generators (alternators/induction generators/synchronous generators), electronic inverters, rectifiers, etc. SWECS design requires several different combinations of these components. For instance, a constant rpm rotor SWECS needs a gearbox and induction generator or a low speed, direct drive synchronous generator as its subsystem. A variable rpm rotor SWECS design requires an alternator, a rectifier and an inverter as its power train subsystem. An example efficiency file for a constant rpm rotor is shown in Table A-3. A file for a variable rpm rotor is shown in Table A-4. Table A-3 is a two dimensional table which indicates the power train efficiency as a function of the power ratio which is defined as:

Power ratio $=$ generator output power $/$ generator rated power 
TABLE $\mathrm{A}-2$

Special Rotor rpm Input File - RPMFIL

\begin{tabular}{|c|c|c|}
\hline 25 & $\begin{array}{r}7.000 \\
8.000 \\
9.000 \\
10.000 \\
11.000 \\
12.000 \\
13.000 \\
14.000 \\
15.000 \\
16.000 \\
17.000 \\
18.000 \\
19.030 \\
20.000 \\
22.000 \\
24.000 \\
26.000 \\
28.000 \\
30.000 \\
32.000 \\
34.000 \\
36.000 \\
33.000 \\
40.000 \\
44.000\end{array}$ & $\begin{array}{r}.000 \\
15.000 \\
40.000 \\
30.000 \\
100.000 \\
105.000 \\
110.000 \\
110.000 \\
110.000 \\
110.000 \\
110.000 \\
110.000 \\
110.000 \\
110.030 \\
110.000 \\
110.030 \\
110.000 \\
110.000 \\
110.000 \\
30.000 \\
50.030 \\
40.000 \\
20.000 \\
10.000 \\
1.030\end{array}$ \\
\hline
\end{tabular}


TABLE A-3

Power Train Efficiency Input File (2-Dimensional) - PTEFF1

$\begin{array}{rl}3.0 & 0.0 \\ 13.1 & 0.016 \\ 53.5 & 0.129 \\ 65.5 & 0.276 \\ 65.1 & 0.229 \\ 67.5 & 0.334 \\ 73.8 & 0.433 \\ 72.6 & 0.329 \\ 72.1 & 0.537 \\ 73.1 & 0.735 \\ 72.5 & 0.777 \\ 72.8 & 0.812 \\ 74.5 & 0.915 \\ 72.5 & 0.335 \\ 72.5 & 0.748 \\ 0.0 & 0.0\end{array}$

The file name of this table is designated as PTEFF1; no other name is recognized by the computer. Computer statements for read-in are as follows:

DO $20 \mathrm{I}=1,100$

READ FREE (4) EFF (I), POWERAT (I)

10 FORMAT (F5.1, F8.4)

IF (EFF(I) .EQ. 0.0) GO TO 30

20 CONTINUE

30 IF (I .EQ. 1) GO TO 20

40 CONTINUE

Each column of this data file should be ended with zeros to terminate the read loop. The variables are defined as:

$$
\operatorname{EFF}(I)=\begin{aligned}
& \text { power train efficiencies in decimals (for } 100 \% \\
& \text { efficiency } E F F(I)=1.0 \text { ) (maximum of } 26 \text { points) }
\end{aligned}
$$

$\operatorname{POWERAT}(I)=$ power ratios 
Table A-4 is a three-dimensional table which indicates the power train efficiencies as a function of both power ratios and rpm ratios. The rpm ratios are defined as:

$$
\text { rpm } \text { ratio }=\text { generator } \mathrm{rpm} / \mathrm{gener} \text { ator } \text { rated } \mathrm{rpm}
$$

The file name is designated as TUDEE. No other name will be recognized by the computer.

The computer statements are as follows:

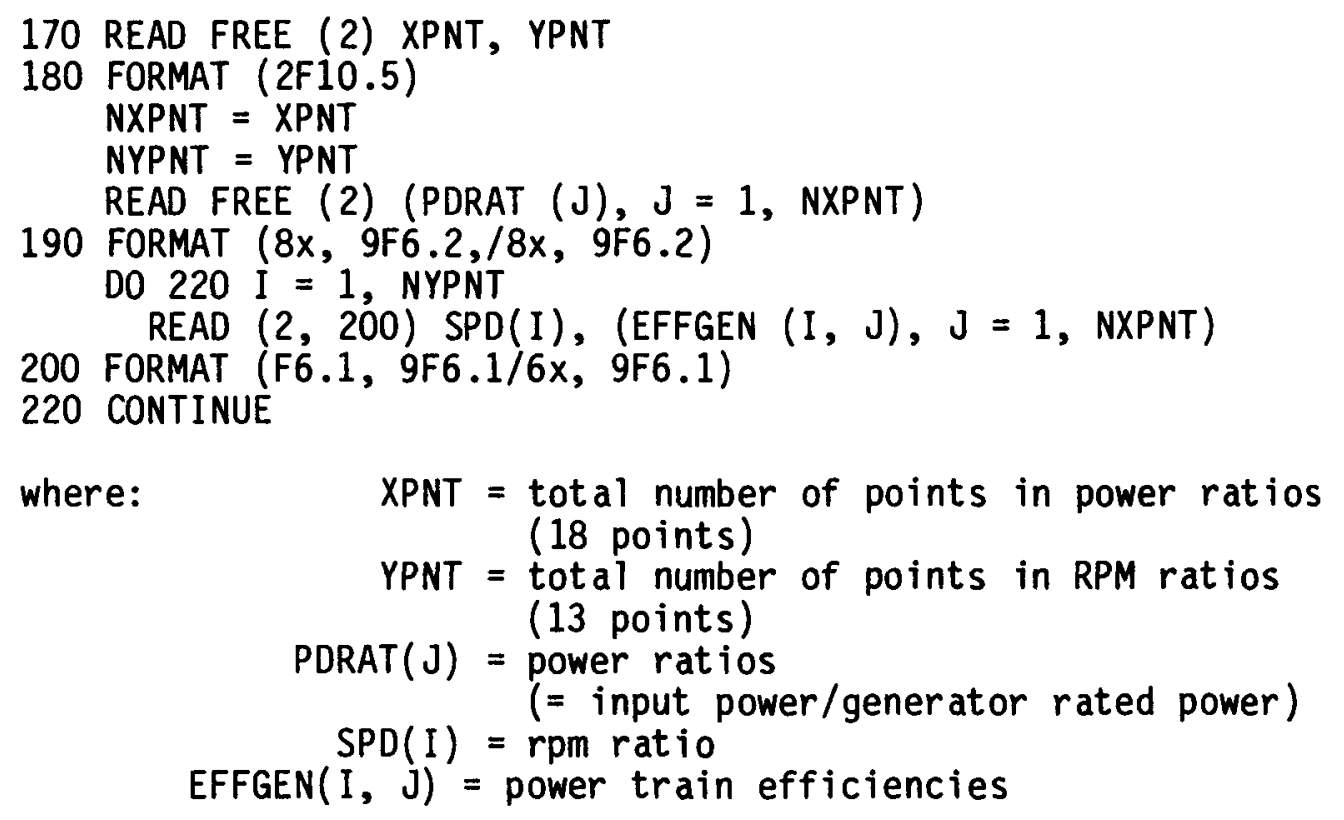

Tables A-3 and A-4 can be derived from either dynamometer test results or manufacturer's specifications. When estimating a system power output or yearly energy yield, the power train efficiency plays a vital role in the final prediction. 
TABLE A-4

Power Train Efficiency Input File (3-Dimensional) - TUDEE

18.

13.

\begin{tabular}{|c|c|c|c|c|c|c|c|c|c|}
\hline $\begin{array}{l}0.4 \\
0.6 \\
0.8 \\
0.9 \\
1.0 \\
1.1 \\
1.2 \\
1.3 \\
1.4 \\
1.5 \\
1.6 \\
1.5\end{array}$ & $\begin{array}{r}0.0 \\
3.7 \\
0.0 \\
0.0 \\
0.0 \\
13.4 \\
0.0 \\
34.2 \\
0.0 \\
56.7 \\
0.0 \\
54.8 \\
0.0 \\
54.8 \\
0.0 \\
23.9 \\
0.0 \\
55.7 \\
0.0 \\
57.5 \\
0.0 \\
59.4 \\
0.0 \\
03.3 \\
0.0 \\
71.1 \\
0.0 \\
0.0\end{array}$ & $\begin{array}{r}0.04 \\
3.3 \\
0.0 \\
0.0 \\
13.5 \\
13.4 \\
22.5 \\
34.2 \\
27.0 \\
55.5 \\
30.5 \\
54.8 \\
34.2 \\
55.7 \\
37.3 \\
54.5 \\
40.5 \\
55.7 \\
45.0 \\
53.6 \\
49.5 \\
57.5 \\
52.2 \\
58.4 \\
54.0 \\
09.3 \\
0.0\end{array}$ & $\begin{array}{l}9.09 \\
3.9 \\
0.0 \\
0.0 \\
15.3 \\
13.5 \\
33.3 \\
33.3 \\
40.5 \\
55.8 \\
45.0 \\
54.8 \\
45.0 \\
56.6 \\
49.6 \\
55.7 \\
52.2 \\
54.8 \\
54.0 \\
55 . ? \\
55.8 \\
55.7 \\
56.7 \\
56.6 \\
56.7 \\
57.5 \\
0.0\end{array}$ & $\begin{array}{l}3.12 \\
1.0 \\
0.0 \\
0.0 \\
16.7 \\
13.5 \\
38.7 \\
32.4 \\
45.0 \\
54.9 \\
47.7 \\
64.8 \\
48.6 \\
56.6 \\
49.5 \\
55.7 \\
54.0 \\
64.8 \\
35.8 \\
54.9 \\
57.6 \\
54.9 \\
59.5 \\
54.8 \\
56.5 \\
55.7 \\
0.9\end{array}$ & $\begin{array}{c}0.23 \\
1.1 \\
0.0 \\
0.0 \\
16.2 \\
12.6 \\
37.8 \\
32.4 \\
50.3 \\
51.3 \\
50.3 \\
63.0 \\
51.2 \\
53.9 \\
51.2 \\
56.6 \\
62.1 \\
63.0 \\
52.1 \\
53.0 \\
63.0 \\
33.9 \\
53.0 \\
63.9 \\
53.0 \\
54.8 \\
0.0\end{array}$ & $\begin{array}{r}0.30 \\
1.24 \\
0.0 \\
0.0 \\
14.4 \\
12.6 \\
36.0 \\
31.5 \\
52.1 \\
45.0 \\
61.2 \\
54.0 \\
51.2 \\
53.0 \\
52.1 \\
56.6 \\
53.0 \\
53.0 \\
54.8 \\
52.1 \\
55.7 \\
63.0 \\
57.5 \\
53.0 \\
58.4 \\
53.9\end{array}$ & $\begin{array}{r}3.4 \\
1.5 \\
0.0 \\
0.0 \\
14.4 \\
11.7 \\
34.2 \\
24.3 \\
57.6 \\
34.2 \\
32.1 \\
43.2 \\
61.2\end{array}$ & $\begin{array}{r}3.5 \\
1.95 \\
0.0 \\
0.0 \\
14.4 \\
7.2 \\
34.2 \\
16.2 \\
57.6 \\
22.5 \\
54.8 \\
27.0 \\
51.2 \\
31.5 \\
53.0 \\
77.8 \\
55.7 \\
38.7 \\
57.5 \\
40.5 \\
59.3 \\
45.0 \\
70.2 \\
49.5 \\
72.0 \\
54.0 \\
0.0 \\
0.0\end{array}$ & $\begin{array}{r}3.6 \\
2.0 \\
0.0 \\
0.0 \\
14.4 \\
0.0 \\
34.2 \\
0.0 \\
56.7 \\
0.0 \\
54.8\end{array}$ \\
\hline
\end{tabular}




\section{A.2.4 Diurnal Wind Speed File}

If the local wind site diurnal wind speed distribution is known (Ref. 9), the diurnal power output of a SWECS can be estimated. The result helps the understanding of power mismatch and the sizing of the SWECS in regard to the energy demands.

Computer statements for the diurnal wind speed file are as follows:

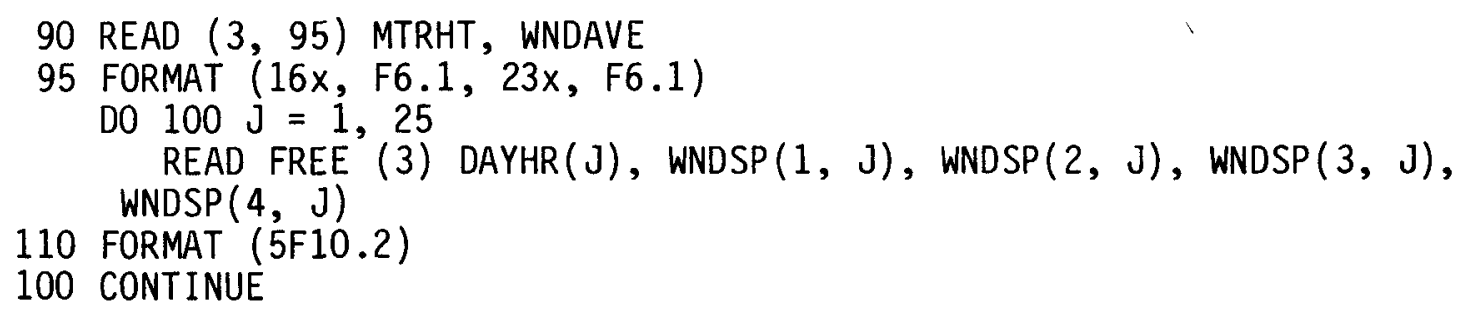

The file name for this input file is designated as WINDDI. No other names will be recognized by the computer. An example is shown in Table A-5.

\section{A.2.5 Diurnal Load Distribution File}

This file helps the estimate of energy supply/demand mismatch for SWECS applications. The computer statements for the file are:

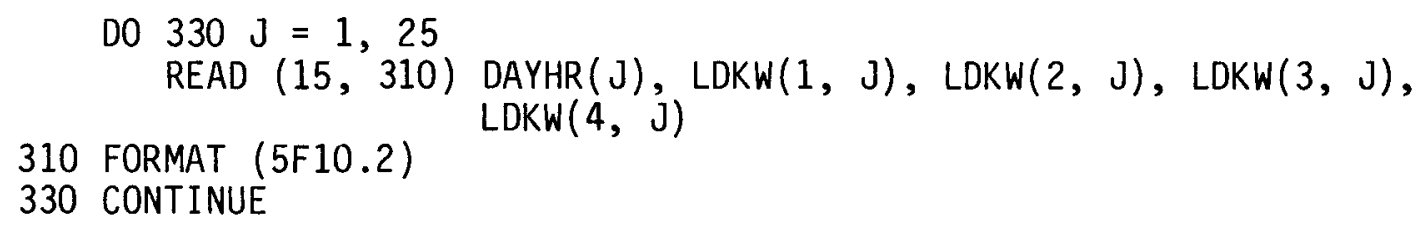




\section{TABLE A-5}

\section{Diurnal Wind Speed Distribution - WINDDI}

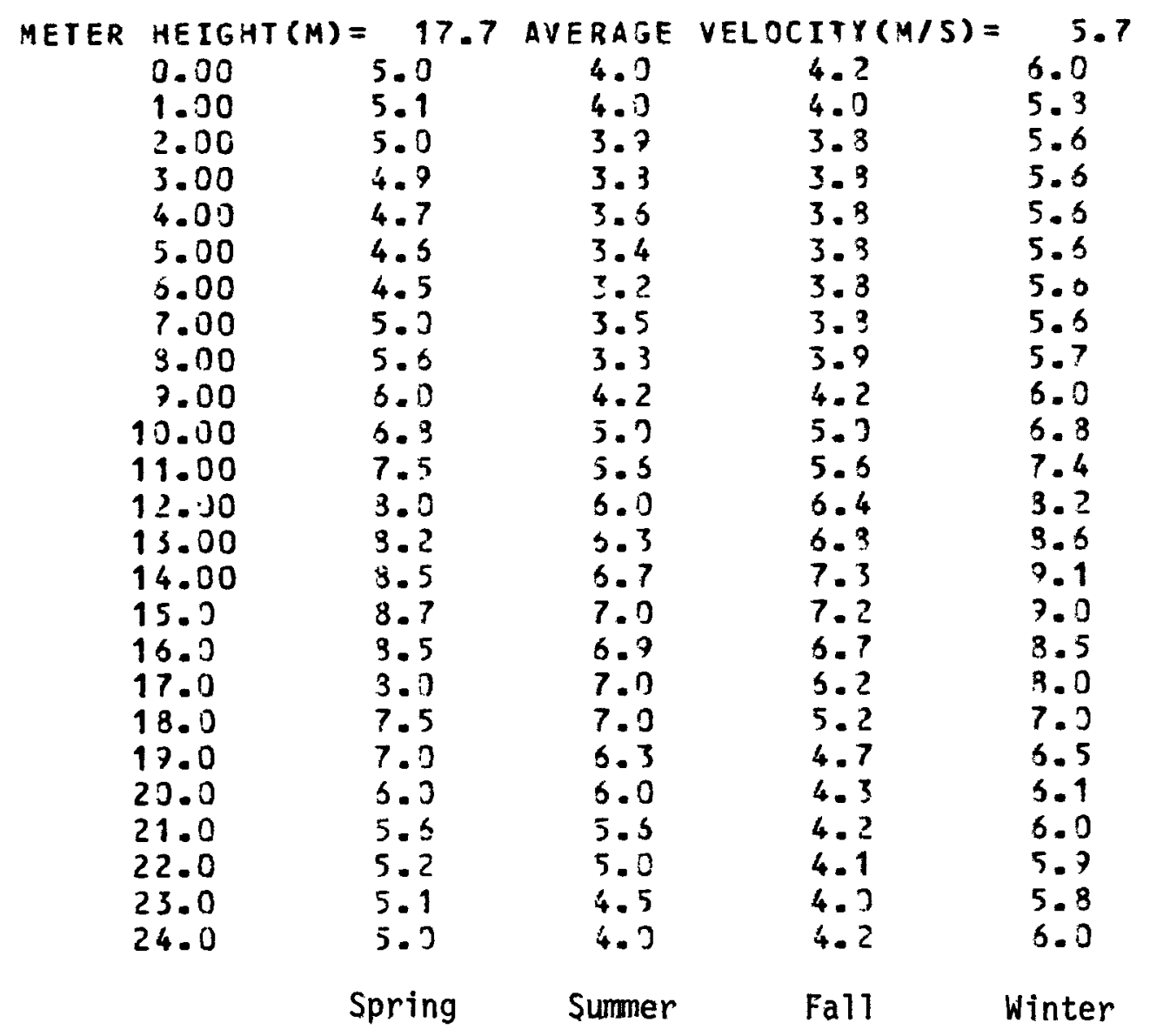


where: $\operatorname{DAYHR}(\mathrm{J})=$ hour of the day

$$
\begin{aligned}
& \operatorname{LDKW}(1, \mathrm{~J})=\text { diurnal loads during spring, } \mathrm{KW} \\
& \operatorname{LDKW}(2, \mathrm{~J})=\text { diurnal loads during sumer, } \mathrm{KW} \\
& \operatorname{LDKW}(3, \mathrm{~J})=\text { diuranl loads during fall, } \mathrm{kW} \\
& \operatorname{LDKW}(4, \mathrm{~J})=\text { diurnal loads during winter, } \mathrm{kW}
\end{aligned}
$$

The file is designated as LOADDI. No other names would be recognized by

\begin{tabular}{|c|c|c|c|c|}
\hline $\begin{array}{l}3.0 \\
1.3 \\
2.0 \\
3.0 \\
4.0 \\
5.3 \\
5.3 \\
7.3 \\
3.0 \\
7.3 \\
13.3 \\
11.3 \\
12.3 \\
13.0 \\
14.3 \\
15.3 \\
16.3 \\
17.3 \\
13.0 \\
13.0 \\
23.1 \\
21.3 \\
22.3 \\
23.3 \\
24.3\end{array}$ & $\begin{array}{l}2.75 \\
2.75 \\
3.20 \\
2.75 \\
5.32 \\
2.75 \\
7.25 \\
5.30 \\
5.30 \\
2.75 \\
3.3 \\
2.75 \\
5.30 \\
3.3 \\
2.75 \\
3.3 \\
3.75 \\
2.75 \\
2.75 \\
5.20 \\
5.30 \\
3.75 \\
4.50 \\
2.75 \\
2.75 \\
\end{array}$ & $\begin{array}{l}0.3 \\
2.25 \\
2.25 \\
2.75 \\
0.2 \\
2.35 \\
2.25 \\
4.50 \\
4.50 \\
3.3 \\
2.25 \\
2.25 \\
4.30 \\
4.70 \\
4.70 \\
4.70 \\
4.70 \\
4.70 \\
4.70 \\
3.75 \\
4.35 \\
2.35 \\
5.35 \\
2.35 \\
2.35\end{array}$ & $\begin{array}{l}2.75 \\
2.75 \\
5.70 \\
2.75 \\
2.75 \\
2.75 \\
5.30 \\
5.30 \\
5.30 \\
3.3 \\
2.75 \\
2.75 \\
5.30 \\
2.75 \\
3.3 \\
2.75 \\
3.3 \\
2.75 \\
2.75 \\
3.30 \\
12.25 \\
2.75 \\
7.25 \\
2.75 \\
2.75\end{array}$ & $\begin{array}{r}5.50 \\
5.50 \\
7.75 \\
5.50 \\
5.50 \\
5.50 \\
7.75 \\
17.25 \\
7.75 \\
5.50 \\
5.50 \\
5.30 \\
7.75 \\
5.50 \\
2.75 \\
3.75 \\
2.75 \\
5.50 \\
5.50 \\
7.75 \\
7.75 \\
5.50 \\
10.70 \\
5.70 \\
5.50\end{array}$ \\
\hline & Spring & Summer & $\mathrm{Fall}$ & Winter \\
\hline
\end{tabular}
the computer. An example is listed in Table A-6.

TABLE A-6

Diurnal Load Distribution - LOADDI 
In summary, there is a total of six input files which need to be prepared according to various investigation purposes. These six files are:

1. ROTORIN or other names - "PROP" code input file

2. RPMFIL - special rotor rpm vs. wind speed file

3. PTEFF1 - describe power train efficiency (2-D)

4. TUDEE - describe power train efficiency (3-D)

5. WINDDI - describe seasonal diurnal wind speeds

6. LOADDI - describe seasonal diurnal load profile 


\section{A.3 Execution of SEACC}

An SEACC execution steps flow chart is given in Table A-7. Prospective users may compare the chart with the step-by-step description set forth in this section. For various rotor system designs, appropriate steps have to be taken to ensure the computational continuity. It is suggested that the user sort the routes from the chart according to the desired SWECS design and run the SEACC accordingly.

STEP 1

Log-on procedures (such as user's name, passwords, user's account, etc.) STEP 2

To start the SEACC the user enters the following commands to prompt the procedure file "SEACC":

SEACC $S$ ROTOR FILE NAME

where s means space between the words.

STEP 3

Computer: DELETED TUOUT

DELETED WINDOUT

ENTER XMIN, XMAX, DELX, OMEGA, THETP, GO, XETA, BLD

NOTE :

1. Output data files, TUOUT and WINDOUT, are cleared out for new data.

2. $\underline{X M I N}=$ Minimum value of tip-speed ratios $(\lambda)$ for the $C p$ vs. $\lambda$ table. Usually XMIN $=1.0$ is used.

$\underline{X M A X}=$ Maximum value of $\lambda$. Depending upon other variables are used, the XMAX should be large enough to show negative Cp's where cut-in wind speed can be estimated. Usually XMAX = $15-20$ is used. User should experiment to find the best value for XMAX.

(Contd. on page 62.) 
TABLE A-7

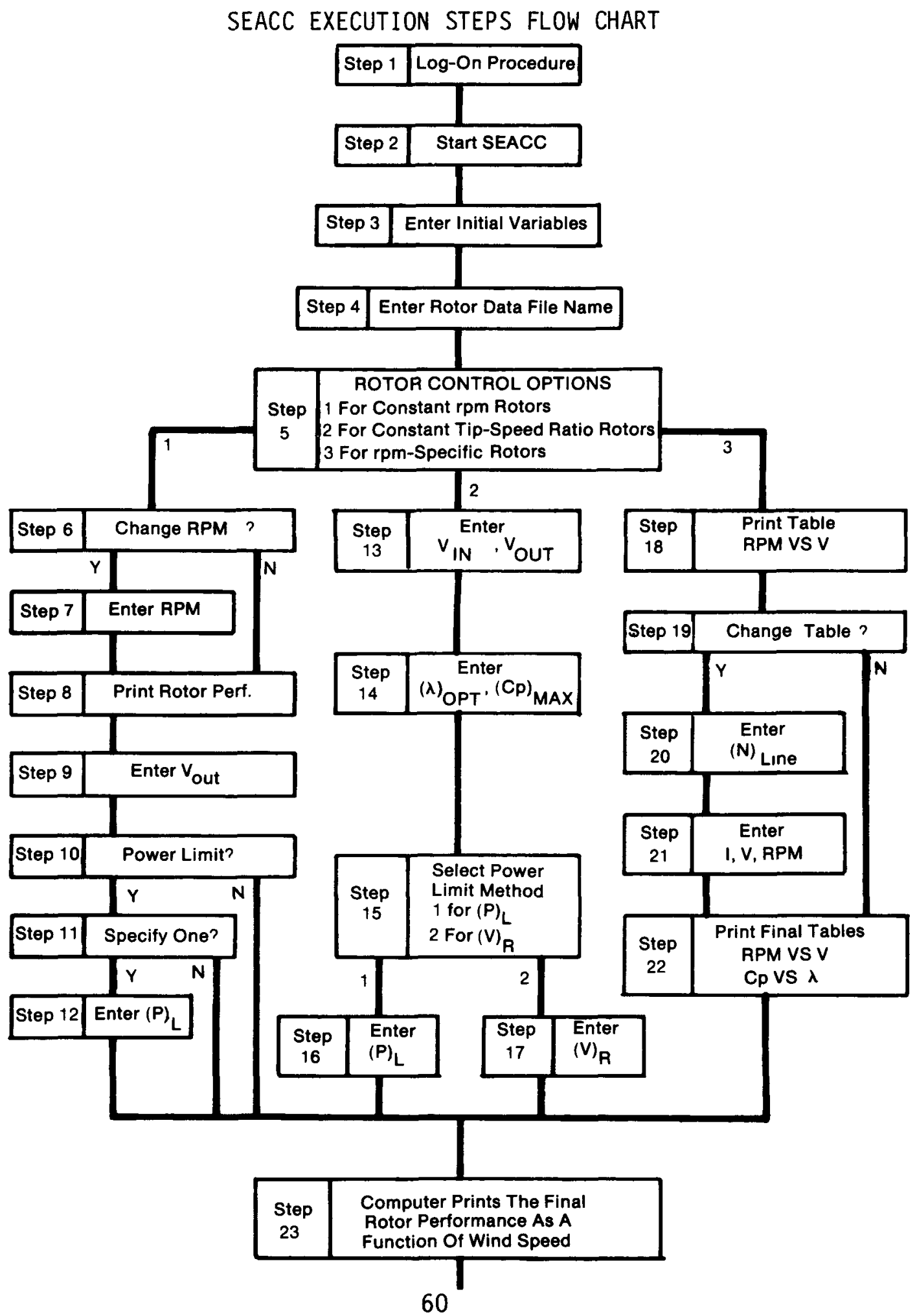


TABLE A-7 (continued)

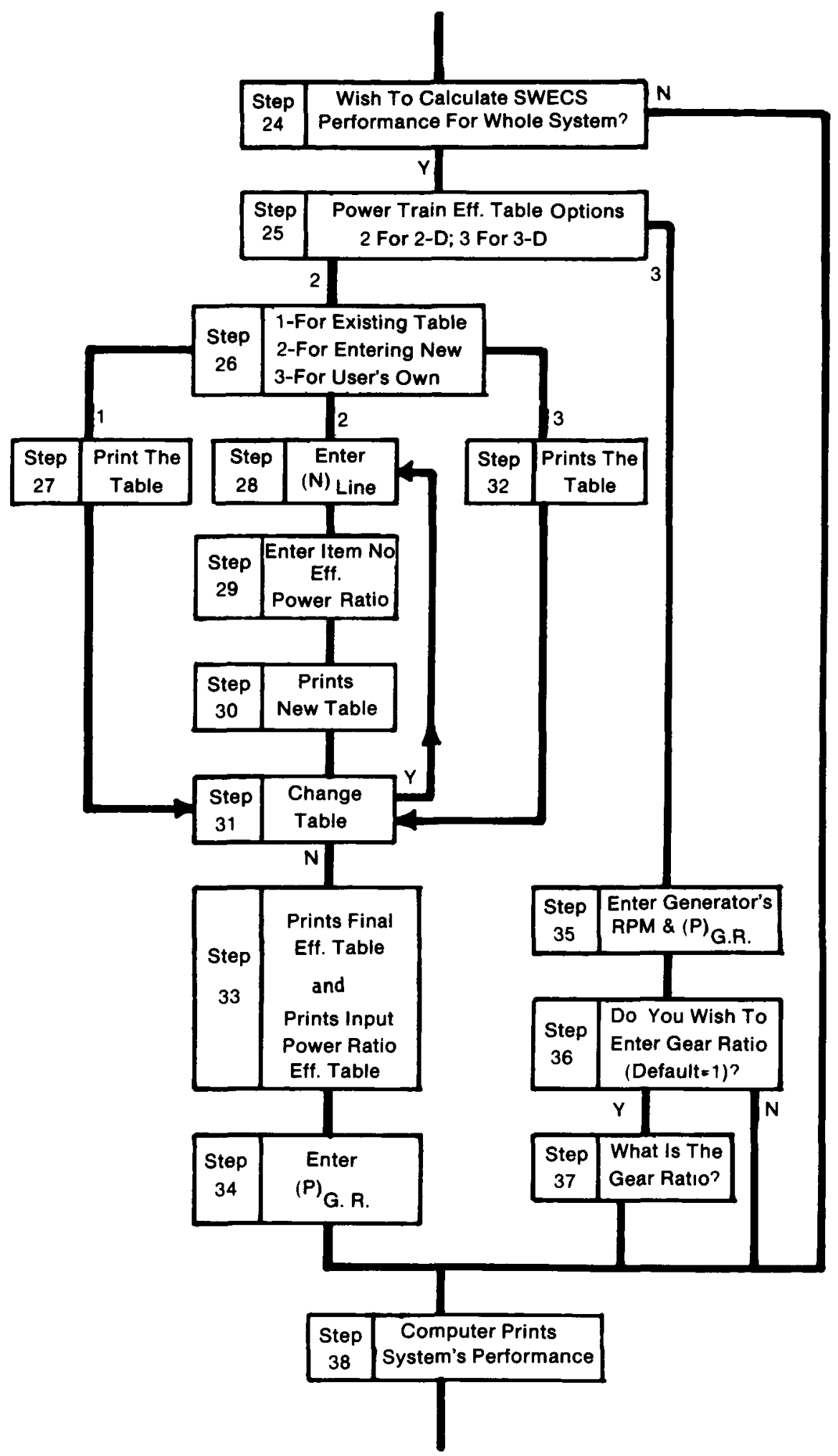


TABLE A-7 (contınued)

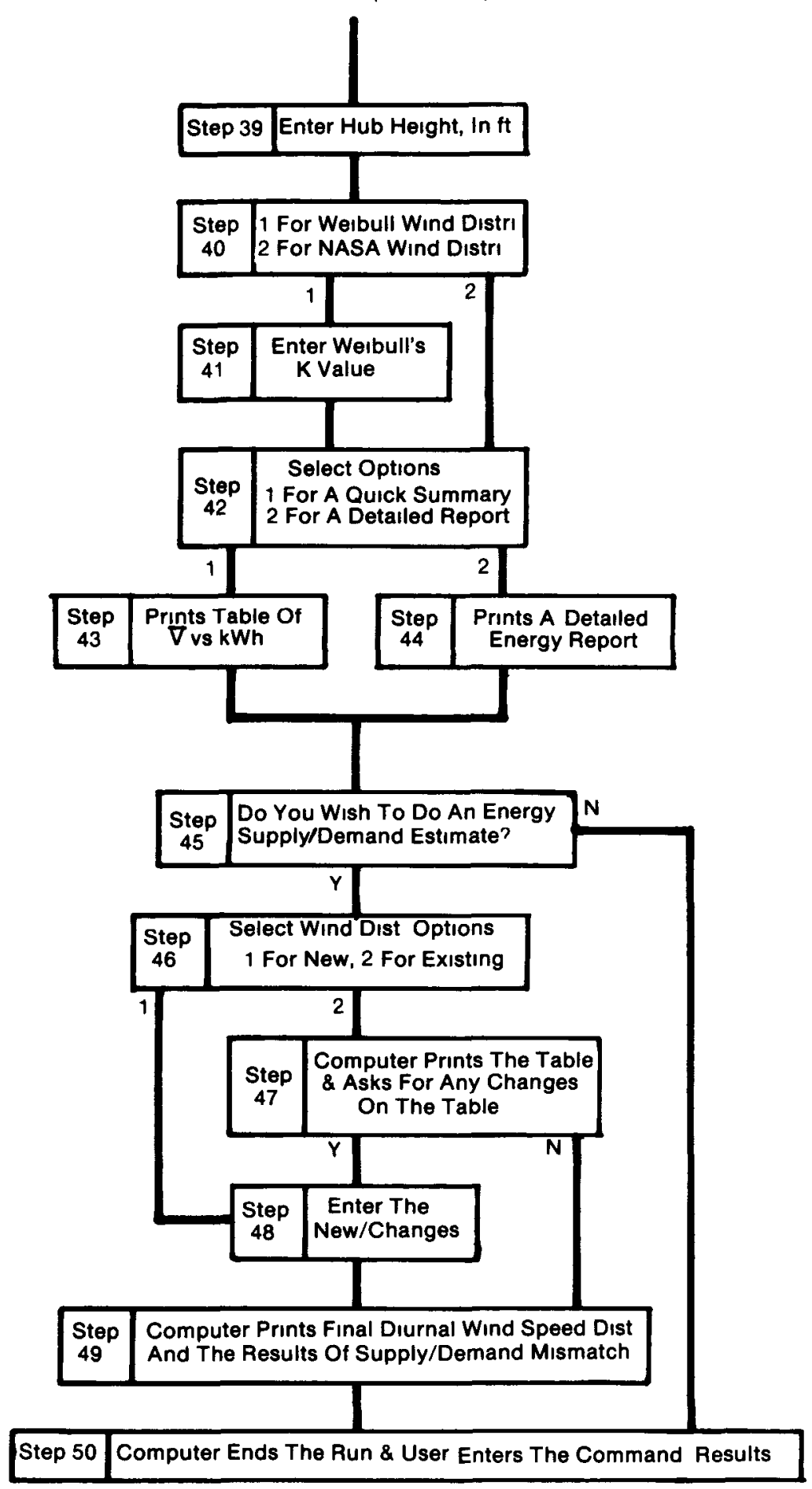




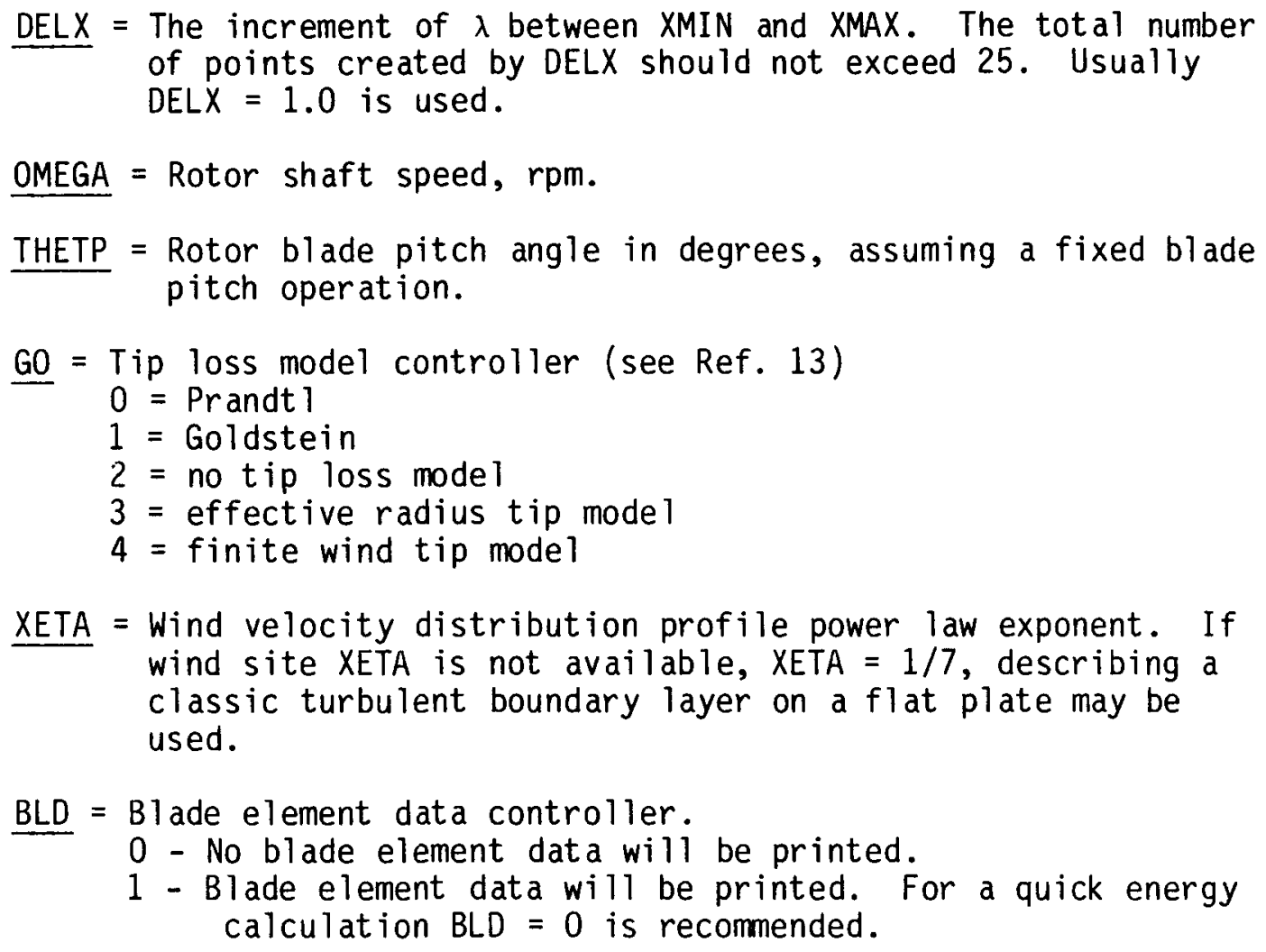
of points created by DELX should not exceed 25 . Usually DELX $=1.0$ is used.

$\underline{O M E G A}=$ Rotor shaft speed, rpm.

$\underline{\text { THETP }}=$ Rotor blade pitch angle in degrees, assuming a fixed blade pitch operation.

$\underline{G 0}=$ Tip loss model controller (see Ref. 13)

$0=$ Prandt 1

$1=$ Goldstein

$2=$ no tip loss model

3 = effective radius tip mode 1

4 = finite wind tip model

$\underline{X E T A}=$ Wind velocity distribution profile power law exponent. If wind site XETA is not available, XETA $=1 / 7$, describing a classic turbulent boundary layer on a flat plate may be used.

$\underline{B L D}=B 1$ ade element data controller.

0 - No blade element data will be printed.

1 - Blade element data will be printed. For a quick energy calculation BLD $=0$ is recommended.

User: Enters appropriate data for the above variables

STEP 4:

Computer: Stop

Enter the datafile name for prop

User: Enters data file name

Computer: The data file name and a table showing $C_{p}$ vs. $\lambda$ will be printed by computer. This table is the result given by PROP code

STEP 5:

Computer: Please select your rotor control options:

1. For constant rpm rotors

2. For constant tip-speed ratio rotors

3. For rotors having a special rpm vs. wind speed schedule 
User: Enters 1, 2, or 3

NOTE: When 1 is entered, STEP 6 will be taken

When 2 is entered, STEP 13 will be taken

When 3 is entered, STEP 18 will be taken

STEP 6:

Computer: Do you wish to change prop's rotor rpm?

User: Enters $Y$ (for yes) or $N$ (for no)

NOTE: The user specified a rotor rpm when OMEGA was specified in STEP 3. This step is to enable the user to make a change on the rotor $\mathrm{rpm}$ before the calculation which follows. If a $\mathrm{N}$ (for no) is prompted, the computer will skip STEP 7 and go to STEP 8 directly.

STEP 7:

Computer: Enter rotor rpm

User: Enters a new rotor rpm

STEP 8:

Computer: Prints a table showing rotor power, tip-speed ratio, power coefficient, and rotor $r p m$ as a function of wind speed.

STEP 9:

Computer: Enter maximum power cutoff wind speed in mph

User: Enters Vout

STEP 10:

Computer: Do you want a max. power output limit?

User: Enters $\mathrm{Y}$ or $\mathrm{N}$

NOTE: Generator's rated power often determine the max. rotor power output

When $Y$ is entered, STEP 11 will be taken

When $N$ is entered, STEP 23 will be taken 
STEP 11:

Computer: Do you wish to specify the limiting power?

User: Enters $\mathrm{Y}$ or $\mathrm{N}$

NOTE: When $\mathrm{N}$ is entered, the computer will use the calculated max. power as the limiting power and skip STEP 12

STEP 12:

Computer: What is the limiting power?

User: Enters $(P)_{1 \text { imit }}$

NOTE: The computer will continue on to STEP 23 for this rotor option (constant $\mathrm{rpm}$ rotor). However, when a rotor design option of a constant $\lambda$ SWECS is desired, and 2 is entered by user at STEP 5, STEPS 13-17 will be taken by computer. Please consult Table A-7 for continuity.

STEP 13:

Computer: Enter cut-in and cut-out wind speeds in mph

User: Enters $V_{\text {in }}$ and $V_{\text {out }}$

STEP 14:

Computer: Enter tip-speed ratio and power coefficient, $C_{p}$

User: Enters $(\lambda)$ opt and $\left(C_{p}\right)_{m}$ (these values can be found from $C p$ vs. $\lambda$ table printed out previously. The power coefficient is the $\max C p$ and the "tip speed ratio" is the corresponding $\lambda$ value)

STEP 15:

Computer: Enter your choice of using power (type in 1) or rated wind speed (type in 2) to limit max. power

User: Enters 1 or 2

NOTE: When 1 is entered, STEP 16 will be taken; 2, STEP 17

STEP 16:

Computer: What is the limiting power?

User: Enters a ( $P$ ) limit (computer will skip STEP 17 after this) 
Computer: What is the rated wind speed?

User: Enters $(V)_{\text {rated }}$

NOTE: Computer will continued on to STEP 23 after this step.

STEP 18:

NOTE: The following, STEPS 18-22, is the procedure for rotor option 3 at STEP 5, a SWECS design with special rotor rpm vs. wind speed schedule. The user should have an input file, RPMFIL, prepared.

Computer: Prints the RPMFIL file again (this is a table showing rotor rpm as a function of wind speed)

STEP 19:

Computer: Do you wish to change this table? (Y/N)

User: Enters $\mathrm{Y}$ or $\mathrm{N}$

NOTE: When $Y$ is entered, computer will go to STEP 20

When $N$ is entered, computer will go to STEP 22

STEP 20:

Computer: Enter number of lines you wish to change (or enter)

User: Enters $(N)$ line

STEP 21:

Computer: Enter I, WSPD(I), RPM(I):

User: Enters appropriate values

STEP 22:

Computer: Prints final rpm table and $C_{p}$ vs. $\lambda$ table (the results from PROP) 
STEP 23:

Computer: Prints the final rotor performance data showing rotor power (kW), tip-speed ratio, power coefficient, and rotor rpm as a function of wind speed in mph.

STEP 24:

Computer: Do you wish to obtain SWECS performance by adding power train efficiency to the system? ( $Y / N)$

User: Enters $\mathrm{Y}$ or $\mathrm{N}$

NOTE: If $N$ is entered the computer will skip all the power train efficiency evaluation procedures and go to the final SWECS performance data table, STEP 23.

If $Y$ is entered, the computer will go to STEP 25. At this step, the user should be aware that a power train efficiency table should be provided either in the computer input file or at hand ready to be entered into computer.

STEP 25:

Computer: Enter 2 for a 2-D table or 3 for a 3-D table

User: Enters 2 or 3

NOTE: A 2-D table is the table showing power train efficiency as a function of power $r$ atio (= output power/generator's rated power). This table is often used for a constant rpm rotor SWECS. Whereas a 3-D table shows the power train efficiency as a function of power ratio and rpm ratio (= generator's $\mathrm{rpm} / \mathrm{rated}$ generator $\mathrm{rpm})$. This table is often used for a constant tip-speed ratio (or a variable rpm) rotor SWECS or a rpm-specific rotor SWECS. When 2 is entered, STEP 26 will be taken; 3, STEP 35.

STEP 26:

Computer: Enter your preference for constructing power train eff. table:

1. For using the existing table

2. For entering a new table

3. For user supplied table (file OWNEFF) 
User: Enters 1,2, or 3

NOTE: When 1 is entered, STEP 27 will be taken When 2 is entered, STEP 28 will be taken When 3 is entered, STEP 32 will be taken

STEP 27:

Computer: Prints the power train efficiency table and goes to STEP 31

STEP 28:

Computer: Enter number of lines you wish to change (or enter)

User: Enters $(N)$ line

STEP 29:

Computer: Enter item number, efficiency, power ratio

User: Enters appropriate data

STEP 30:

Computer: Prints the power train efficiency table

STEP 31:

Computer: Do you wish to make change to the above table $(Y / N)$ ?

User: Enters $\mathrm{Y}$ or $\mathrm{N}$

NOTE: If $Y$ is entered, the computer will go to STEP 28 to repeat the changing process. If $\mathrm{N}$ is entered, the computer will go to STEP 33.

STEP 32:

Computer: Prints the user supplied power train efficiency table and goes to STEP 31 to see whether the user wishes to change this table.

STEP 33:

Computer: Prints the final power train efficiency table in two versions: One is based on output power ratio; the other one is based on input power ratio 
STEP 34:

Computer: Enter the generator's rated power

User: Enters $(P)_{G . R .}$

NOTE: The computer continues on STEP 38 after this step.

STEP 35:

Computer: Enter the rated power and rpm of the generator

User: Enters $(P)_{G . R}$. and $(R P M)_{G . R}$.

STEP 36:

Computer: Do you wish to enter the gear ratio (DEFAULT $=1$ )

User: Enters $\mathrm{Y}$ or $\mathrm{N}$

NOTE: If $Y$ is entered, the computer will go to STEP 37, otherwise STEP 38

STEP 37 :

Computer: What is the gear ratio?

User: Enters the gear ratio

STEP 38:

Computer: Prints the final SWECS performance

STEP 39:

Computer: Enter hub height, in $\mathrm{ft}$

User: Enters the hub height value

STEP 40 :

Computer: Enter 1 for WEIBULL, 2 for NASA distribution

User: Enters 1 or 2

NOTE: When 1 is entered, the computer goes to STEP $41 ; 2$, STEP 42 
STEP 41:

Computer: Enter WEIBULL distribution's $k$ value

User: Enters the $K$

STEP 42:

Computer: For energy output enter 1 for a quick surmary, 2 for a detailed report

User: Enters 1 or 2

NOTE: If 1 is entered, computer goes to STEP $43 ; 2$, STEP 44

STEP 43:

Computer: Prints the annual energy production as a function of annual average wind speed from 5 to $18 \mathrm{mph}$

STEP 44:

Computer: The computer prints out a detailed report with the following output as a function of annual average wind speed:

- annual energy yield in kWh

- annual average power output in kW (= annual energy yield/ $8766 \mathrm{hr}$ )

- most probable wind speed (= the most frequently occurring wind speed during the year)

- most probable power output (= the most frequently occurring power during the year)

- wind speed for maximum energy density (= the wind speed contributes the most energy, kWh, during the year)

STEP 45:

Computer: Do you want an energy supply/demand mismatch estimate $(Y / N)$ ?

User: Enters $\mathrm{Y}$ or $\mathrm{N}$

NOTE: When $Y$ is entered, computer goes to STEP 46; N, STEP 50, the end of the run 
STEP 46 :

Computer: Select the following options for determining the wind speed distribution

1. For entering a new distribution by the user

2. For using an existing distribution

User: Enters 1 or 2

NOTE: When 1 is entered, computer goes to STEP 48; 2, STEP 47

STEP $47:$

Computer: Prints the wind speed distribution and asks:

Do you wish to change this table?

User: Enters $\mathrm{Y}$ or $\mathrm{N}$

NOTE: When $Y$ is entered, a change subroutine will be initiated by the computer STEP 48; otherwise, STEP 49 will be taken

STEP 48:

Computer: How many points do you wish to change (or enter)?

User: Enters $(\boldsymbol{N})$ point

Computer: Enter season $-1=$ spr, 2 = summer, etc., hour, wind speed

User: Enters appropriate values.

STEP 49:

Computer: The computer will print the final diurnal wind speed dist. \& proceed to make energy supply/demand mismatch estimate to show the total and average values of SWECS' kWh, load kWh, and net $k$ Wh during four seasons. A positive net kWh means surplus of energy produced by SWECS. A negative net $\mathrm{kWh}$ means that the supplied wind energy may be totally absorbed by the load.

STEP 50:

Computer: Completes this routine and is waiting for new initiation as shown in STEP 2. When a printout (hard copy) of the above results is desired, User can enter the command: RESULTS. 


\section{A.4 A Sample Calculation}

Included in this section is a sample calculation using input files provided elsewhwere in this report, including rotor input file ROTORIN, Table A-1; the power train efficiency input file PTEFF1, Table A-3; the diurnal wind speed distribution file WINDDI, Table A-5; and the diurnal load distribution file LOADDI, Table A-6. Operation of this sample will validate the SEACC when it is installed in a user's computer and demonstrate how some of the design options are provided by the code. Only one route through the computation was taken; i.e., the route for the design of a constant rpm rotor system with a simple 2-D power train efficiency table. The following shows the steps used, the user's input, and computer's output at the computer terminal. 
SEACC ROTORIN

ENTER XMIN, XMAX, DELX, OMEGA, THETP, GO, XETA, BLD

$1,20,2,346,2,3,0.143,0$

STOP

ENTER THE DATAFILE NAME FOR FROF

ROTORIN

THE AIRFOIL IIATAFILE USEI IS ROTORIN

THE FOLLOWING IS FROP'S ROTOR TIP SFEED RATIO V.S. CP TABLE: TIF SPEED RATIO POWER COEF., CP

$\begin{array}{rr}.990 & .010 \\ 2.971 & .024 \\ 4.951 & .141 \\ 6.932 & .266 \\ 8.912 & .314 \\ 10.893 & .305 \\ 12.873 & .254 \\ 14.854 & .165 \\ 16.835 & .047 \\ 18.815 & -.111\end{array}$

PLEASE SELECT YOUR OPTIONS:

1 FOR CONSTANT RPM ROTORS

2 FOR CONSTANT TIP SPEED RATIO ROTORS

3 FOR ROTORS WITH A SFECIAL RFM US WIND SPEED FUNCTION

1

DIO YOU WISH TO CHANGE FROP'S ROTOR RPM ?

$\mathbf{N}$

ROTUR PERFORMANCE IIATA GIVEN EY PROF COIE ARE:

\begin{tabular}{crrrr}
$\begin{array}{c}\text { WIND SPEELS } \\
\text { MPH }\end{array}$ & \multicolumn{1}{c}{$\begin{array}{l}\text { PGWER } \\
\text { KW }\end{array}$} & $\begin{array}{c}\text { TIP SPEED } \\
\text { RATIOS }\end{array}$ & $\begin{array}{c}\text { FOWER COEF } \\
\text { CF }\end{array}$ & $\begin{array}{c}\text { RQITOR } \\
\text { RFM }\end{array}$ \\
130.972 & 9.822 & .990 & .010 & 346.000 \\
43.657 & .888 & 2.971 & .024 & 346.000 \\
26.194 & 1.123 & 4.951 & .141 & 346.000 \\
18.710 & .777 & 6.932 & .266 & 346.000 \\
14.552 & .431 & 8.912 & .314 & 346.000 \\
11.907 & .230 & 10.893 & .305 & 346.000 \\
10.075 & .117 & 12.873 & .254 & 346.000 \\
8.731 & .050 & 14.854 & .165 & 346.000 \\
7.704 & .011 & 16.835 & .047 & 346.000 \\
6.893 & -.015 & 18.815 & -.111 & 346.000
\end{tabular}

ENTER MAXIMUM POWER CUT-GFF WINI SFEED IN MFH

50

IO YOU WANT A MAX. PQWER CUITPUT LIMIT? 
FINAL ROTOR PERFORMANCE DATA ARE AS FCLLOWS:

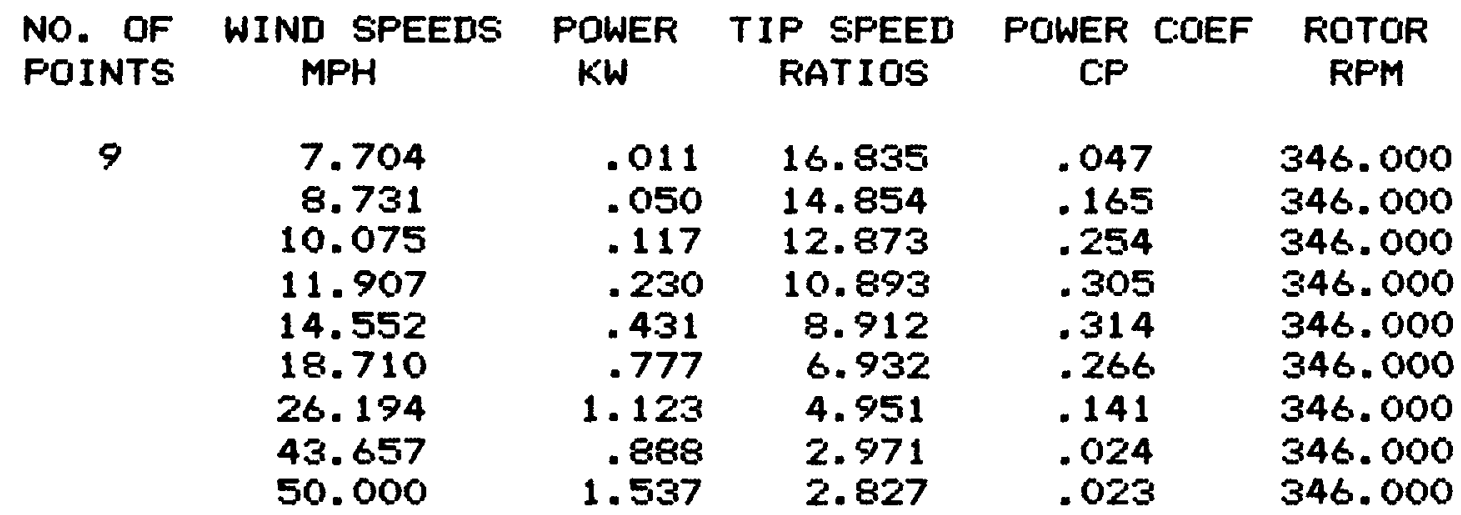

DO YOU WISH TO OBTAIN SWECS FERFORMANCE EY

ADUING POWER-TRAN EFFICIENCY TO THE SYSTEM? $(Y / N)$

$Y$

ENTER 2 FOR A $2-0$ TABLE OR 3 FOR A $3-D$ TABLE

ENTER YOUR PREFERENCE OF CONSTRUCTING THE FOWER-TRAIN EFFICIENCY TAELE

1 FOR USING THE EXISTING TABLE

2 FOR ENTERING A NEW TABLE

3 FOR USER SUPFLIED TABLE (FILE OWNEFF)

1

THIS IS YOUR EXISTING FOWER TRAN EFF. TABLE, BASEI ON LOAD FOWER RATICIS:

ITEM NO. EFFICIENCIES

1

2

3

4

5

6

7

8

9

10

11

12

13

14

15
POWER RATIO

.0000

.0160

.1290

.2760

.2890

.3340

.4380

.5290

.5570

.7560

.7970

.8120

.9150

.9350

.9480

DO YOU WISH TO MAKE CHANGES TO THE ABGVE TABLE?(Y/N)

$N$ 
THIS IS THE POWER TRAN EFF. TAELE BASED ON INPUT POWER RATIOS: ITEM NO. EFFIC:IENC:IES

POWER RATIOS

$\begin{array}{rrr}1 & .0 & .0000 \\ 2 & 13.1 & .1221 \\ 3 & 50.5 & .2554 \\ 4 & 65.5 & .4214 \\ 5 & 65.1 & .4439 \\ 6 & 67.5 & .4948 \\ 7 & 70.3 & .6230 \\ 8 & 72.6 & .7287 \\ 9 & 72.1 & .7725 \\ 10 & 73.1 & 1.0342 \\ 11 & 72.9 & 1.0933 \\ 12 & 72.8 & 1.1154 \\ 13 & 74.5 & 1.2282 \\ 14 & 72.5 & 1.2897 \\ 15 & 72.3 & 1.3112 \\ \text { ENTER THE GENERATOR-S RATED FOWER }\end{array}$

1.5

FINAL SWECS PERFORMANCE DATA ARE AS FQLLOWS:

$\begin{array}{cccccc}\text { NO. OF } & \text { WIND SPEEDS } & \text { SYSTEM } & \text { TIF SPEED } & \text { SYSTEM } & \text { ROTOR } \\ \text { POINTS } & \text { MPH } & \begin{array}{c}\text { POWER } \\ \text { KW }\end{array} & \text { RATIOS POWER COEF } & \text { RPM } \\ & & & & \text { CF } & \end{array}$

$\begin{array}{rrrrr}7.704 & .000 & 16.835 & .000 & 346.000 \\ 8.731 & .001 & 14.854 & .003 & 346.000 \\ 10.075 & .007 & 12.873 & .015 & 346.000 \\ 11.907 & .055 & 10.893 & .073 & 346.000 \\ 14.552 & .241 & 8.912 & .175 & 346.000 \\ 18.710 & .528 & 6.932 & .181 & 346.000 \\ 26.194 & .812 & 4.951 & .102 & 346.000 \\ 43.657 & .618 & 2.971 & .017 & 346.000 \\ 50.000 & 1.124 & 2.827 & .017 & 346.000\end{array}$

ENTER HUB HEIGHT, IN FT.

55

ENTER 1 FOR WEIBULL, 2 FOR NASA IISTRIBUTION

FOR ENERGY DUTFUT ENTER 1 FOR A QUICK SUMMARY, 2 FOR A DETAILED REPORT 
AVERAGE WINI SFEED

MPH

5.00

6.00

7.00

8.00

9.00

10.00

11.00

12.00

13.00

14.00

15.00

16.00

17.00

18.00
ENERGY YIELD

KWH

23.

101.

264.

515.

838.

1207.

1594.

1975.

2332 .

2653.

2934.

3175.

3379.

3550.

DO YQU WANT THE ENERGY SUPFLY/LEMAND MISMATCH ESTIMATE $(Y / N)$ ?

\begin{abstract}
SELEC:T THE FQLLOWING OPTIONS FOR
IIETERMINING THE WIND SPEED IISTRIEUTION

1- FOR ENTERING A NEW DISTRIBUTION BY THE USER

2- FOR USING THE EXISTING IISTRIEUTION

2
\end{abstract}

THE FOLLOWING IS THE 4 SEASONS DIURNAL WIND SFEED DISTRIBUTION TABLE

\begin{tabular}{ccccc} 
IAYHF & \multicolumn{2}{c}{ WINLSFEED IN MFH } & & \\
& SFRING & SUMMER & FALL & WINTER \\
.000 & 13.065 & 10.452 & 10.974 & 15.678 \\
1.000 & 13.926 & 10.452 & 10.452 & 15.155 \\
2.000 & 13.065 & 10.190 & 9.929 & 14.632 \\
3.000 & 12.803 & 9.929 & 9.929 & 14.632 \\
4.000 & 12.281 & 9.407 & 9.929 & 14.632 \\
5.000 & 12.019 & 8.884 & 9.929 & 14.632 \\
6.000 & 11.758 & 8.361 & 9.929 & 14.632 \\
7.000 & 13.065 & 9.145 & 9.929 & 14.632 \\
8.000 & 14.632 & 9.929 & 10.190 & 14.894 \\
9.000 & 15.678 & 10.974 & 10.974 & 15.673 \\
10.000 & 17.768 & 13.065 & 13.065 & 17.768 \\
11.000 & 19.597 & 14.632 & 14.632 & 19.336 \\
12.000 & 20.903 & 15.678 & 16.723 & 21.426 \\
13.000 & 21.426 & 16.461 & 17.768 & 22.471 \\
14.000 & 22.210 & 17.507 & 19.074 & 23.778 \\
15.000 & 22.733 & 18.291 & 18.813 & 23.516 \\
16.000 & 22.210 & 18.029 & 17.507 & 22.210 \\
17.000 & 20.903 & 18.291 & 16.200 & 20.903 \\
18.000 & 19.597 & 18.291 & 13.587 & 18.291 \\
19.000 & 18.291 & 16.461 & 12.281 & 16.984 \\
20.000 & 15.678 & 15.678 & 11.236 & 15.939 \\
21.000 & 14.632 & 14.632 & 10.974 & 15.678 \\
22.000 & 13.587 & 13.065 & 10.713 & 15.416 \\
23.000 & 13.326 & 11.758 & 10.452 & 15.155 \\
24.000 & 13.065 & 10.452 & 10.974 & 15.678
\end{tabular}


DO YOU WISH TO CHANGE THE TABLE?

$\mathbf{N}$

THE LOAD DISTRIBUTION TABLE

DIAYHOUR SFRING SUMMER FALL WINTER

$\begin{array}{rrrrr}.00 & 2.75 & .00 & 2.75 & 5.50 \\ 1.00 & 2.75 & 2.35 & 2.75 & 5.50 \\ 2.00 & 5.00 & 2.25 & 5.00 & 7.75 \\ 3.00 & 2.75 & 2.35 & 2.75 & 5.50 \\ 4.00 & 5.50 & .00 & 2.75 & 5.50 \\ 5.00 & 2.75 & 2.35 & 2.75 & 5.50 \\ 6.00 & 7.25 & 2.25 & 5.00 & 7.75 \\ 7.00 & 5.00 & 4.60 & 5.00 & 10.25 \\ 8.00 & 5.00 & 4.60 & 5.00 & 7.75 \\ 9.00 & 2.75 & .00 & .00 & 5.50 \\ 10.00 & .00 & 2.35 & 2.75 & 5.50 \\ 11.00 & 2.75 & 2.35 & 2.75 & 5.50 \\ 12.00 & 5.00 & 4.60 & 5.00 & 7.75 \\ 13.00 & .00 & 4.70 & 2.75 & 5.50 \\ 14.00 & 2.75 & 4.70 & .00 & 2.75 \\ 15.00 & .00 & 4.70 & 2.75 & 2.75 \\ 16.00 & 2.75 & 4.70 & .00 & 2.75 \\ 17.00 & 2.75 & 4.70 & 2.75 & 5.50 \\ 18.00 & 2.75 & 4.70 & 2.75 & 5.50 \\ 19.00 & 5.00 & 6.95 & 5.00 & 7.75 \\ 20.00 & 5.00 & 6.75 & 10.25 & 7.75 \\ 21.00 & 2.75 & 2.35 & 2.75 & 5.50 \\ 22.00 & 4.50 & 6.85 & 7.25 & 10.00 \\ 23.00 & 2.75 & 2.35 & 2.75 & 5.50 \\ 24.00 & 2.75 & 2.35 & 2.75 & 5.50\end{array}$

DAILY ENERGY SUPFLY AND DEMAND SUMMARY ARE:

ENERGY TYPE SPRING SUMMER FALL WINTER TOTAL AVEFAGE

$\begin{array}{lrrrrrr}\text { SWECS KWH } & 8.62 & 4.77 & 3.61 & 10.41 & 27.41 & 6.85 \\ \text { LOAD KWH } & 83.00 & 86.05 & 86.00 & 152.00 & 407.05 & 101.76 \\ \text { NET KWH } & -74.38 & -81.28 & -82.39 & -141.59 & -379.64 & -94.91\end{array}$


APPENDIX B

Steps for establishing the computer code in a Data General "Eclipse" computer:

B.1 The computer program has to be compiled in Fortran with the following commands:

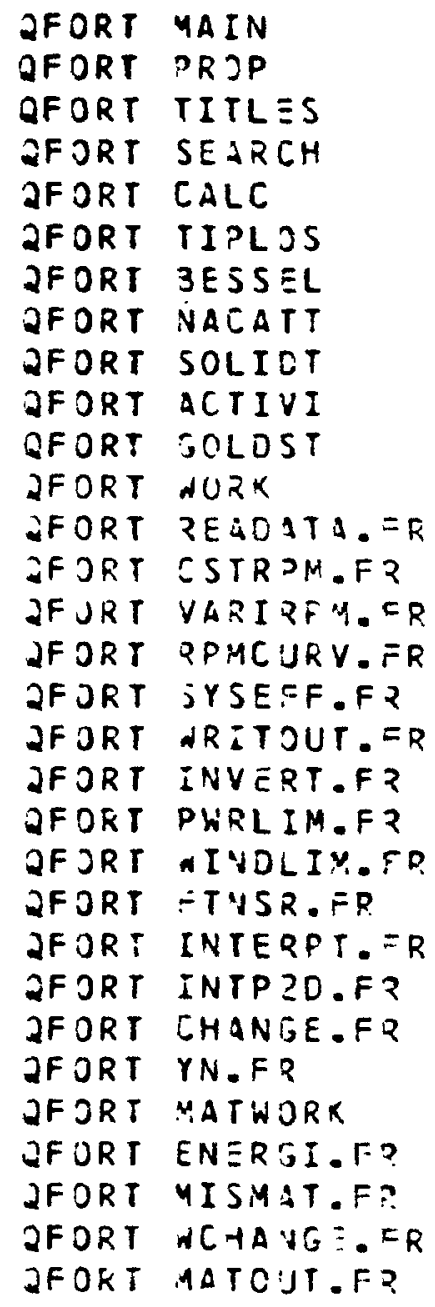


B.2 After all subprograms are compiled, the following statement should be used to complete the final integration of subprograms:

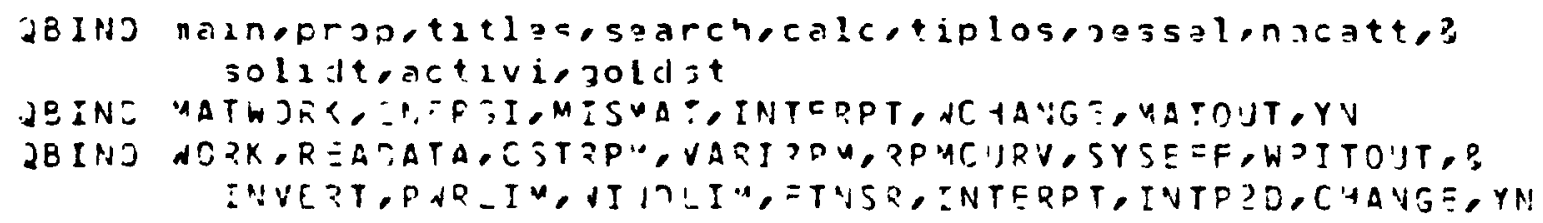

B.3 An execution file has to be made as follows:

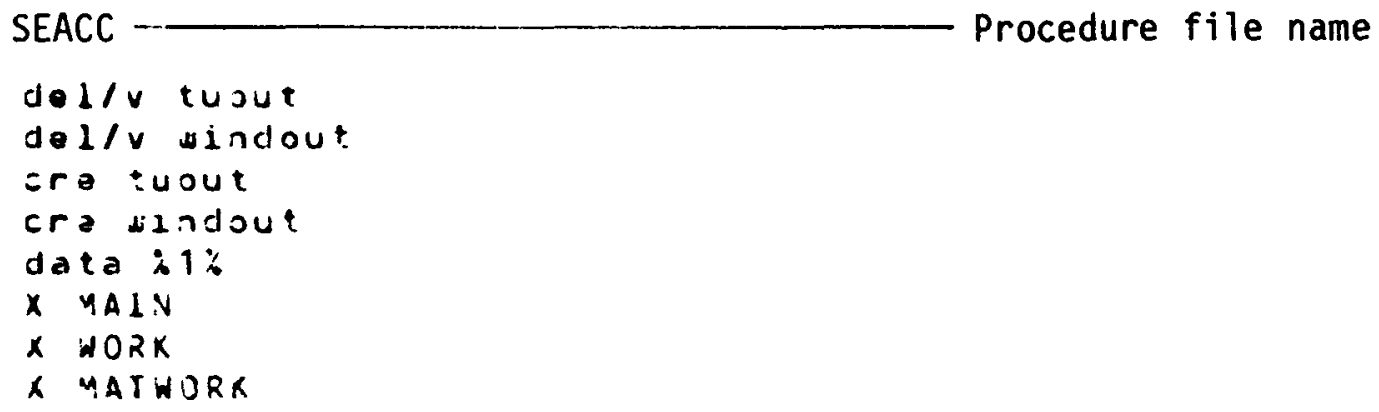

B.4 Finally, the output procedure file may be made as:

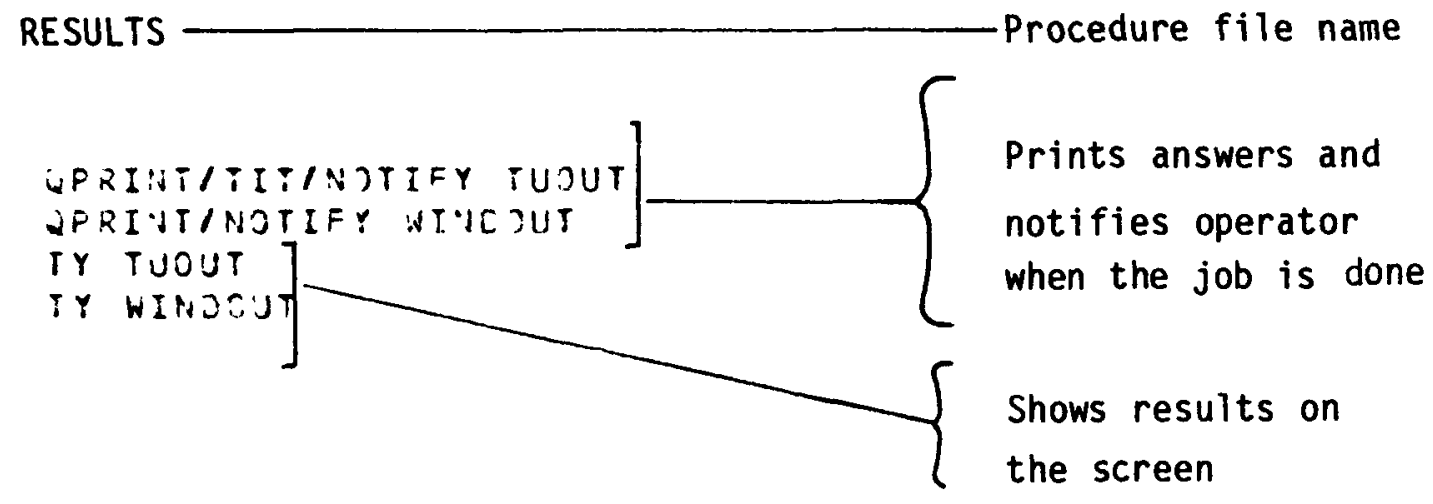


APPENDIX C

Computer Code Listings

$81 / 82$ 
This Systems Engineering and Analysis (SEA) computer program evaluating the performance of a horizontalaxis small wind energy conversion system (HA-SWECS) has been developed by Rockwell Internetional under the U.S. Department of Energy Rocky Flats Wind System Program.

The SEA computer program starts with a modified version of the "PROP" code, a well known horizontal-axis wind turbine aerodynamic performanco program. The HA-SWECS rotor performance (power coefficient versus tip-speed ratio) is established using the modified "PROP" (blade eloment/momentum) code for given blade airfoil aerodynamic characteristics and rotor geometry. The SEA. computer program then constructs a rotor power curve (power versus windspeed) for three mejor rotor configurations: 1) a constant shaft speed rotor: 2) a constant tip-speed ratio rotor: and 3 ) a rotor with a specified RPM scheoule as a function of windspeeds. Whan the efficiencies of components such as the gearbox. electric generator and electronic inverter are included in the computation. the power curve then depicts the system power output. The final step of the SEA computer program is to evaluate wind system annual energy output as a function of annual average windspeed, assuming a standard wind distribution model or a user specified wind profile.

As has been demostrated the SEA program can be usea to determine the effect on HA-SWECS system s performance on the following parameters and configuration changes:

1. The effect of airfoil geometry on rotor performance

2. The effect of pitch setting on annuai energy production for a fixed pitch rotor.

3. The effects of rotor shaft speed and annual average windspeeds on annual energy yield for a constant RPM rotor system.

4. The net increase in annual energy production of a constant tip-speed ratio rotor system as compared with a constant RPM system.

5. The effects of sub-system efficiencies on the power and energy production.

The last

topic to be addressed is the option for determining the wind system user s diurnal energy supply/demand match as a function of local wind distribution characteristics and energy load profile. 
Date: April 1982 
...... VERSION - SEPT $1981 \ldots . . .$.

ANALYSIS AND PROGRAM MODIFIED BY JAMES L TANGLER

AND THOMAS E HAUSFELD

ROCKWELL INTERNATIONAL

GOLDEN COLORADO

..... ORIGINAL VERSION - 15 MARCH $1976 \ldots . . .$.

ANALYSIS AND PROGRAM DEVELOPED BY STEL N WALRES AND

ROBERT WILSON, OREGON STATE UNIVERSITY,

CORVALLIS, OREGON.

-..... MAIN PROGRAM .......

PRDP CALCULATES THE THEORETICAL PERForMANCE PARAMETERS OF a

PROPELLER TYPE WIND TURBINE. IT UTILIIES A SIMPSON"S-RULE

METHOD, THREE PASS TECHNIQUE OF NUMERICAL INTEGRATION.

OPEN 55,"SYSDAT"

OPEN 56,"PHRDAT"

OPEN 59,"DATAIN"

OPEN 61,"STOALL"

OPEN 63,"PERFOR"

OPEN 62 "POUT"

JIMENSION RR(35), CI $(35)$, THETI $(35)$, AAT $(5,60)$, CLT $(5,60)$,

$+C D T(5,60), V V(25), R L O(5), X X(25), T P(25), C P A V(25), 20 Y(25)$

COMHON R,DR,HB,B,V, X,THETP,AMOD,H,SI,GO,OMEGA,RHO,VIS,HL,PI,

$+R X, W, A P F, T 1, T 2, T 3, T 4, T 5, T 6, T$ T,T 8,TEST,XETA,HH,ALO,30,BLD,NPROF, RLO

$c$

C

C

INPUT PARAMETERS\%

-..BlD--Blade element data controller

$\ldots \ldots \ldots . . . .0$ - NONE

$\ldots \ldots \ldots . . . .1$ - blade element data

....XMAX--MAXIMUM TIP SPEED RATIO

...XMIN--MINIMUM TIP SPEED RATIO

....DELX--TIP SPEED RATIO INCREMENT

-...R--RADIUS OF BLADE - FT

....HB--HUB RADIUS - FT

.... DR--INCREMENTAL PERCENTAGE

... THETP-PITCH ANGLE - DEgREES

-...B-NUMBER of blades

.... V- HIND VELOCITY - MPH

-..XETA--VELOCITY POWER LAH EXPONENT

-. OMEgA--ANGULAR VElocitr of PROP - RPM

AMOD-DAXIL INTERFERENCE MODEL CODE

-........ 0 D. STANDARD

$\ldots \ldots \ldots . . .1--$ WILSON 
....h--altitude of hub above sea leyel - ft

.....hH--ALtitude of hub aBove ground LeVEL - ft

... SI--CONING ANGLE - DEGREES

-NF--NUMBER OF INPUTED STATION"S FOR BLADE GEOMETRY

.GO-OTIP LOSS MODEL CONTROLLER

......... - PRANJTL

$\ldots \ldots \ldots \ldots 1$ - GOLDSTEIN

$\ldots \ldots \ldots . . . .2$ - NO TIP LOSS MODEL

........... - EFFECTIVE RAOIUS TIP MODEL

$\ldots \ldots \ldots \ldots 4$ - FINITE WING TIP MODEL

....HL--HUB LOSS MDDEL CONTROLLER

$\ldots \ldots \ldots$ - NONE

$\ldots \ldots \ldots 1$ - PRANOTL

....BO--MOSTAB TIP LOSS MODEL PARAMETER

APF--ANGULAR INTERFERENCE LOCKOUT

$\ldots \ldots . . . .0$ - ANGULAR INTERFERENCE FACTOR CALCULATED

......... 1 - ANGULAR INTERFERENCE FACTOR SET EQUAL TO 0

... RR(I)--PERCENT RADIUS FOR STATIONS

....CI(I)--CMORD FOR STATIONS - FT

....THET(I)--TWIST ANGLE fOR STATIONS - DEgREES

.... TH--MAX THICKNESS/CHORD RATIO

-.. ALO--ANGLE OF ATTACK FOR ZERO LIFT - DEgREES

....CLT(I)--COEF. OF LIFT DATA

-...CDT(I)--COEF. OF DRAG DATA

-..AAT(I)-Aangle of atTACK - Degrees

-... RLO(I)--REYNOLOS NUHBER fOR EACH AERODYNAMIC DATA TABLE

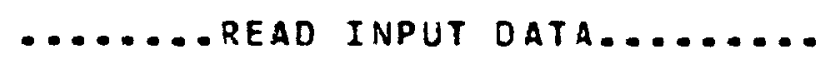

REWIND 59

NNN $=1$

NNPROF $=8388$

$N R L O=1$

READ FREE(9) XR, XHB, XB, XSI

READ FREE (9)

$X D R$, NNF

READ FREE ( 9 )

READ FREE (9)

READ FREE ( 9$)$

(RR (I), CI (I), THETI $(I), I=1, N N F)$

NFS

READ FREE (9) (AAT (NNN,I), $C L T(N N N, I), C D T(N N N, I), I=1, N F S)$

$C E=C I(N N F)-.8 *(C I(N N F)-C I(1))$

$A R=X R / C E$

COMAX $=1.11+.018 * A R$

$B 1=$ CDMAX 


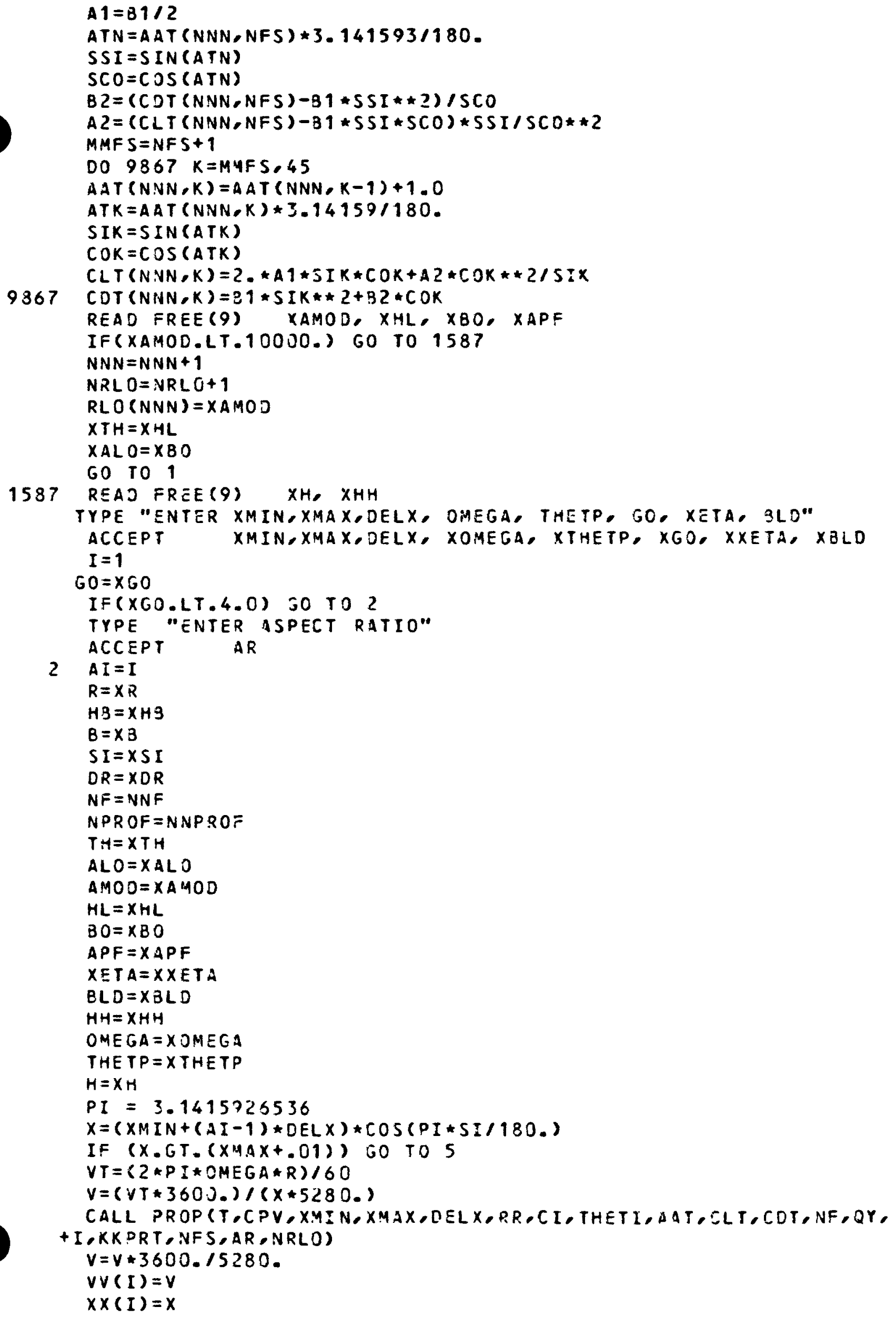




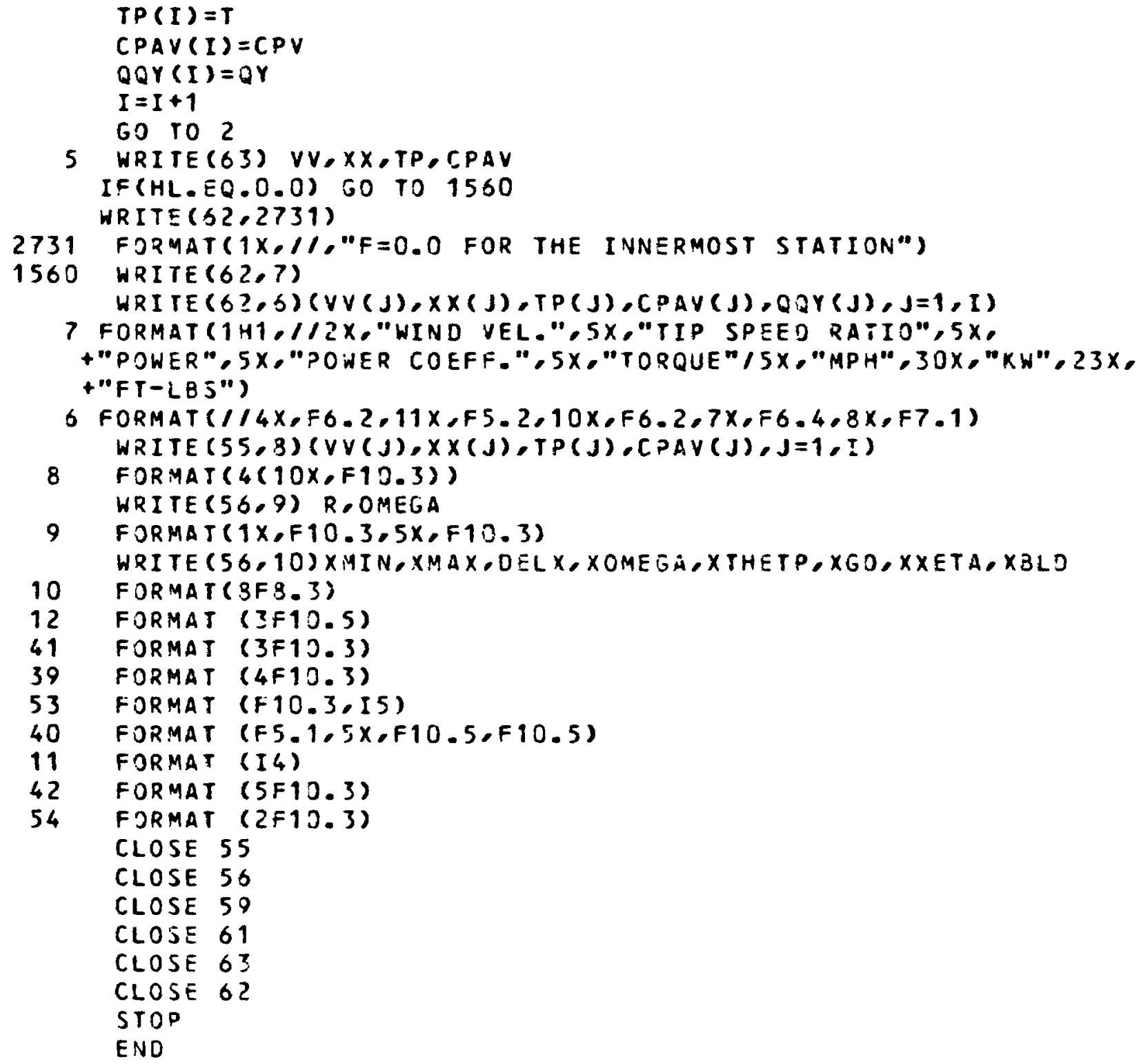


SUBROUTINE PROP (TP,CPAV,XMIN,XMAX,DELX,RR,CI,THETI, AAT,CLT, $+C D T$, NF , QY, IPRT , KKPRT , NF S, AR , NRLO)

DIMENSION RR(35), CI (35), THETI (35), AAT 5.60$), C L T(5,60)$, $+\operatorname{CDT}(5,60), R L D(5)$

COMMON R,DR,HB,B,V,X,THETP,AMOD,H,SI,GO,OMEGA,RHO,VIS,HL,PI, $+R X, W, A P F, T 1, T 2, T 3, T 4, T 5, T 6, T 7, T B, T E S T, X E T A, H H, A L O, B O, B L D, N P R O F$,

$+R L O$

CONTINUE

$P I=3.1415926536$

C

c

C

PRINT INPUT AND TITLES FOR OUTPUT ......

IF (IPRT.EQ.1) GO TO 58

GO TO 57

58 CALL TITLES (RR,CI, THETI,NF, SOLD,XMIN,XMAX,OELX)

DO $8969 K L K=1$, NRLO

WRITE $(61,60)$ NFS, RLO(KLK)

8969 WRITE $(51,61)$ (AAT $(K L K, I), C L T(K L K, I), C D T(X L K, I), I=1,45)$

C

C

...... InItIalization and constant parameter calculations .....

C

$57 W=200$.

$T 1=0.0$

$T 2=0.0$

$T 3=0.3$

$T_{4}=0.0$

$T 5=0.0$

$T_{6}=0.0$

$T 7=0.0$

$T 3=0.0$

$X M X X=0.0$

$X M Y X=0.0$

$Q X=0.0$

$T X=0.0$

$F \times \times P 1=0.0$

$F Y F=0.0$

QY $=0.0$

$T Y=0.0$

$P Y=0.0$

$X M X Y=0.0$

XMYY $=0.0$

ASTOP $=0.0$

CC *******INITE WING TIP LOS5******

IF(GO.LT.4.J) GO TO 2222

$G 0=2.0$

DO $5555 \quad I=1.45$

$A A T(I)=A A T(I)+19.24 * C L T(I) / A R$

$5555 \operatorname{CDT}(I)=C D T(I)+0.3183 * C L T(I) \star \star 2 / A R$

$2222 \quad A=0.0$

$A P=0.0$

CONTRDL $=3.0$

$V=V * 5280.13600$.

$S I=S I * P I / 180$.

$R E F=B O * R * \cos (S I)$

THETP = THETP*PI/180.

RHO $=0.6023769199 * E \times P(-0.297 * H / 10000$.

VIS $=0.0000003719-0.00000000204 * H / 1000$.

$O M E G A=V * X / R$

$N N=(R-H B) /(R \star D R)+2$. 


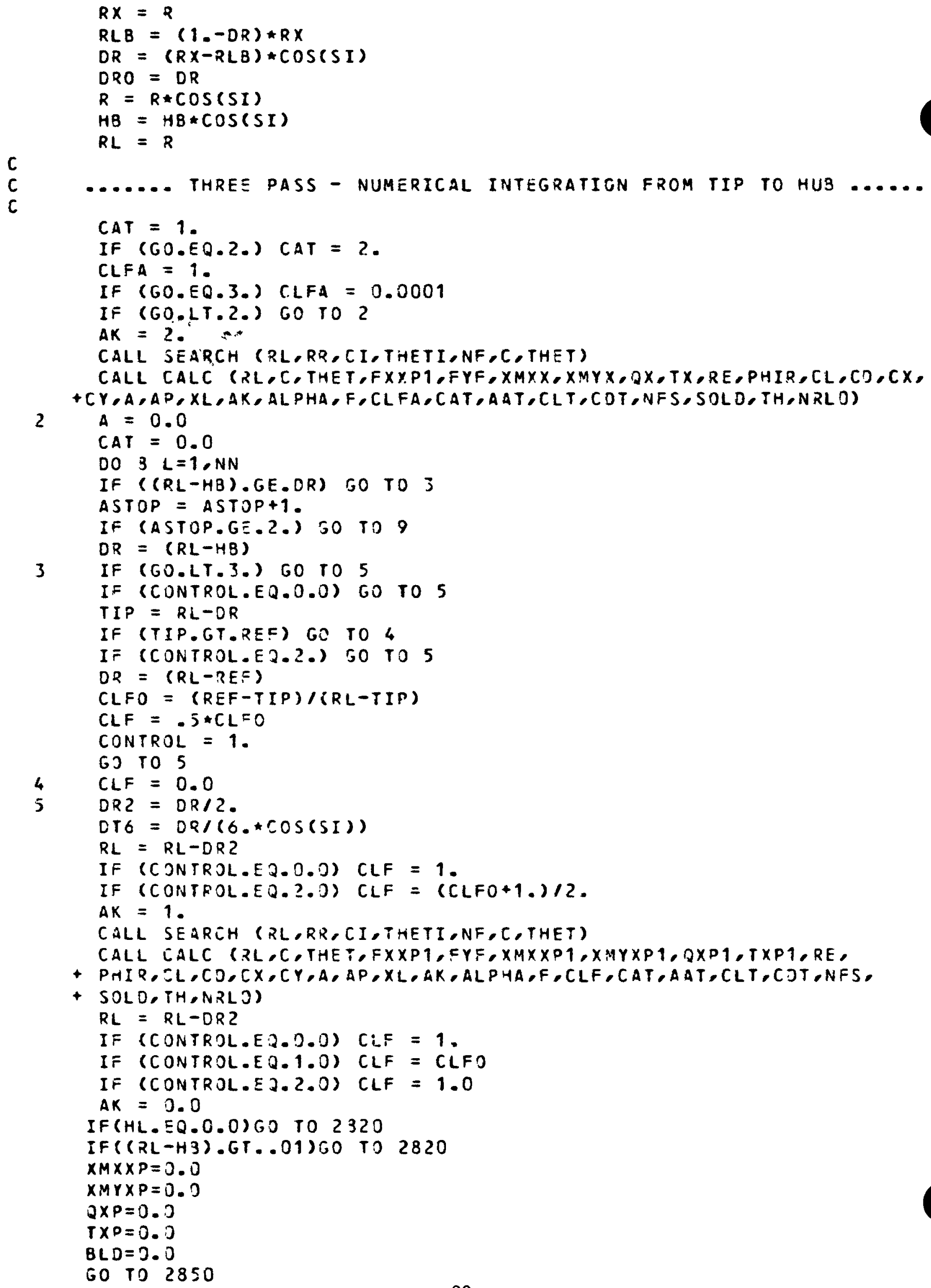


CALL SEARCH (RL,RR,CI,THETI,NF,C,THET)

CALL CALC (RL,C,THET,FXY,FYF, XMXXP, XMYXP, QXP,TXP,RE,PHIR,CL,CD,

$+$

$C X, C Y, A, A P, X L, A K, A L P H A, F, C L F, C A T, A A T, C L T, C O T, N F S, S O L D, T H, N R L O)$

2850

$Q Y X=D T 6 *(Q X+4 * * Q X P 1+Q X P)$

QY $=Q Y+Q Y X$

$T Y=T Y+D T 6 *(T X+4 * T X P 1+T X P)$

$P Y=P Y+O A E G A \star Q Y X$

$X M X Y=X M X Y+D T 6 *(X M X X+4 \ldots * X M X X P 1+X M X X P)$

$X M Y Y=X M Y Y+D T G *(X M Y X+4 \ldots \star X M Y X P 1+X M Y X P)$

$T I P=R L-D R$

IF (CONTROL.EQ.2.) CONTROL $=0.0$

IF (CONTROL.EQ.0.0) GO TO 6

IF ( $(R L-T I P) . E Q .0 .0) 60$ TO 6

IF (CONTROL.EQ.1.) OR = REF-TIP

IF (CONTROL.EQ.1.) CONTROL $=2$.

GO TO 7

$6 \quad D R=D R O$

7 CONTINUE

$Q X=Q X P$

$T X=T \times P$

$X M X X=X M X X P$

$X M Y X=X M Y X P$

$C T Y=T Y /(.5 * R H O * V \star \star 2 * P I \star R X \star 2 \star 2)$

$C P Y=P Y /(.5 * R H D * V * * 3 * P I * R X * * 2)$

$T P=P Y / 737.6$

PHIO = PHIR*180./PI

ALPHA $=$ ALPHA+180./PI

$P R=R L /(R X * \operatorname{COS}(S I))$

C

IF (BLO.EO.O.O) GO TO 8

$c$

$\ldots . . .$. PRINT OUTPUT .....

WRITE $(62,13)$ RL

WRITE $(61,13)$ RL

WRITE $(61.14) \mathrm{F}$

WRITE $(61,15)$ PHIO

WRITE $(62,15)$ ALPHA

WRITE $(61,15)$ ALPHA

WRITE $(62,17) \mathrm{CL}$

WRITE $(61,17) \mathrm{CL}$

WRITE $(62,18) \quad C D$

WRITE $(61.18)$ CD

WRITE $(61,19)$ CX

WRITE $(61,20) \mathrm{CY}$

WRITE $(61,21)$ FXY

WRITE $(62.21) \mathrm{FXY}$

WRITE $(62.22)$ FYF

WRITE $(61.22)$ FYF

WRITE $(61,23)$ XMXY

WRITE $(61.26)$ XMYY

WRITE $(61.25)$ RE

WRITE $(61.26) \mathrm{W}$

WRITE $(61,27)$ Or

WRITE $(61.28)$ TY

WRITE $(61.29)$ CTY

WRITE $(61.30)$ TP

WRITE $(61,31)$ CPY

WRITE $(61.32)$

CONTINUE 
$9 \quad H P=T P \star 1.3410$

PISTEL $=T 7 /(P I * R X * 5)$

PI $2 S T E L=T 3 \star X /(P I \star R X \star \star 6)$

$D C P=(X E T A * X * R X * 2 /(H H * H H)) *(X E T A \star P I S T E L+(X E T A-1) * P I 2 S T E L.) \star B / 4$.

CPAY $=$ CPY+DCP

FYKDE $=R X / V \star T 1$

FYKDG $=-T 2$

$X M C K D E=-R \times / V * T 3$

$X M C K D G=T 4$

$X M Z K D E=R X I V * T 3$

$X M Z K D E=-T 4$

CQKDE $=-R \times / V * T 5$

$C Q K D G=T 6$

IF (IPRT.EQ.1) KKPRT $=0$

IF (IPRT.EQ.1) GO TO 10

IF $(X . G T .(X M A X+.01))$ GO TO 10

IF ( (IPRT/5).EQ.KKPRT) GO TO 10

GO TO 56

10

CONTINUE

KKPRT = KKPRT+1

WRITE $(61,31)$ CPY

WRITE $(61,32)$

WRITE $(61,33)$

WRITE $(61,34)$ TP

WRITE $(61.35)$ HP

WRITE $(61,36)$ CPY

WRITE $(51,37)$ CPAV

WRITE ( 51.33$)$ CTY

WRITE $(51,43)$ FYKDE

WRIIE $(01,44)$ FYKJG

WRITE (51.45) XMCKDE

WRITE $(61,45)$ XMCKDG

WRITE (51,47) XMZKDE

WRITE $(51,43)$ XMZKDG

WRIJE (31,47) CQKDE

WRITE (61,50) CQKJG

WRITE $(61.51)$ PISTEL

WRITE $(61.52)$ PI2STEL

C

C

C

C

C

11 FORMAI (I4)

12 FORMAT (3F10.5)

13

14

15

16

17

18

19

20

21

22 $+)$

FORMAT

FORMAT

FORMAT

FORMAT

FORMAT

FORMAT

FORMAT

FORMAT

FORMAT

FORMAT $+15.4)$

23 FORMAT $+F(5.4)$

\section{FORMATS FOR INPUT AND OUTPUT STATEMENTS}

$$
(1,10 X, 21 \mathrm{H} \text { LOCAL RADIUS - FT }=, F 10.4)
$$

$(1,10 \times, 22 H$ TIP LOSS FACTOR, $F=. F 7.4)$

$(1.13 X .23 H$ ANGLE PHI - DEGREES = ,F10.4)

$(1,10 X, 36 H$ ANGLE OF ATTACK, MLPHA - DEGREES =, F10.4)

$(1,13 X, 37 H$ COEFFICIENT OF SECTIONAL LIFT, $C L=, F 20.4)$

$(1,10 X, 374$ COEFFICIENT OF SECTIONAL ORAG, CD $=, F 20.4)$

$(1,10 X, 43 H$ COEFFICIENT OF FORCS IN X DIRECTION, CX =,FT.4)

$(1,10 X, 43 H$ COEFFICIENT OF FORCE IN Y OIRECTION, CY $=. F 7.4)$

$(1.10 \times .43 H$ FORCE IN X DIRECTION PER SLADE, FX - LB =.F15.4

$6 /, 10 X, 47 H$ FORCE IN Y DIRECTION PER BLADE, FY - LBS FT = $(1,13 X, 47 H$ MOMENT IN X OIRECTION PER ELADE, MX - FT-LE = , 
FORMAT $(/, 10 X, 47 H$ MOMENT IN Y DIRECTION PER BLADE, MY - FT-L8 = , $+F 15.4$ )

25 FORMAT $(1,10 X, 26 H$ REYNOLDS NUMBER, RE NO =,E10.4)

26 FORMAT $(1,10 X, 32 H$ RELATIVE VELOCITY,W - FT/SEC = .F15.4)

27 FORMAT ( $1,10 X, 21 \mathrm{H}$ TORQUE, Q - FT-LB = .F15.4)

28 FORMAT ( $/ .10 X .17 H$ THRUST,T - LB $=. F 15.4)$

FORMAT $(1,13 X, 26 \mathrm{H}$ THRUST COEFFICIENT, $C T=, F 7.4)$

FORMAT $(1,13 X, 24 H$ POWER, $P$ - KILOWATTS $=, F 10.2)$

31

32

48 FORMAT ( $/$ "(YAHING MOMENT DUE TO SHEAR/BLADE)/(SIN(THETK)*COS(THETK) $\$)=", F 10.4)$

49 FORMAT ( $/ 42$ H(TORQUE VARIATION DUE TO CONING $/$ BLADE) $=, F 10.4$ )

50 FORMAT (/"(TORQUE VARIATION DUE TO SHEAR / BLADE) / (SIN(THETK)) $\$=", F 10.4$ )

51 FORMAT (/53H TORQUE VARIATIOV DUE TO AERODYNAMIC SECONO GERIVATIVE $\$=, F 15.4)$

52 FORMAT (/514 TORQUE VARIATION DLE TO SHEAR SECONO DERIVATIVE = " SF 15.4)

53 FORMAT (F10.3, I5)

54 FORMAT (2F10.3)

60 FORMAT $(141, / / / / 10 X, " T H E$ NO. OF POINTS = ",I4," REYMOLOS NUMBER= $+\cdots, F 10.1)$

61 FORMAT (//1JX,"AAT",2JX,"CLT",20X,"CDT"//(7X,F10.5,

$\$ 12 X, F 13.6,14 X, F(3.9))$

END 
SUBROUTINE TITLES (RR,CI,THETI,NF,SOLO, XMIN,XMAX,DELX)

C ....... TITLES - PRINTS OUT INPUT OATA IN A DESCRIPTIVE

C FORM, AND PRINTS DESCRIPIIONS OF SYMBOLSITITLES FOR OUTPUT.

C

DIMENSION RR (35), CI (35), THETI(35), RLD(5)

COMMON R,OR,HB, S,V, X, THETP,AMOD, H, SI, GO,OMEGA,RHO,VIS,HL, PI, $+R X, W, A P F, T 1, T 2, T 3, T 4, T 5, T 6, T 7, T B, T E S T, X E T A, H A, A L O, B O$, SLD,NPROF,RLO

WRITE $(62,12)$

HRITE $(61,12)$

WRITE $(61,13)$

WRITE $(51,14)$

WRITE $(61,15) \mathrm{V}$

WRITE $(61,16)$ XETA

WRITE $(61,17) \mathrm{HH}$

WRITE $(61,13) \mathrm{H}$

WRITE $(61,19)$ OMESA

WRITE $(61,20) X$

WRITE $(61,21)$ THETP

$R X=Q$

$C S I=S I$

$S I=S I * P I / 180$.

$C R L=.75 * R$

CALL SEARCH (CRL,RR,CI,THETI,NF,C, JHET)

$S I=C S I$

BANG = THET*130.IPI +THETP

WRITE $(61,2 ?)$ BANG

WRITE $(51.23)$ SI

WRITE $(61,24)$

WRITE $(61.25)$ B

WRITE $(61,25)$ R

WRITE $(51,27) \mathrm{HB}$

CALL SOLIOT (RR,CI,NF,B,R,PI,SOLD)

WRITE $(61,28)$ SOLD

CALL ACIIVI (RR,CI,NF,B,R,PI, ACF)

WRITE $(61,29)$ ACF

WRITE $(61,30)$ NORJF

WRITE $(61,31)$ NF

WRITE $(61,32)$

WRITE $(61,33)$

WRITE $(61,34) \quad$ (RR(I),CI(I),THETI (I), I=1,NF)

WRITE $(51.35)$

WRITE $(61,35)$ DR

IF (APF.EQ.0.0) GO TO 1

WRITE $(62,37)$

WRITE $(61,37)$

IF (AMOO.EQ.0.0) 50 TO 2

WRITE $(62,33)$

WRITE $(61,33)$

GO TO 3

2 WRITE $(31,37)$

WRITE $(62.39)$

3 IF (E.GT.2.D) 60 I0 4

IF $(G O . E Q .0 .0)$ GO TO 8

IF $(G 0 . \equiv 0.1 .0)$ GO TO 5

IF (GO.EQ.2.0) GO TO 6

IF (GO.EQ.3.0) GO TO 7

IF $(G 0 . E 2.4 .0)$ GO TO 50

GO TO 9

IF $(G 0 . E Q .2 .0)$ GO TO 6 


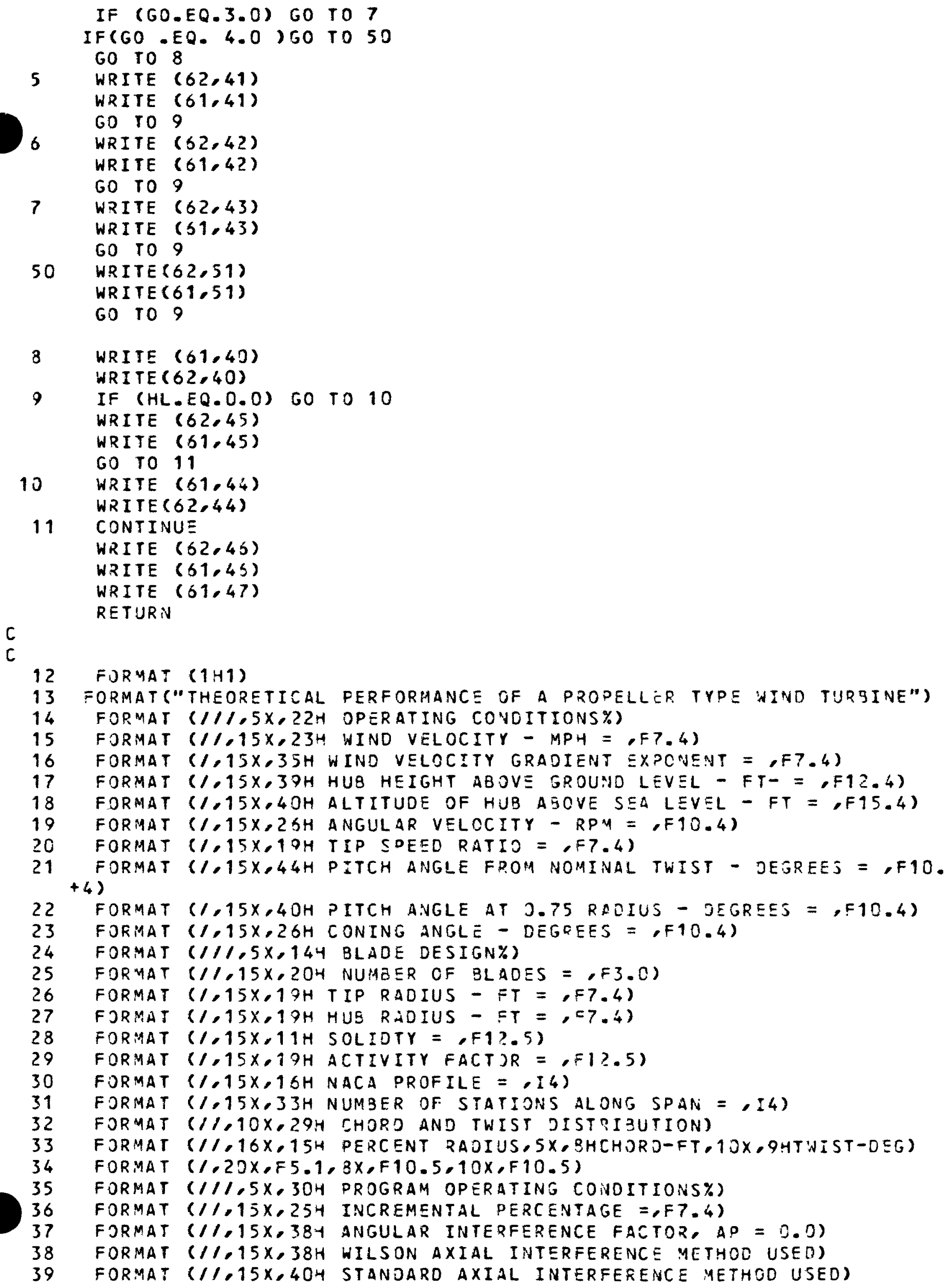


END 
SUBROUTINE SEARCH (RL,RR,CI,THETI, NF,C,THET)

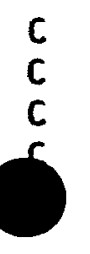

-.... SEARCh - DETERMINES THE CHORD and THE thist angle at A GIVEN RADIUS ALONG THE SPAN. IT UTILIZES A LINEAR INTERPOLATION TECHNIQUE.

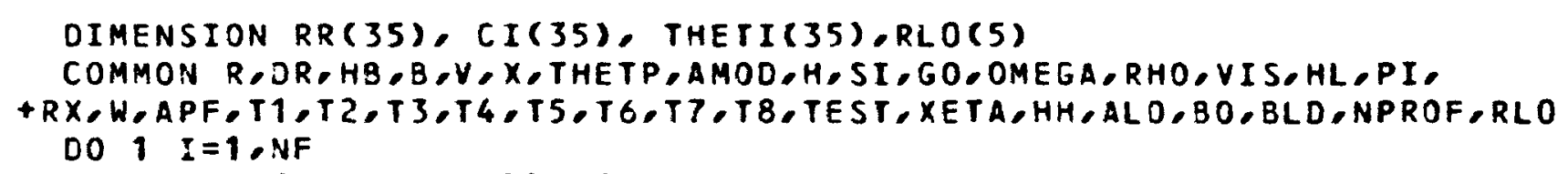

97 
SUBROUTINE CALC (RL,C,THET,FXF,FYF, XMFXF, XMFYF,QF,TF,RE,PHIR,CL,CD $+, C X, C Y, A, A P, X L, A K, A L P H A, F, C L F, C A T, A A T, C L T, C D T, N F S, S O L D, T H, N R L O)$

C

C

c

C

C

C

C

6 IF $(C A T . E Q .1) F=$.

IF (CAT.EQ.1.) GO TO 7

CALL IIPLOS ( $X X L, X X L O, F, B, G O, H L, P I, R, R L, P H I, R H)$

C

$7 \quad C X=C L * S I N(P H I)-C D * \operatorname{COS}(P H I)$

$C Y=C L * C O S(P H I)+C D * S I N(P H I)$

$C X X=C L \star S I N(P H I)$ UPON THESE PARAMETERS.

DIMENSION AAT $(5,60), \operatorname{CLT}(5,60), \operatorname{COT}(5,60), R L O(5)$

$X L=R L * O M E G A / V$

IF $(A . G T \ldots .5) \quad A=0$.

IF $(A . G T \ldots .5)$ AP $=0$.

$E P S=0.1$

$R H=H B$

DO $15 \mathrm{~J}=1,40$

BETA $=A$

DELTA = AP

$A D D D=(1 .+A P) * X L$

IF (ADDJ.EQ.0.) GO TO 30

PHI $=$ ATAN $(1,-A) * \operatorname{COS}(S I) /((1 .+A P) * X L))$

IF (PHI.EQ.0.0) PHI $=0.0001$

GD TO 31

$P H I=P I / 2$

$X X L=\operatorname{COS}(P H I A A) / S I N(P H I A A)$

$X X L O=X X L \star R / R L$

PHIR $=$ PHI

ALPHA = PHI-THET-THETP

DDTC $=\operatorname{ATAN}((1 .-A) /(X L \star(1 .+2 . * A P)))-\operatorname{ATAN}((1 .-A) / X L)$

DAT = DOTC 14 .

$D A 2=((4.115) *.(S O L D * T H) / X) /((1 . / X) * * 2+(R L / R) * 2)$

DALPHA = DA1+DA2

ALPHA = ALPHA-DALPHA

ALPHAD = ALPHA+0.DO1

$W I=5 O R T((V \star Z O S(S I)) \star \star 2+(R L \star O M E G A) \star \star 2)$

$R E 1=R * H O W * C / V I S * . P 6$

..... calculation of sectional lift and dRag coefficients +NRLO,RE1)

+ -RLD, VRLO,RE1)

IF (GO.LT.3.) GO TO 6

$C L=C L F \star C L$

$C L D=C L F * C L D$

$F=1$.

60 TO 7

.... Calculation of TIP AND hus LOSSES .....

THE AXIAL AND ANGULAR INTERFERENCE FACTORS AT A GIVEN RADIUS ANO DETERMINES FUNCTIONS DEPENDENT

COMMON R,OR,HB,Z,V,X,THETP,AMOD,H,SI,GO,OMEGA,RHO,VIS,HL,PI, $+R X, H, A P F, T 1, T 2, T 3, T 4, T 5, T 6, T 7, T 8, T E S T, X E T A, H H, A L O, B O, B L D, N P R O F, R L O$

CALL NACATT (RL,RX, SI,ALPHA,CL,CD,ALO,W,AAT,CLT,CDT,NFS,SOLD,RLD,

CALL NACATT (RL,RX, SI,ALPHAD,CLD,CDD,ALD,W,AAT,CLT,CDT,NFS,SOLD 
CYY $=C L * \operatorname{COS}(P H I)$

$S I G=(B \star C) /(P I \star R L)$

IF (AMOD.EQ.O.) GO TO 8

$V B R=((-125 * 5 I G *[Y Y) *(\cos (5 I) * 2)) /(S I N(P H I) * 2)$

VAR $=(0.125 * S I G * C X X) /(F \star S I N(P H I) * C D S(P H I))$

$C A N=F \star F+4 . * V B R * F \star(1 .-F)$

IF (CAN.LT.O.O) CAN = O.O

$A=(2 . \star V B R+F-S Q R T(C A N)) /(2 * \star(V B R+F * F))$

$A P=V A R /((1,-A * F) /(1 .-A)-V A R)$

34 IF (APF.EQ.1.) $A P=0.0$

GO TO 9

$3 \quad V B R=0.125 * S I G * C Y Y *(\operatorname{COS}(S I) * 2)$

$V A R=0.125 * S I G * C \times X$

$A=V B R /(F \star S I V(P H I) \star \star 2+V B R)$

IF $(A . G T \cdot 0.38)$ GO TO 32

$33 A P=V A R /(F * S I N(P H I) * \operatorname{COS}(P H I)-V A R)$

GO TO 34

$32 Y T E M=S I G * C L * \operatorname{COS}(S I) *(1 .+A P) * X L /(2 *$ SIN $(P H I))$

$A=(Y T \equiv M-0.5776 * F) /(Y T E M+0.96 * F)$

GO TO 33

9 IF (APF.EQ.1.) $\triangle P=0.0$

$P C R=R L /(R X * \operatorname{COS}(S I))$

...... DAMPENING OF AXIAL AND ANGULAR INTERFERENCE FACTOR ITERATIONS.

C

If $(J-4) 13,12,10$

10 If $(J-10) 13,12,11$

11 IF $(J-15) 13,12,100$

100 IF $(J-20) 13,12,60$

60 IF $(J-30) 13,61,62$

$12 A=(A+3 E T A) * .5$

$A P=(A D+D E L T A) * .5$

GO TO 13

61 ODELA $=0.1$

IF (A.LT.O..OR.A.GT.1.) $A=0.3$

GO TO 63

62 ODELA $=$ DELA

63 DELA $=A-B E T A$

c

...... OELA IS GREAT THAN ZERO.......

65 IF $((D E L A * O J E L A) . L T .0$.$) EPS =E P S * 0.2$

$A=B E T A+\subseteq P S$

G) TO 13

C ....... DELA IS lESS THAN IERO.......

34 IF ( (DELA*ODELA).LT.O.) EPS =EPS $\$ 0.2$ $A=B E T A-E P S$

c

13 CONTINUE

C

...... TEST FOR CONVERTENCE .....

IF (APF.EQ.1.) GO TO 14

IF $(A P, E Q .0 .0)$ GO TO 14

IF $(A 3 S((A P-D E L T A) / A P) . L E \ldots 0001)$ GO TO 16

GO TO 15

C

14 IF (ABS(CA-BETA)/A).LE..0DO1) GOTO 16

15 CONTINUE

16 IF (AK.GE.1.) GO TO 13

IF (BLD.EQ.J.O) GO TO 18

c

FOR OPERATION OF VORTEX RING STATE REPLACE THE FOLLOWINGC CAROS 
c

17 CONTINUS

$$
\begin{aligned}
& \text { PCCR }=\text { RL/RX } \\
& \text { WRITE }(62,21) \text { PCR } \\
& \text { WRITE }(51,21) \text { DCR } \\
& \text { WRITE }(62,22) \text { BETA } \\
& \text { WRITE }(61,22) \text { BETA } \\
& \text { WRITE }(62.23) \text { A } \\
& \text { WRITE }(61,23) \text { A } \\
& \text { WRITE }(61.81) \text { VAR } \\
& \text { WRITE }(61.82) \text { AP } \\
& \text { WRITE }(52.24) \text { DELTA } \\
& \text { WRITE }(51.24) \text { OELTA } \\
& \text { WRITE }(62.25) \text { AP } \\
& \text { WRITE }(61.25) \text { AP } \\
& \text { WRITE }(61.25) \text { J } \\
& \text { IF (J.LT.40) J0 TO } 17 \\
& \text { WRITE }(61.27)
\end{aligned}
$$

c

c

C

18 CONTINUE

$$
\begin{aligned}
& W=S Z R T(((1 .-A) \star V \star \operatorname{COS}(5 I)) \star 2+((1 .+A P) \star R L \star O H E G A) \star \star 2) \\
& \text { RE = RHD* N*E/VIS } \\
& \text { CONST }=(0.5 * R H O \star(W * 2) \star C) \\
& F X F=\text { CONST*CX } \\
& F Y F=C O N S T * C Y \\
& X M F X F=F X F *(R L-H B) / C O S(S I) \\
& X M F Y F=F Y F *(R L-H B) / C O S(S I) \\
& C T 1=(0.5 * R H D * 3 * C) *(W * W) \\
& Q F=C T 1 * R L * C X \\
& T F=C T 1 * C Y+\operatorname{COS}(S I) \\
& D P C R=D R /(2 * R X) \\
& C R=C / R X \\
& C L A=(C L J-E L) / 0.201 \\
& C D A=(C O D-C D) / 3.301 \\
& C \times P=C L A * S I N(P H I)-C O A+C O S(P H I)+C Y \\
& C Y P=C L A * C O S(P 4 I)+C D A+S I N(P H I)-C X \\
& T A N=S I N(P H I) / C O S(P H I) \\
& F T=(2 . \star C X+C X P / T A N) *(1 .-A) \star C R * P C R \\
& F V=(2 . * C Y+C Y P / T A N) \star(1 .-A) \star C R \star P C R \\
& \text { IF }(A K . G E .1 .) \text { GO TO } 19 \\
& \text { TEST }=\text { TEST+1. } \\
& \text { IF (TEST.EQ.1.) GO TO } 17 \\
& \text { C WRITE }(51,23) \text { FV } \\
& \text { TEST }=0 \text {. } \\
& 19 \text { CONTINUE } \\
& T 1=T 1+F T \star J P C R \\
& T Z=T 2+F T *(1 .-A) * D P C R \\
& T 3=T 3+F N * P(R *) P C R \\
& T 4=T 4+F N \star(1 .-A)+P(R \star 2 \star O P C R \\
& T S=T S+F T * P C R \star D P C R \\
& T 6=T 6+F T *(1 .-A) * P(R * D P C R \\
& T 7=T 7+(C(2 .+\operatorname{COS}(P A I) \star 2) * C L * S I N(P H I)-\operatorname{COS}(P H I) * 3 \star C D+2 * \operatorname{COS}(P H I \\
& +C L A) *(1 .-A) * 2 * R L * 3 * C) * D R / 2 \text {. } \\
& T 3=T 8+(((1 .+5 I N(P H I) * 2) / C O S(P H I) * C L-C D * S I N(P H I)+C L A * S I N(P H I)) \\
& +(1 .+A P) \star(1 .-A) * R L * 4 * C) \star D R / 2 \text {. }
\end{aligned}
$$$$
\text { C WRITE }(61.27) \mathrm{FT}
$$ 
C RETURN

C

20 FORMAT ("YOU HAVE SPECIFIED A NACA PROFILE NOT STORED, USE 4418")

21 FORMAT ( $1 /, 5 X, 39 H$ STATION - (LOCAL RADIUSITIP RADIUS) = ,F7.4) 
$c$
$c$
$c$
$c$

SUBROUTINE TIPLOS (U,UO,F,Q,GO,HL,PI,R,RL,PHI,RH)

..... TIPLOS - DETERMINES THE TIP AND HUB LOSSES

C BASEO UPON GOLOSTEIN"S THEORY, OR PRANDTL"S THEORY,

C DR FOR THE CASE OF NO LOSSES.

$$
\begin{aligned}
& \text { SUM2 }=0.0 \\
& \text { SUM }=0.0
\end{aligned}
$$$$
A K=1 \text {. }
$$$$
A M M=1 .
$$$$
A M=0.0
$$$$
\text { IF }(Q . G T .2 .0) \text { GO TO } 1
$$$$
\text { IF }(G 0 . E Q .0 .0) \text { GO TO } 2
$$$$
I F(G 0 . E Q .1 .0) \text { GO TO } 4
$$$$
\text { IF }(G 0 . E Q .2 .0) 60 \text { TO } 3
$$

IF (GO.EQ.2.0) 60 TO 3

2 CONTINUE

$C C C=-(Q *(R-Q L)) /(2 . R L * S Q R T(S I N(P H I) \star 2 * .3001))$

IF $(C C C . L T .(-50))$ GJ TO 3

$+)$

$F=(2 . I P I) * A \operatorname{COS}(E \times P(-(2 \star(R-R !)) /(2 * R L \star S Q R T(S I N S P H I) \star 2+.0 D O 1)))$

$F=1.0$

60 TO 5

$I=((A B S(S I N(P H I))) . L T . .0001)$ GO TO 2

CALL GOLOST (U, UO,F, G, GO,PI, R,RL,PHI, SUM2, SUM, AK, AMM,AM)

C HUILJSS CALCULATIONS

C

5 IF (HL.EQ.1.0) 60 TO 6

$F I=1.0$

GO TO 7

C -..AVOIJING THE PROBLEM OE UNDERFLOW IN THE EXPRESSIOM FI,

C ...BY AJOENT AN I = STATEMENT.

$6 \quad 0000=-(2 *(P . L-Q H)) /(2 . R *$ RQRT $(S I N(P+I) * 2+.0001))$

IF (DDJJ.LE. $(-50$.$) ) GJ TO 8$

$F I=(2 . / P I) \star A C D S(E \times P(-(Q \star(R L-R H)) /(2 . * R H \star S Q R T(S I N(P H I) \star \star 2 * .0001))))$

GO TO 7

$3 \quad F I=1$.

7 CONTIVUE

$F=F * F I$

RETURV

EVD 
SUBROUTINE GESSEL $(Z, V, A I)$

$c$
$c$
$c$
$C$

...... BesSEL Calculates besSel functions for the golostein TIP LOSS MODEL.......

$S=0.0$

$A K=0.0$

$C=1$.

DO $3 x=1,10$

$B=(.25 * Z * Z) * A K$

$0=V+A K$

$P=1$.

$1 T K=D-1$.

IF (TK.LE. O.O G) GOTO 2

$P=D * T K \star P$

$D=0-2$.

$2 \quad E=P$

$S=B /(C \star E)+S$

$A K=A K+1$.

$C=A K \star C$

3 CONTINUE

$A I=((.5 * Z) * * V) * 5$

RETURN

END 
SUBROUTINE NACATT (RL,RX,SI,ALPHA,CL,CD,ALO,H,AAT,CLT,CDT,NFS,SOLD

C + -RLO,NRLD,RE)

C

NACATT - IS AN INTERPOLATING SUBROUTINE TO INTERPOLATE AIRFOIL DATA INPUTED IN TABLE FORM.

C

DIMENSION AAT $(5,60), \operatorname{CLT}(5,60), \operatorname{CDT}(5,60), R L O(5)$

$A=A L P H A * 180.13 .141593-A L O$

$K=0$

IF (NRLO.EQ.1)GO TO 888

DO $S K=1$, NRLO

$I F(R E \cdot L T \cdot R L O(1)) R E=R L O(1)$

6 IF(RE.LE.RLO(K))GO TO 7

$K=K-1$

$R E=R L O(K)$

$7 K K=K$

$P E R R L=(R E-R L O(K K-1)) /(R L O(K K)-R L O(K K-1))$

27 DO 1 I $I=1,45$

IF (A.LE.AAT $(K K, 1))$ GO TO 4

IF (A.LE.AAT $(K K, I))$ GO TO 2

1 CONTINUE

$2 J=I+1$

PER $=(A-A A T(K K, J-1)) /(A A T(K K, J-2)-A A T(K K, J-1))$

$C L L O W=P E R *(C L T(K K-1, J-2)-C L T(K K-1, J-1))+C L T(K K-1, J-1)$

999

$C D L O W=P E R *(\operatorname{COT}(K K-1, J-2)-\operatorname{CDT}(K K-1, J-1))+\operatorname{COT}(K K-1, J-1)$

$97 \quad C L H I G H=P E R \star(C L T(K K, J-2)-C L T(K K, J-1))+C L T(K K, J-1)$

CDHIGH $=P E R *(C O T(K K, J-2)-C D T(K K, J-1))+C J T(K K, J-1)$

$C L=P E R R L *(C L H I G H-C L L O W)+C L L O W$

$C D=P E R R L \star(C D H I G H-C D L O W)+C D L O W$

$G O$ TO 5

4

$C D=P E R R L *(C D T(K K, 1)-\operatorname{COT}(K K-1,1))+\operatorname{COT}(K K-1,1)$

$C L=P E R R L \star(C L T(K K, 1)-C L T(K K-1,1))+C L T(K K-1,1)$

GO TO 5

888 DO 91 II $I=1,45$

IF (A.LE.AAT $(1,1)) G O$ TO 94

91

IF (A.LE.AAT (1,II))GO TO 92

CONTINUE

$J \mathrm{~J}=\mathrm{I} I+1$

$P E R=(A-A A T(1, J J-1)) /(A A T(1, J J-2)-A A T(1, J J-1))$

$C L=P E R \star(C L T(1, J J-2)-C L T(1, J J-1))+C L T(1, J J-1)$

$C D=P E R \star(\operatorname{COT}(1, J J-2)-\operatorname{CDT}(1, J J-1))+\operatorname{CDT}(1, J J-1)$

$G O$ TO 5

$94 \quad C L=C L T(1,1)$

$C D=\operatorname{CDT}(1,1)$

5 RETURN

END 
SUBROUTINE SOLIDT (RR,CI,NF,B,R,PI, SOLO)

$c$

C ..... SOLIOT - DETERMINES THE TOTAL SOLIDITY OF THE

C WIND TURBINE DESIGN.

C

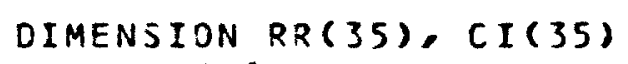

DIMENSION RR (35), CI (35)

$N F X=N F-1$

$S 1=0$.

DO $1 I=1, N F X$

SOL $=((C I(I+1)+C I(I)) / 2) *.(R R(I)-R R(I+1)) * R / 100$.

1 CONTINUE

$S 1=S 1+S O L$

SOLD $=B \star 51 /(P I * R \star 2)$

RETURN

END 
SUBROUTINE ACTIVI (RR,CI,NF,B,R,PI, ACF)

$c$ ACTIVI - DETERMINES THE ACTIVITY FACTOR OF THE

C WIND TURSINE DESIGN.

C

$$
\begin{aligned}
& \text { DIMENSION RR(35), CI(35) } \\
& \text { NFX }=\text { NF-1 }
\end{aligned}
$$$$
S 1=0 \text {. }
$$$$
\text { DO } 1 I=1, N F X
$$$$
C 1=(C I(I+1)+C I(I)) / 2 \text {. }
$$$$
R O R=((R R(I)-R R(I+1)) / 2 .+R R(I+I)) / 100 .
$$$$
D R O R=(R R(I)-R R(I+1)) / 100 \text {. }
$$$$
F A C=(C 1 /(2 * * R)) * R O R * 3 * D R O R
$$

$S 1=S 1+F A C$

1 CONTINUE

$A C F=S 1 * 103030.116$.

RETURN

END 
.... GOLDST - DETERMINES THE GOLDSTEN TIP LOSS

FACTORS FOR THE 2 BLADED DESIGN CASE. FOR DESIGN CASES

WITH BLADE NUMBERS OTHER THAN TWO THE PRANDTL

MODEL IS USEJ. THIS CAN BE CHANGED IF NECESSARY, AND

THE GOLDSTEN MODEL FOR ANY NUMBER OF BLADES MAY BE SUBSTITUTED FOR THIS ROUTINE.

C

DO $5 M=1,3$

$V=(2 . * A M+1$.

$20=U O * V$

$v_{2}=v * v$

$Z=U * V$

$Z 2=Z * Z$

CALL BESSEL $(Z, V, A I)$

CALL BESSEL (ZO,V,AIO)

IF $(2 . G E .3 .5)$ GO TO 1

$A=2 . * 2$.

$B=4 . \star 4$.

$C=6 . * 6$.

$D=8 . * 3$.

TIVZ $=22 /(A-V Z 2)+(Z 2 * 22) /((A-V Z) *(B-V Z))+(2 Z * * 3) /((A-V Z) *(B-V 2)$

$+*(C-V 2))+(Z 2 * 44) /((A-V 2) *(B-V Z) *(C-V 2) *(D-V 2))$

$C T 1 V Z=(V * P I * A I) /(2 . * S I N(.5 * V * P I))-T I V Z$

GO TO 2

$T O=(U * U) /(1 .+U * 1))$

$T_{2}=4 \cdot * U * U *(1 .-U * U) /((1 .+U * U) * * 4)$

$T 4=16 * * U * j *(1 .-14 * \forall * U+21 * * U * * 4-4 . U * * 6) /((1 .+U * U) * * 7)$

T $6=64 * * U * U *(3 .-75 * U * U+603 * * U * * 4-1065 * U * * 6+450 . * U * * 8-36 * U * *$

$+10) /((1 .+U * U) * 10)$

CTIVI $=T 0+T 2 / V 2+T 4 /(V 2 * 2)+T S /(V 2 * 3)$

$F V U=(U * U) /(1 .+U * U)-C T 1 V Z$

SUM $=$ SUM+FVU/V 2

IF (AM.NE.O.O) GOTO 3

$E=-0.098 /($ UO * $* .668)$

IF (AM.NE.1.0) GO TO 4

$E=0.031 /(U O * 1.285)$

4

IF $(A M . G T .1 .0) E=0.0$

SUM2 $=$ SUM $2+((U O * U O * A M M) /(1 .+U O * U O)-E) *(A I / A I D)$

$A M=A M+1$.

$A K=((2 . * A M-1) * A K) /.(2 * A M)$

$A M M=A K /(2 . * A M+1$.

$G=(U * U) /(1 .+U * U)-(8 . /(P I \star P I)) * S U M$

CIRC $=6-(2 . / P I) *$ SUM2

$F=((1 .+U * U) /(U * U)) * C I R C$

RETUR IN

END 
Based on the performance data (power coefficient vs. tip-speed ratio) from PROP code, this program calculates a SWECS rotor or system power curve (pouer output as a function of windspeed) for three rotor designs:

1. A constant rom rotor

2. A constant tip-speed ratio rotor

3. A rotor with specified rpm vs. windspeed schedule The SWECS aust be a horizontal-axis, fixed blade pitch machine. Under the constant tip-speed ratio designe an automatic blade pitch control is assumed so that a required maximum power can be achieved and maintained in high winds abvove the rated windspeed. When the power-train efficiencies are included in the calculation. the power curve then reflects the system output.

Developed by: Peter Tu

Written by: Peter Tu

Veronica Kertesz

NTESTC - Number of data points

Vy - Free stream wind speed [mph]

$x x$ - Rotor blade tip speed to uind speed ratio

TP - Rotor power [KW]

CPAV - Average rotor power coefficient

OMEGA - Rotor shaft speed [rpm]

$R$ - Rotor radius [ $f t]$

\section{DATA FILES}

SYSDAT - Input file from PROP containing VV,XX,TP,CPAV

PWROAT - Input file from PROP containing R,OMEGA. $X M I N, D E L X, X M A X, O M E G A$, THETP,GO,XETA,BLDCdefined in PROP)

TUDEE - 3-D Efficiency data

PTEFF1 - 2-D Efficiency data

RPMFIL - User supplied rpm vs-uindspeed data

TUOUT - Permanent output file

ENGDAT - Outout file used as input for HINDMAT

PLTDAT1- Input file for the plotting routineesYSPLOT

DUTPUT - Output onto CRT 


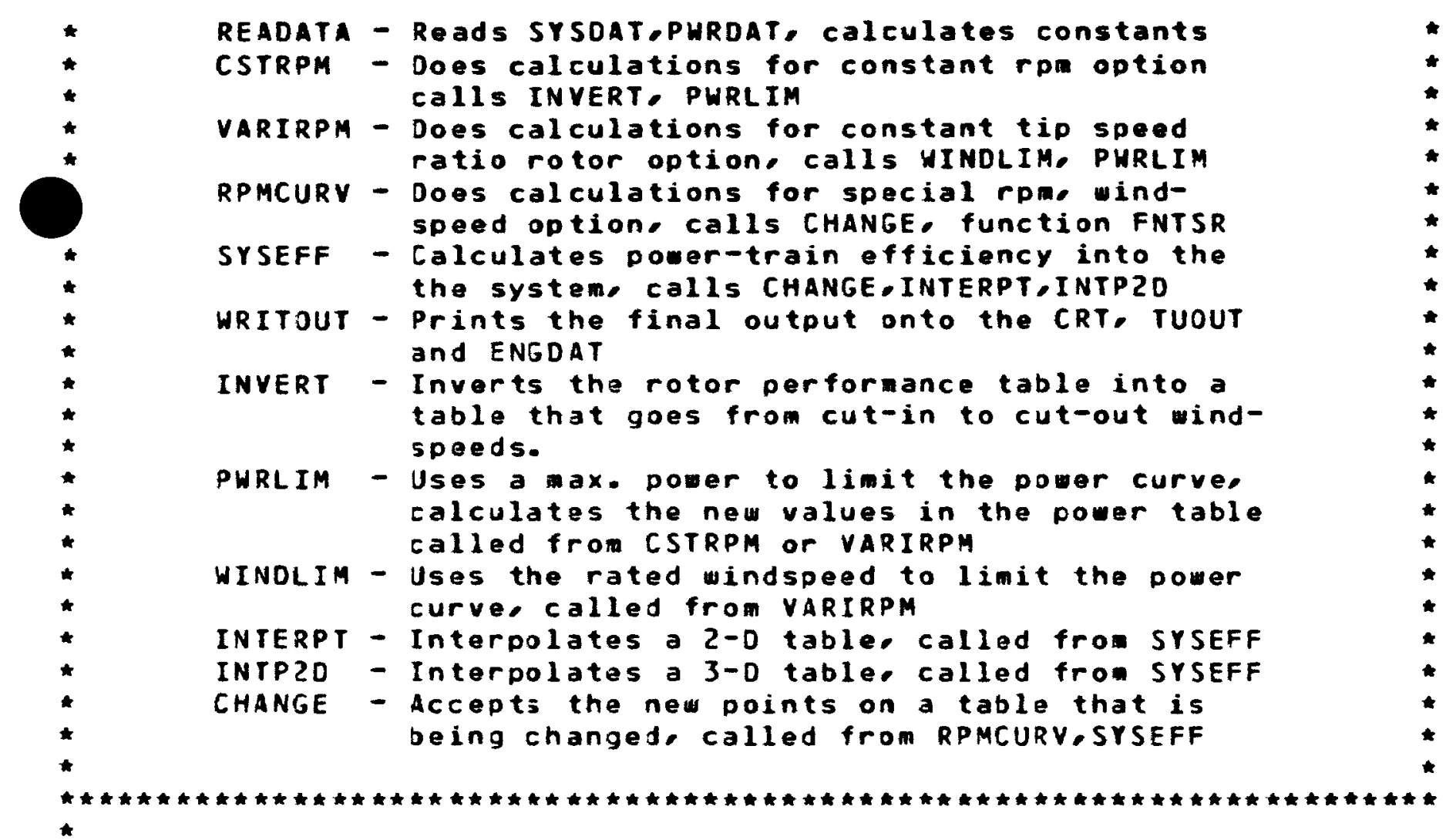

openING ALL THE FILES

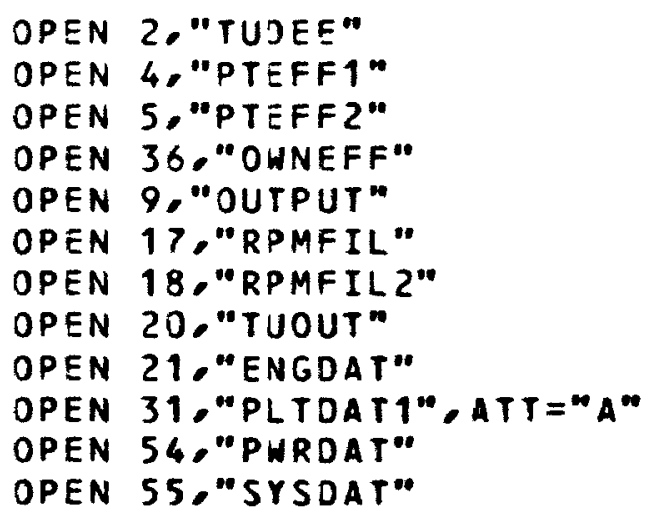

DIMENSION VV(26), XX(26),TP(26),CPAV(26),HSPD(26),RPMT(26),

$+\operatorname{AVV}(26), A X X(26), A T P(26), A C P A V(26), R P M(26), T X(26), T C P(26)$,

+ EFF( 26$)$, POHERAT (26), XC (26), YC (26),PORAT(13), SPD(13),EFFGEN $(13,18)$

INTEGER YN

COMMON /FUNCT/TX,TCP,KTOT

COMMON/INT1D/XC,YC,IPOINT

COMMON/INTPT/X,Y,Z

COMMON/INTZD/NXPNT , NYPNT, EFFGEN,PDRAT, SPD

COMMON/PLIM/TP, XX, CPAY,VV,RPM, NTESTC,VHIN, YMAX,OPTION

COMMON/CONST /RAREA,POWK,CTSR,TSR,RD,PI, CPMAX

COYMON/INVRT /OMEGA / NOOA, NDOB

COMMON/WRIT/ENT

COMMON/FLAG/MFLAG

CALL READATA

TYPE "PLEASE SELECT YOUR OPTIONS:"

TYPE "1 FOR CONSTANT RPM ROTORS" 


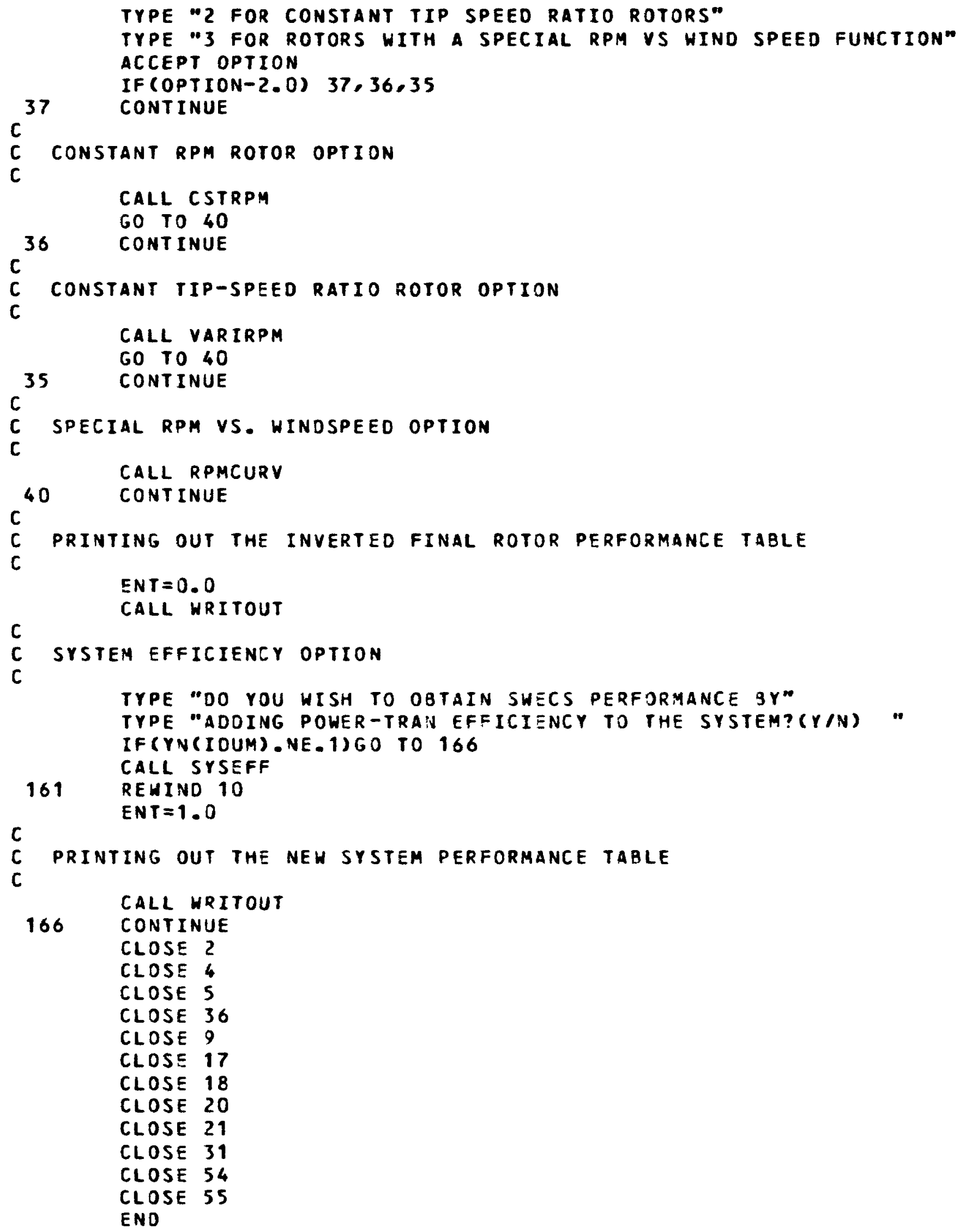




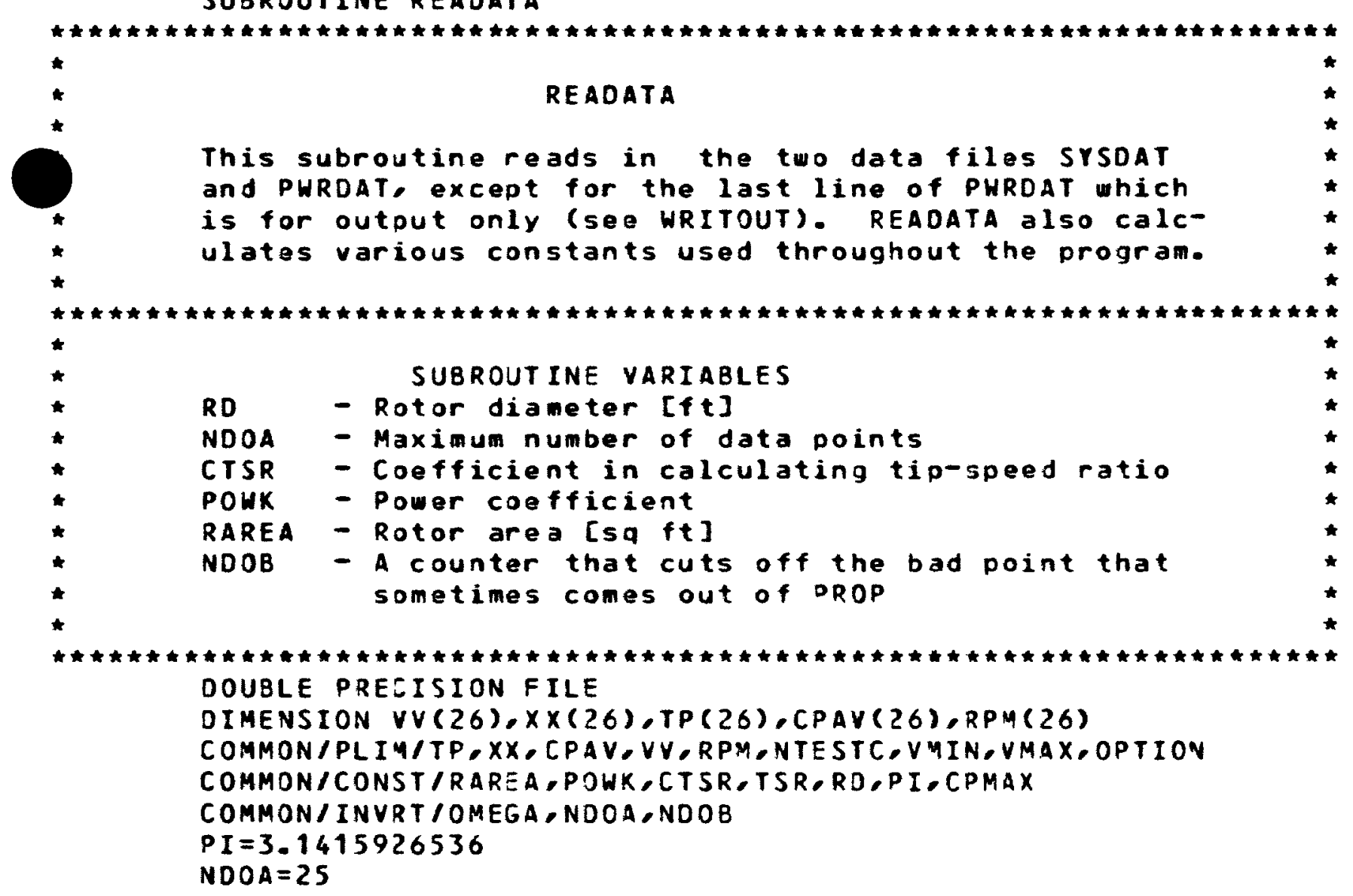

$+$

* reading in the rotor performance tagle from prop

$+$

$+$

10

20

30

*

* reading in re omega, rho from prop

- oata file pWrdat

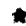

READ (54,5O) R,OMEGA,RHO

$+$

CALCULATING CONSTANTS

$R D=R+R$

$C T S R=(3600.0 / 5280.0) *(P I * R D / 60.0)$

$P O W K=(1.0 / 2.0) *((5280.0 / 3600.0) * 3) *(1 . / 737.6) * R H O$

RAREA $=(P I) *(R * 2)$

$N D O B=I-1$

PRINTING THE TIP-SPEED RATIO VS. CP TABLE ONTO

THE CRT AND TUOUT

TYPE "ENTER the datafile nAME fOR PROP " READ (10.55)FILE

55

FORMAT (S20) 
WRITE $(9,57)$ FILE

WRITE $(20,57)$ FILE

57 FORMAT("THE AIRFOIL DATAFILE USED IS ". $5201 /$ )

WRITE $(9,60)$

WRITE $(20,60)$

60

FORMAT ("THE

WRITE $(9,70)$

WRITE $(20,70)$

70

FORMAT ( $5 X, " T I P$ SPEED RATIO",5X,"PONER COEF., CP")

DO $90 \mathrm{I}=1$, NDOB

HRITE (9,30) $\times X(I)$, CPAY (I)

HRITE(20,8) $\times X(I)$, CPAV(I)

80

FORMAT $(8 X, F 10.3,9 x, F 10.3)$

90 CONTINUE

RETURN

END 
This subroutine is used by the constant rom rotor option. It allows the changing of the rom and does the necessary calculations to correct the other variables. It takes the cut-out windspeed and cuts out all windspeeds above the 1 imit. it then inverts the rotor performance table into increasing windspeed. An option for limiting the power curve by a power is provided. Called by POHERCV.

Subroutines called - INVERT

- PWRLIM

DIMENSION VV(23),XX(26),TP(26),CPAV(26),AVV(26),AXX(26),

+ ATP(26),ACPAV (26),RPM(26)

INTEGER YN

COMMON /PLIM/TP,XX,CPAV,VV,RPM,NTESTC,VMIN,VMAX,OPTION

COMMON/CONST/RAREA,POHK, CTSR, TSR,RD,PI , CPMAX

COMMON/INVRT IOMEGA,NDOA, NDOB

COMMON/FLAG/MFLAG

$+$

4 $+$

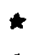
1

10

20

30

40

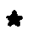

* printing the rah table onto the screen

$+$

HRITE $(9,11)$

11 FORMAT ( $/$ "ROTOR PERFORMANCE DATA GIVEN BY PROP CODE ARE:") HRITE $(9,12)$

12 FORMATC19X,"WIND SPEEDS",2X,"POWER",2X,"TIP SPEED",2X,"POWER COEF", $\left.+2 X, " R O T O R " 112 X, " M P H ", 3 X, " K H^{*}, 6 X, " R A T I O S^{*}, 6 X, " C P ", B X, " R P M " 1\right)$

WRITE(9,13) (VV(J),TP(J),XX(J),CPAV(J),RPM(J), J=1,NDOB)

FORMAT $(9 x, F 8,3,3 X, F 8,3,2 x, F 7,3,3 x, F 6.3,4 x, F 8,3)$

WRITE $(20,11)$

WRITE $(20.12)$

HRITE $(20,13)$

$(V \vee(J), T P(J), X \times(J), C P A V(J), R P M(J), J=1, N D O B)$ 
* entering the cut-out hindspeed

TYPE "ENTER MAXIMUM POWER CUT-OFF HIND SPEED IN MPH" ACCEPT VMAX

* calling the inverting subroutine, invert

CALL INVERT

* poner limiting option. suboutine phrlim

$\star$

TYPE "DO YOU WANT A MAX. POWER OUTPUT LIMIT?" IF (YN (IDUM). NE.1)GO TO 100

100 CONTINUE RE TURN

END 
SUBROUTINE VARIRPM

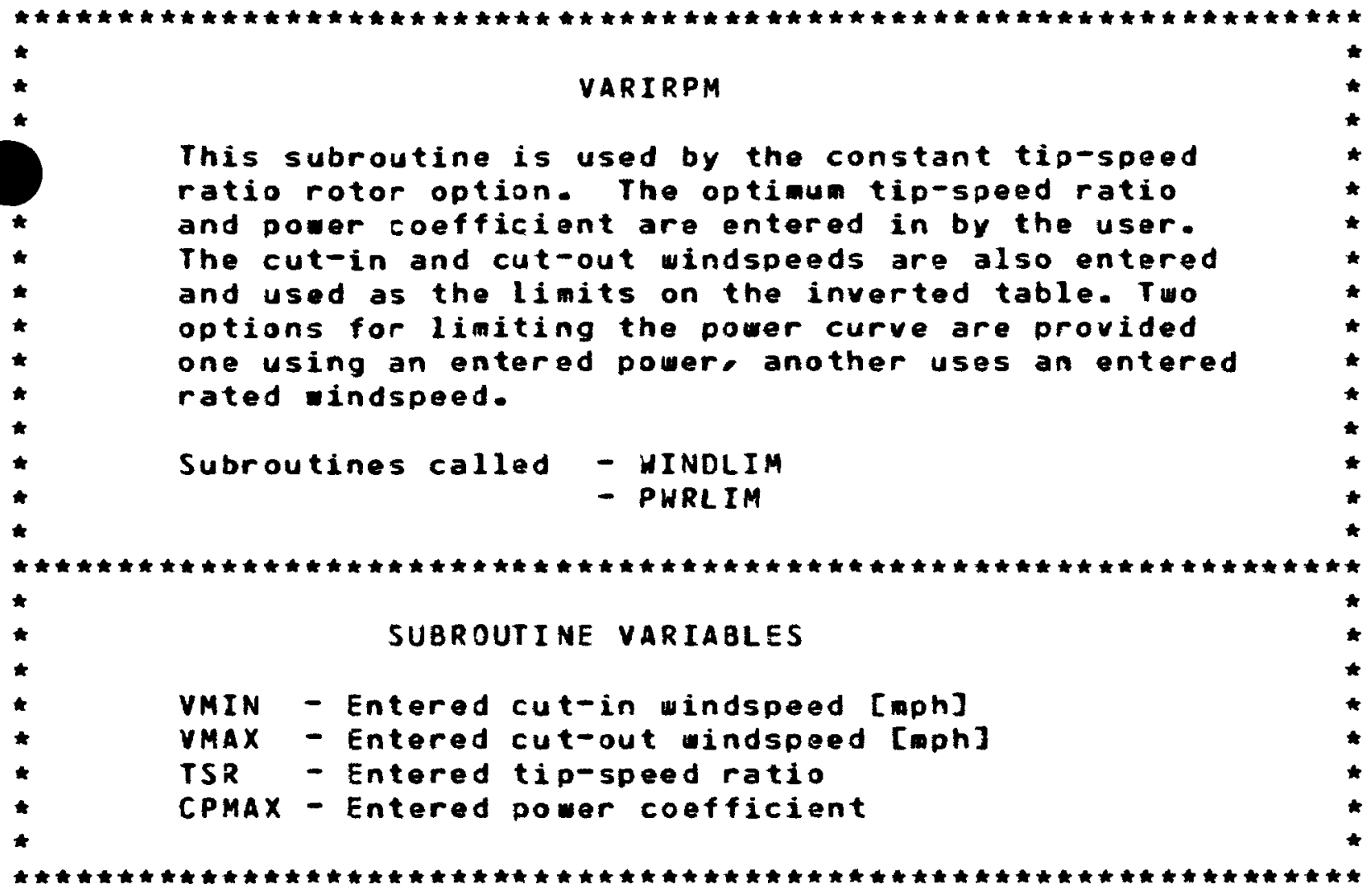

OIMENSION TP(26), XX(26),RPM(26),CPAV(26),VV(26)

INTEGER YN

COMMON /PLIM/TP,XX,CPAV, VY ORPM,NTESTC, VMIN,VMAX, OPTION

COMMON/CONST/RAREA , POWK, CTSR , TSR , RO,PI , CPMAX

*

* aCCEPT USER INPUT VARIABles

เ

TYPE "ENTER CUT-IN AND CUT-OUT WIND SPEEDS IN MPH"

ACCEPT VMIN, VMAX

TYPE "ENTER TIP SPEED RATIO AND POHER COEFFICIENT,CP "

ACCEPT TSR,CPMAX

TYPE "ENTER YOUR CHOICE OF USING POWER (TYPE IN 1) OR"

TYPE "RATED WIND SPEED (TYPE IN 2) TO LIMIT MAX. POWER

ACCEPT AMAXP

IF (AMAXP.EQ. 1.0) GO TO 50

$\star$

* RATEO HINDSPEED LIMITING OPTION. SUBROUTINE WINDLIM

-

CALL WINOLIM

GO TO 100

50 CONTINUE

* POHER limitimg option. SUbroutine pHrLiM

$+$

CALL PHRLIM

100 CONTINUE

RETURN

END 
SUBROUTINE RPMCURV

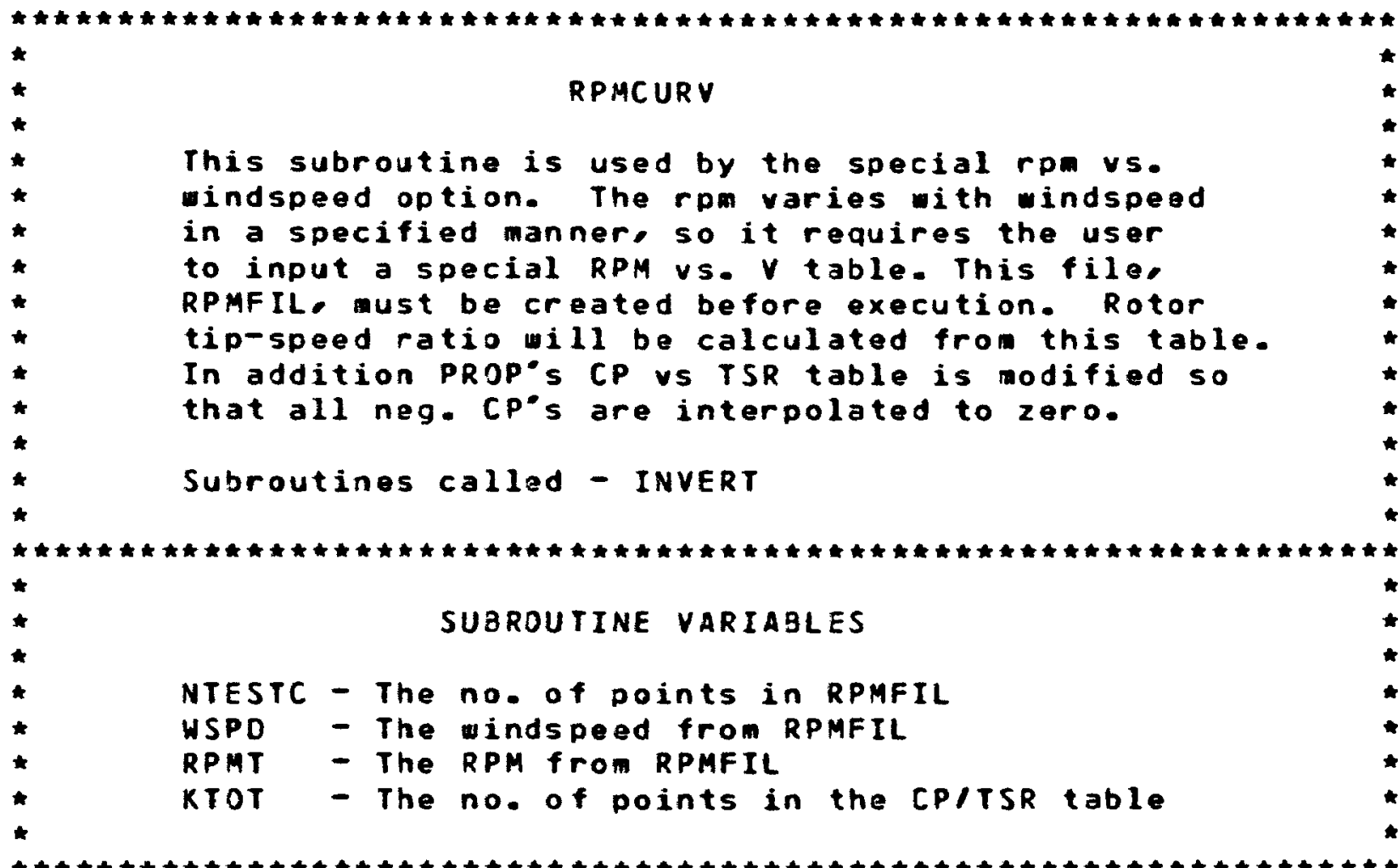

DIMENSION $V V(26), X X(26), T P(26),(P A V(26), W S P D(26), \operatorname{RPMT}(26)$

+ RPM( 26),TX(26),TCP(26)

INTEGER YN

COMMON/INVRT /OMEGA , NDOA , NDOB

COMMON /FUNCTITX,TCP,KTOT

COMMON/PLIM/TP,XX, CPAV,VV,RPM,NTESTC,VMIN, VMAX, OPTION

COMMON/CONST/RAREA , POWK, CTSR, TSR, RD, PI , CPMAX

COMMON/CHNG/NLINE

* ReAd in the rPa VS. hINDSPEed table

* PRTNTING the table onto the CRT

*

55 FORMATC(IS, 5X,F10.3,F10.3)

READ FREE (17) NTESTC,HSPD(1),RPMT(1)

DO 56 I $=2$. NTESTC

READ FREE (17) WSPD (I) , RPMT (I)

57 FORMAT (10X,F10.3,F 10.3)

56 CONTINUE

WR ITE (9.52)

52 FORMAT("THE FOLLOWING RPM TABLE HAS BEEN STORED IN THE FILE:") WR ITE $(9,58)$

58 FORMAT $(/ 4 X, "$ TOTAL NO.OF POINTS",2X,"WIND SPEEDS",4X,"RPM"/)

HRITE $(9,59)$ NTESTC,HSPD (1),RPMT (1)

59 FORMAT (1OX,I $4,8 X, F 10.3,2 X, F 10.3)$

DO $60 I=2$, NTESTC

HRITE (9.61) HSPD(I),RPMT (I)

61 FORMAT $(22 X, F 10.3,2 x, F 10.3)$

60 CONTINUE

$\star$

* $+$

OPTION FOR CHANGING THE TABLE

TYPE "DO YOU WISH TO CHANGE THIS TABLE(YIN)? -

IF (YNCIOUM). NE . 1 , GO TO 70

CALL CHANGE (1, USPD,RPMT) 
HRITE $(9.68)$
68 FORMAT ("RPM WRITE $(9,58)$

WRITE (18.55) NTESTC,HSPD(1),RPMT(1)

WRITE(9.59) NTESTC,WSPD(1),RPMT(1)

DO $69 I=2$, NTESTC

WRITE $(18,57)$ WSPD $(I), R P M T(I)$

WRITE(9.61) WSPD(I),RPMT (I)

69 CONTINUE

70 CONTINUE

$\star$

CREATING A USEFUL CP VS. TIP-SPEED RATIO TABLE

FROM THE PROP CODE TABLE AND

PRINT OUT THE FINAL TABLE

CALL CPCORR(KTOT)

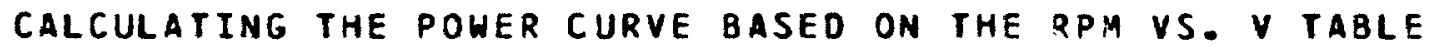
AND THE CP VS. TSR TABLE

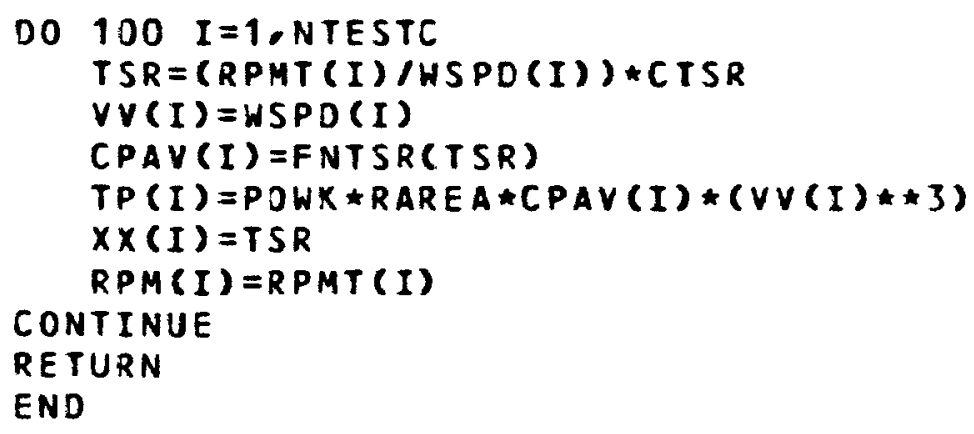


SUBROUTINE SYSEFF

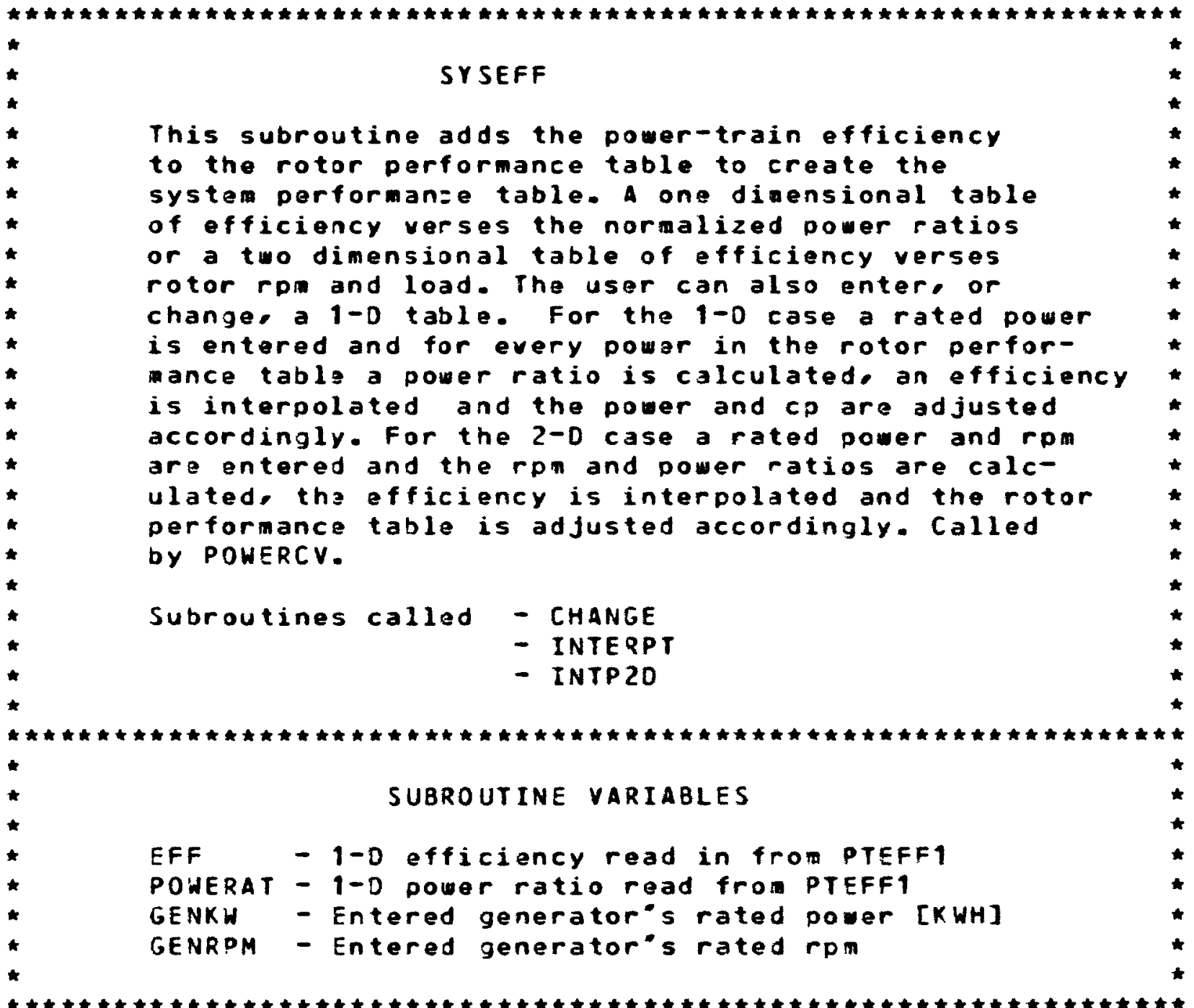

DIMENSION TP(26),XX(26),RPM (26),CPAV(26),VV(26),EFF(26)

DIMENSION POHERAT (26), EFFGEN $(13,18), X C(26), Y C(26)$, SPD (13)

DIMENSION PDRAT(18)

INTEGER YN

COMMON /PLIM/TP,XX,CPAV, VV,RPM,NTESTC, VMIN,VMAX,OPTION

COMMON/INTID/XC,YC,IPOINT

COMMON/INTPT/X,Y,Z

COMMON/INT ZD/NXPNT, NYPNT, EFFGEN,PORAT, SPD

COMMON/CHNG/NLINE

SELECTING the tYPE OF POWER-TRAIN tABLE

ACCEPT "ENTER 2 FOR a 2-D TABLe OR 3 fOR a 3-0 table "-tabl IF (TABL.EQ.3.0)GO TO 170

TYPE "O

TYPE "ENTER YOUR PREFERENCE OF CONSTRUCTING THE POWER-TRAIN EFFICIENC

TYPE "1 FOR USING THE EXISTING TABLE"

TYPE " 2 FOR ENTERING A NEW TABLE"

TYPE "3 FOR USER SUPPLIED TABLE (FILE OWNEFF)"

ACCEPT SELECT

IF(SELECT.EQ.2.0)GO TO 85

THE 1-D OPTION

READ 1-D EFFICIENCY TABLE- FILE PTEFF1 


\section{IF ILE $=4$}

IF (SELECT.EQ.3.0) IFILE $=36$

$0020 \quad I=1,100$

$$
\text { READ FREE (IFILE) EFF(I), POUERAT(I) }
$$

40 CONTINUE

$$
\text { IPOINT }=I-1
$$

\section{URITE $(9,50)$}

FORMATC"THIS IS YOUR EXISTING PO
$+5 \times$ " BASED ON LOAD POHER RATIOS:"/,

+ ITEM NO.",5X,"EFFICIENCIES".5X,"POWER RATIO")

60 CONTINUE

DO $80 \quad I=1$, IPOINT

WRITE $(9,70)$ I , EFF(I), POHERAT (I)

70 FORMAT $(I 3,11 X, F 5.1,11 X, F 8.6)$

80 CONTINUE

$\star$

OPTION TO CHANGE, OR CREATE, THE 1-D TABLE

HRITE $(9,82)$

82 FORMATE"DO YOU WISH TO MAKE CHANGES TO THE aBOVE TABLE?(Y/N) $\cdots$ IF (YN(IDUA). NE.1)GO TO 90

85 CONTINUE

CALL CHANGE (2,EFF, PONERAT)

DO $86 \mathrm{I}=1$, NLINE

86 CONTINUE

WR ITE(5,10)EFF (I), POHERAT (I)

I POINT $=$ NLI INE

WRITE $(9,88)$

88 FORMAT("THIS IS YOUR FINAL POWER TRAN EFF TA3LE:"/

+"ITEM NO." "5X,"EFFICIENCIES",5X,"POWER RATIO")

60 TO 60

90

CONTINUE

WRITE $(9.100)$

100

FORMAT "THIS IS THE POHER TRAN EFF. TABLE"\%,

+ "BASED ON INPUT PONER RATIOS:" 1,

+"ITEM NO." $" 5 x, "$ "EFFICIENCIES", 5X,"POHER RATIOS"1)

$+$

130

140 CONTINUE

150

CHANGES THE POHER RATIOS FROM INPUT TO OUTPUT POHER OVER THE RATED GENERATOR POWER

\section{DO 140 I=1, I POINT}

IF (POHERAT (I).EQ.0.0)GO TO 130

POWERAT (I) = PONERAT (I)/EFF (I) *100.0

ACCEPTING THE RATED POWER

AND CHANGING THE VARIABLE NAMES FOR THE INTERPOLATION

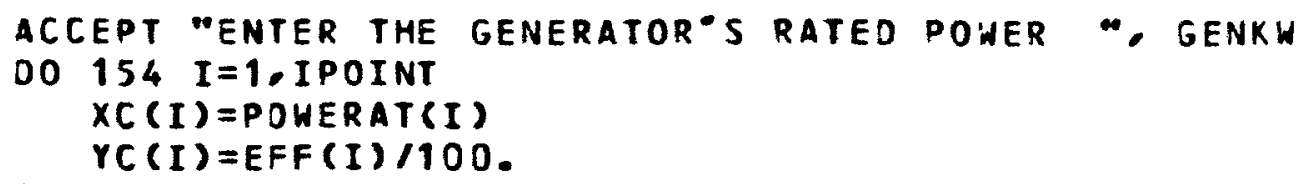


* calling the interpolation routine - interpt

DO $160 I=1$-NTESTC $X=T P(I) / G E N K H$

CALL INTERPT $T P(I)=Y * T P(I)$

160 CONTINUE

$$
\text { CPAV }(I)=\operatorname{CPAV}(I) * Y
$$

GO TO 900

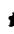

* the 2-d option

$+$

$+$

reading the data file - tudee

180

READ FREE(2) XPNT, YPNT

FORMAT (2F10.5)

NXPNT $=$ XPNT

NYPNT $=$ YPNT

READ FREE (2) (PDRAT ( $J), J=1, N \times P N T$ )

190 FORMAT $(8 \times .9 F 6.2,18 \times, 9 F 6.2)$

DO $220 \quad I=1, N Y P N T$

READ $(2,200) S P D(I),(E F F G E N(I, J), J=1, N \times P N T)$

200

220 FORMAT (F6.1,9F6.1/6X,9F6.1)

$+$

* accepting the rated poner and rpm

ACCEPT "ENTER THE RATED POWER AND RPM OF THE generator ",genKHogenRP WRITE $(9.222)$

222 FORMAT ( /,6X,"POWER",11X,"RPM",11X,"POHER-TRAIN") WRITE $(9.224)$

224 FORMAT $(6 x, "$ RATIO", 11X,"RATIO",9X,"EFFICIENCY")

CALLING THE 2-O INTERPOLATION ROUTINE - INPT20

AND PRINTINS THE INTERPOLATION TABLE

AND CALCULATING THE NEH VALUES

DO $230 I=1$, NTESTC

$X=T P(I) / G E N K W$

$Y=R P M(I) / G E N R P M$

CALL INTP2D

TYPE $X, Y, Z$

$T P(I)=Z * T P(I) / 100.0$

$\operatorname{CPAV}(I)=2 * \operatorname{CPAV}(I) / 100.0$

230

CONTINUE

900 RETURN

END 
This subroutine prints out the final tables and other useful information onto TUOUT, ENGOAT and the CRT. By using ENT it decides whether to use the rotor $(E N T=0)$ or the system $(E N T=1$ ) performance printing statements. Called from POWERCV.

DIMENSION VV $(26), X X(26), T P(25), C P A V(26), R P M(26)$

COMMON/PLIM/TP, XX, CPAV,VV,RPM,NTESTC,VMIN, VMAX,OPTION

COMMON/WRIT/ENT

COMMON/FLAG/MFLAG

IF (ENT.EQ.1.0)GO TO 120

$+$

$+$

$+$

* printing of the type of option used

*

45 FORMAT ( $5 x$, "CONSTANT RPM ROTOR OPTION " $/ 1)$ IF (OPTION.EQ.2.0) HRITE $(20,50)$

50 FORMAT (5X,"CONSTANT TIP SPEED RATIO ROTOR OPTION"//) IF (OPTION.EQ.3.0) WRITE $(20.55)$

55 FORMAT(5X."SPECIAL RPM FUNCTION OPTION $* 1 /)$

t.

* printing the rotor pezformance headings

a

HRITE (9.30)

HRITE $(20,80)$

80 FORMAT ("FINAL ROTOR PERFORMANCE OATA ARE AS FOLLOWS:")

URITE $(9,100)$

WRITE $(20,100)$

100 FORMATC//1X,"NO. OF", 2X, "WIND SPEEDS",2X,"POHER",2X,"TIP SPEED",

$+2 x, " P O H E R$ CDEF", 2X,"ROTOR"/1X,"POINTS",5X,"MPH", 8X,"KW",6X,"RATIOS",

$+6 x, " C P ", 8 x, " R P M " 1)$

GO TO 180

120 CONTINUE

$\star$

* printing the system performance headings

$+$

WRITE $(9,140)$

WRITE $(20.140)$

140 FORMAT( $/{ }^{\circ}$ FINAL SWECS PERFORHANCE DATA ARE AS FOLLOWS:") WRITE $(9,160)$

HRITE $(20,160)$

160 FORMATC/11X,"NO. OF",2X,"WIND SPEEDS",2X," SYSTEM",2X,

$+{ }^{* T I P}$ SPEED", $2 X_{0}$, SYSTEM ", 2X,"ROTOR"/1X,"POINTS",5X,

+ "MPH",7X,"POHER",4X,"RATIOS",2X,"POHER COEF",4X,"RPM"1, 
$+23 x_{0}+K W^{*}, 18 x,{ }^{\circ}\left(P^{*} /\right)$

t.

$+$

$+$

+

$$
\begin{aligned}
& \text { REHIND } 21 \\
& 130 \text { CONTINUE }
\end{aligned}
$$

190

PRINTING OUT THE aCTUAL VALUES

WRITSFREE (31) NTESTC

DO $190 \mathrm{I}=1$, NTESTC

WRITEFREE (31) VV(I),TP(I),XX(I),CPAV(I),RPM(I)

CONTINUE

WRITE (9,200) NTESTC,VV(1),TP(1),XX(1),CPAV(1),RPM(1)

WRITE $(20,200)$ NTESTC,VV(1),TP(1),XX(1),CPAV(1),RPM(1)

WRITE $(21,2 J 0)$ NTESTC,VV(1),TP(1),XX(1),CPAV(1),RPM(1)

WRITE (9,220) (VV(I),TP(I),XX(I),CPAV(I),RPM(I),I=2,NTESTC)

WRITE (20,220) (VV(I),TP(I),XX(I),CPAV(I),RPM(I),I=2,NTESTC)

HRITE (21,220) (VV(I),TP(I),XX(I),CPAV(I),RPM(I),I=2,NTESTC)

200 FORMAT $(1 X, I 4,4 X, F 8,3,3 x, F 8,3,2 x, F 7,3,3 X, F 6.3,4 X, F 8,3)$

220 FORMAT $(9 x, F 8,3,3 x, F 8,3,2 x, F 7,3,3 x, F 6,3,4 x, F 3,3)$

IF (MFLAG.EQ.D)RETURN

WRITE $(9,233)$

WRITE $(20,230)$

230 FORMATC/"NOTE: THE GIVEN CUT-OUT WINOSPEED EXCEEDED THE MAX POSITIVE

$\$ 6 X, " C P$ VALUE. THE CUT-OUT NINDSPEED IS ASSUMED TO BE THE"I

$\$$ 6X, "MAX WINDSPEED ON THE TABLE"/)

$M F L A G=0$

RETURN

END 
SUBROUTINE INVERT

INYER T

This subroutine takes PROP's rotor performance table and limits it to the cut-in to cut-out windspeeds and inverts the original table thus creating a table that goes from cut-in to cut-out windspeeds. In add- * ition any neg. CP*s are interpolated to zero.

Called fron - CSTRPM

Subroutines called - CPCORR

*

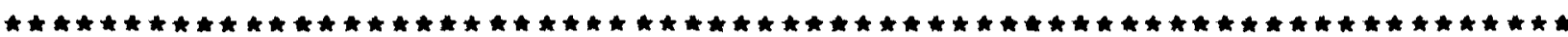

-

VMAX - From CSTRPM the cut-out windspeed

NDOB - The no. of points in the table

NTESTC - ditto

A - - The alternate array used for inverting

INDEX - A counter for the number of points

MFLAG - $=1$ when VMAX is greater than the table

DIMENSION VV $(26), X X(26), T P(26), C P A V(26), A V V(26), A X X(26)$,

$+\quad \operatorname{ATP}(26), A C P A V(26), R P M(26)$

INTEGER YN

COMMON /PLIM/TP,XX ,CPAV, VV,RPM,NTESTC, VMIN, VMAX, OPTION

COMMON/CONST /RAREA , POWK, CTSR,TSR,RD,PI,CPMAX

COMMON/INVRT/OMEGA / NOOA, NDOB

COMMON/FLAG/MFLAG

MFLAG $=0$

CALL TO CUT OFF THE TRAILING NEG.CP'S

INTERPOLATE ANY INTERMEDIATE NEG CP'S TO ZERO

AND PRINT OUT A NEH CP VS TSR TABLE

CALL CPCORR(IND)

NDOB $=$ IND

t.

INVERT THE TABLE

DO $10 I=1, N D O B$

$A V V(I)=V \vee(I)$

$A \times X(I)=X X(I)$

$A \operatorname{TP}(I)=\operatorname{TP}(I)$

10 CONTINUE

$A C P A V(I)=C P A V(I)$

DO $30 \quad I=1, N D O B$

$J=I-1$

$V V(I)=A V V(N D O B-J)$

$X X(I)=A X X(N D O B-J)$

$T P(I)=A T P(N D O B-J)$

CPAV $(I)=A C P A V(N D O B-J)$ 
DO $50 \quad I=1, N D O B$

INDEX $=I$

IF (VV(I).EQ.VMAX)GO TO 60

IF (VV(I).LT.VMAX)GO TO 50

DELTA $=(V M A X-V \vee(I)) /(V \vee(I-1)-V \vee(I))$

$V V(I)=V \operatorname{MAX}$

$X X(I)=D E L T A \star(X X(I-1)-X X(I))+X X(I)$

$T P(I)=D E L T A *(T P(I-1)-T P(I))+T P(I)$

CPAY (I ) = DELTA* (CPAV $(I-1)-C P A V(I))+C P A V(I)$ GO TO 60

50 CONTINUE

MFLAG $=1$

60 CONTINUE

NDOB = I NOEX

NTESTC = INDEX

DO $70 K=1$, NTESTC

RPM $(K)=$ OMEGA

70 CONTINUE

RETURN

END 
SUBROUTINE PHRLIM

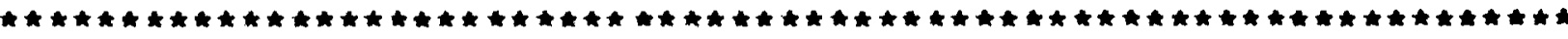

PWRLIM

This subroutine uses either a specified pover or tho maximua power to limit the power curve. It is called from two different subroutines and does a different calculation for ech subroutine.

Called from - CSTRPM

- VARIRPM

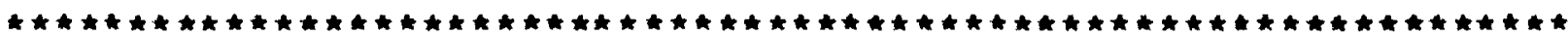

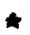

SUBROUTINE VARIABLES

TPMAX - Maximum power in the Rotor Performance table [KWH]

LIM - The index of the max. power

PLIM - User supplied limiting power

KRPM - Control variable for RPM values

RPMC - Control variable for RPM values

DIMENSION TP(26), XX(26), RPM(26),CPAV (26),VV(26)

INTEGER YN

COMMON /PLIM/TP,XX ICPAV,VV,RPM,NTESTC, VMIN, VMAX,OPTION

COMMON/CONST/RAREA,POWK,CTSR,TSR, RD,PI, CPMAX

WRITE $(20,10)$

10

FORMAT ( "POWER LIMITING OPTION")

IF (OPTION.EO.2)GO TO 550

$+$

* subroutine cstrpm calculations

+

TYPE "DO YOU WISH TO SPECIFY THE LIMITINS POHER"

IF(YN (IDUM). EQ.1)GO TO 400

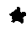

* using the max. power to limit the poher curve

t

TPMAX $=T P(1)$

DO $200 \quad I=2$. NTESTC

IF (TP(I).LE.TP(I-1)) GO TO 250

$T P \operatorname{MAX}=T P(I)$

CONTINUE

GO TO 900

250 CONTINUE

DO $300 \mathrm{~J}=L$ IM,$N$ TESTC

$T P(J)=T P M A X$

300 CONTINUE

GO TO 900

400 CONTINUE

USING A USER SUPPLIED LIMITING POWER

TYPE "WHAT IS THE LIMITING POWER?"

ACCEPT PLIM 


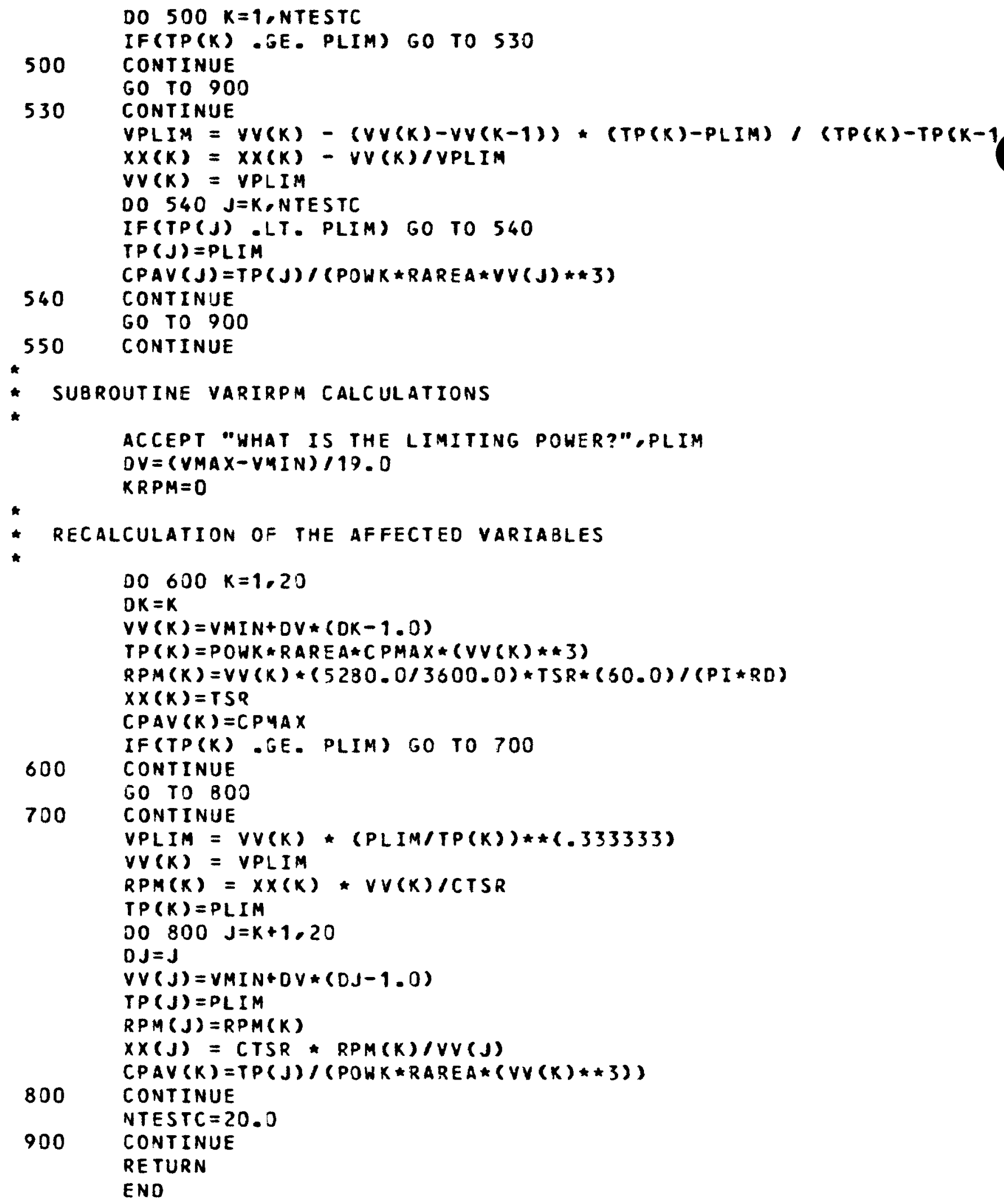


This subroutine uses a specified rated windspeed to Iimit the power curve. All necessary calculations are done on the other variables.

Called fron - VARIRPM

DIMENSION TP(26),XX(26),RPM(26),CPAV (26), VV(26)

INTEGER YN

COMMON/PLIM/TP,XX, CPAV,VV,RPM,NTESTC,VMIN, YMAX,OPTION

COMMON/CONST/RAREA, POUK,CTSR,TSR, RD,PI, CPMAX

* accepting the rated hindspeed - vRAt

$+$

TYPE "WHAT IS THE RATED WIND SPEED?"

ACCEPT VRAT

DV $=(V M A X-V M I N) / 19.0$

DO $10 \quad K=1,20$

*

$+$

-

20

recalculating the unchanged values

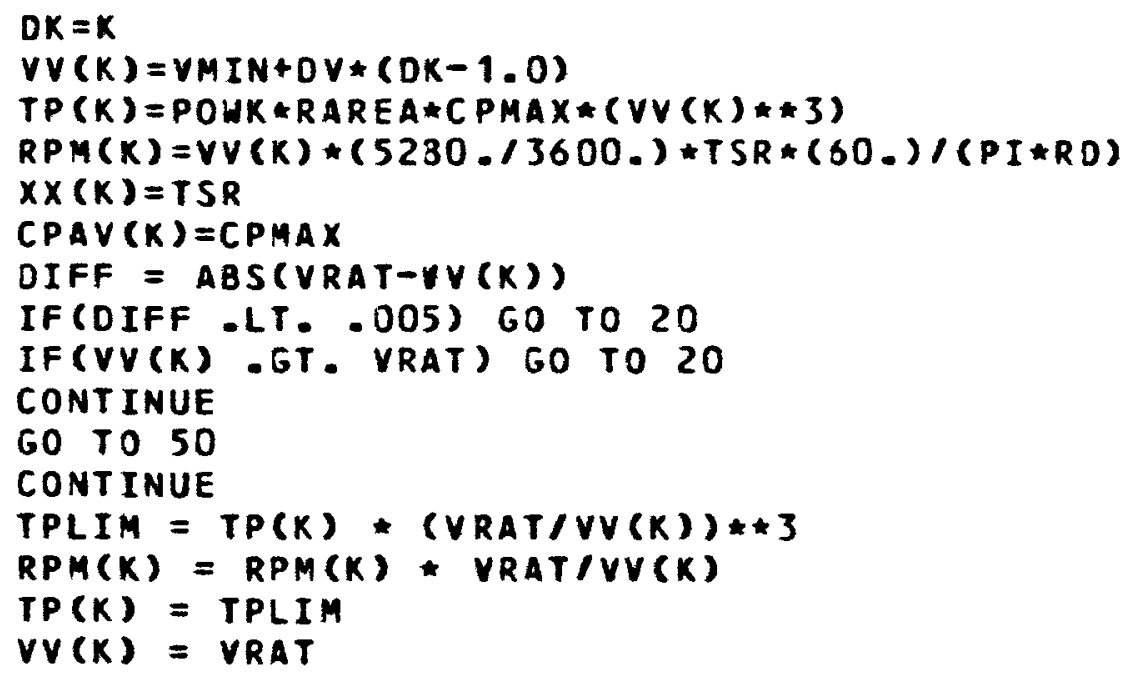




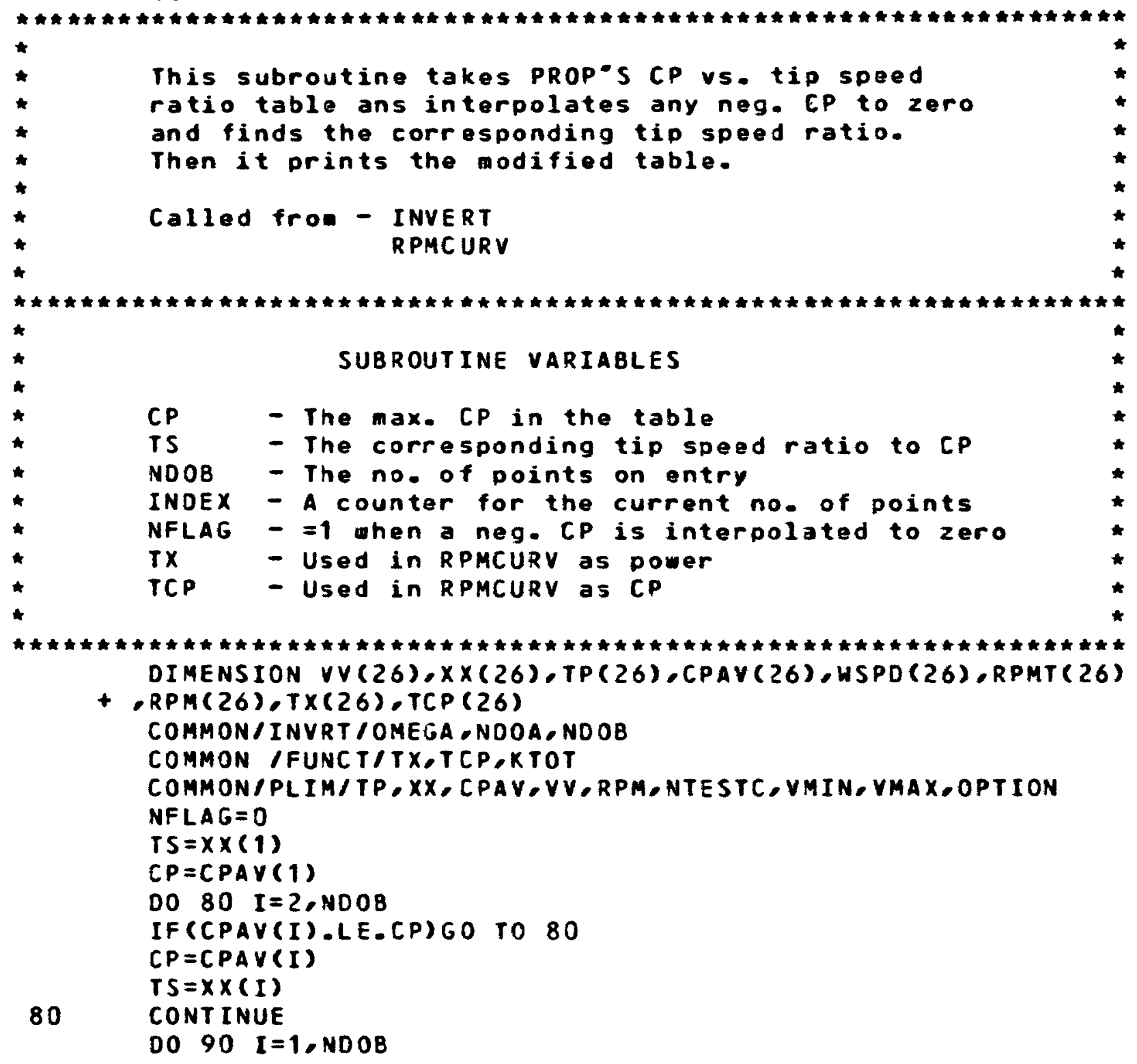

$+$

FIGURING OUT HHICH SIDE OF THE CURVE PTIIS ON

INDEX $=I$

IF $(X X(I) . G T . T S) G 0$ TO 82

FINDING A NEW TSR IF CP IS NEG.

IF(CPAV(I) . GE. 0.0) G0 TO 90

NFLAG $=1$

$D C P=C P A V(I+1)-C P A Y(I)$

$X X(I)=x x(I+1)-(((C P A V(I+1)-0.0) / D(P) *(x X(I+1)-x x(I)))$

$V V(I)=V V(I+1)-(((C P A V(I+1)-0.0) / D C P) *(V V(I+1)-V V(I)))$

$T P(I)=0.0$

CPAV $(I)=0.0$

GO TO 90

82 CONTINUE

AT END INTERPOLATE A TSR AT CP=O IF CP NEG.

IF (CPAV (I) -GE.0.0)GO TO 90

NFLAG $=1$ 


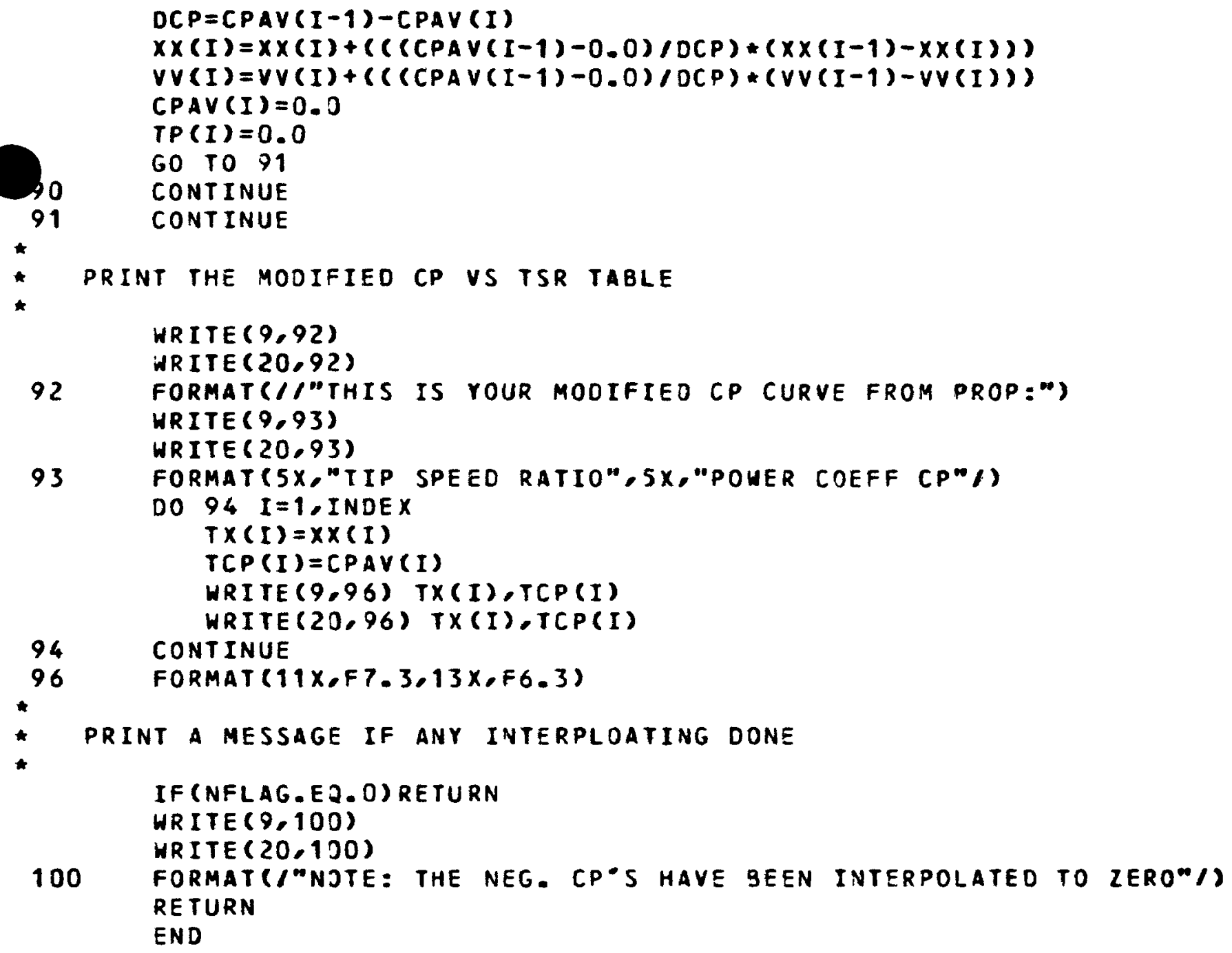

$\star$

* print the modified cp vs tsr table

$\star$

HR I TE $(9,92)$

WR I TE $(20,92)$

92 FORMAT(//"THIS IS YOUR MODIFIEO (P CURVE FROM PROP:") HRITE (9.93) WR ITE $(20.93)$

93

FORMAT (5X,"TIP SPEED RATIO",5X,"POWER COEFF (P"/)

DO $94 I=1$, INDEX

$T X(I)=X X(I)$

$T C P(I)=C P A V(I)$

WRITE (9.96) TX(I),TCP(I)

WRITE $(20,96)$ TX(I),TCP(I)

94 CONTINUE

96 FORMAT (11X,F 7.3,13x,F6.3)

$+$

PRINT A MESSAGE IF ANY INTERPLOATING DONE

IF (NFLAG.EQ. O) RETURN

WR ITE $(9,100)$

HRITE $(20,100)$

100

FORMAT(/"NJTE: THE NEG. CP'S HAVE SEEN INTERPOLATED TO ZERO"/) RETURN

END 
FUNCTION FNTSR $(X)$

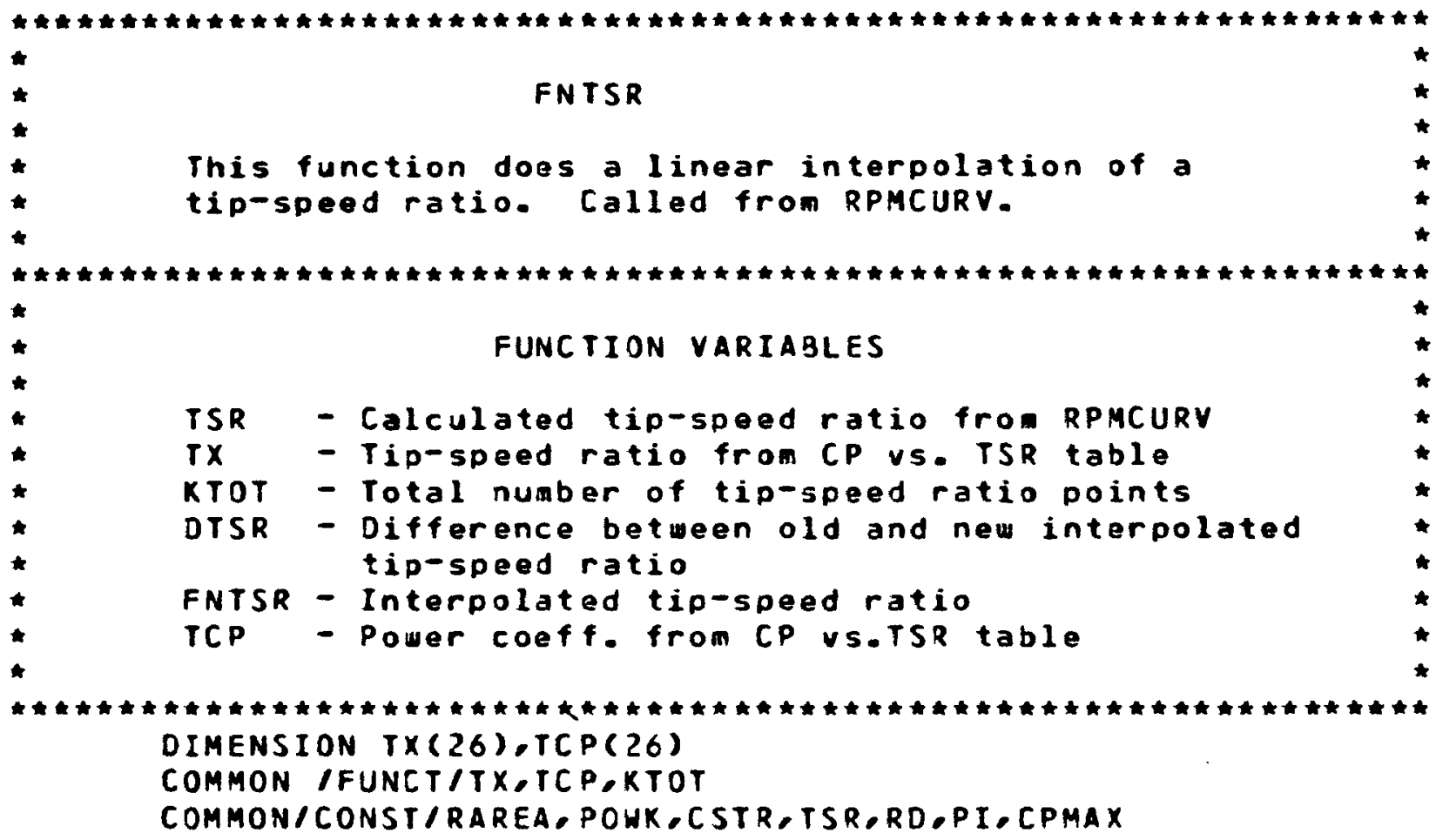

$$
\star
$$

CHECK IF TSR HITHIN TABLE LIMITS

IF(TSR - LT. TX(1)) GO TO 115

IF(TSR . GT. TX(KTOT)) GO TO 115

*

INTERPOLATING TSR FROM THE TABLE

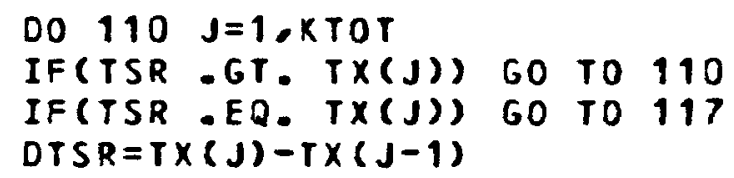

FNTSR $=T C P(J)-(((T X(J)-T S R) / D T S R) *(T C P(J)-T C P(J-1)))$

GO TO 118

110 CONTINUE

GO TO 118

115 CONTINUE

If TSR is out of the tables limits, set to zero

HRI TE $(9,116)$ TSR

116 FORMAT("TIP SPD RATIO ",F7.3." IS OUT OF LIMITS, PLEASE DISCARD") FNT SR $=0.0$

GO TO 118

117 CONTINUE

*

เ

FNTSR $=$ TCP (J)

118 CONTINUE

RETURN

ENO 
SUBROUTINE INTERPT

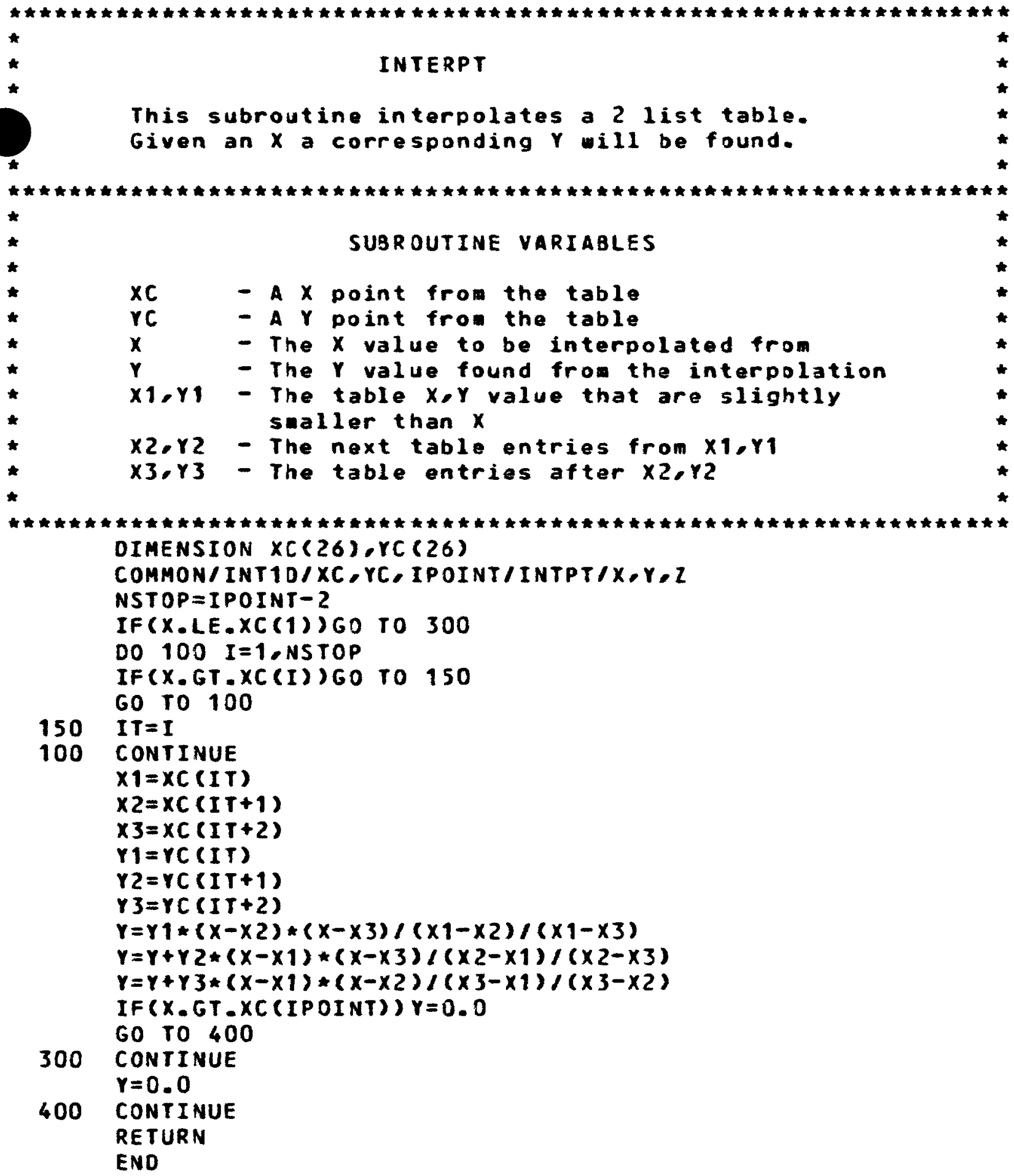


70 CONTINUE

C WRITE $(9,85) 21,22,23,24,2 \mathrm{H}, 2 \mathrm{~L}$

C 85 FORMAT $(6 F 10.5)$

C PRINT $(9,80) X, Y, Z$

C 80 FORMAT(3F10.4)

RETURN

END 
SUBROUTINE CHANGE (ENTRY, QITEM1, OITEM 2)

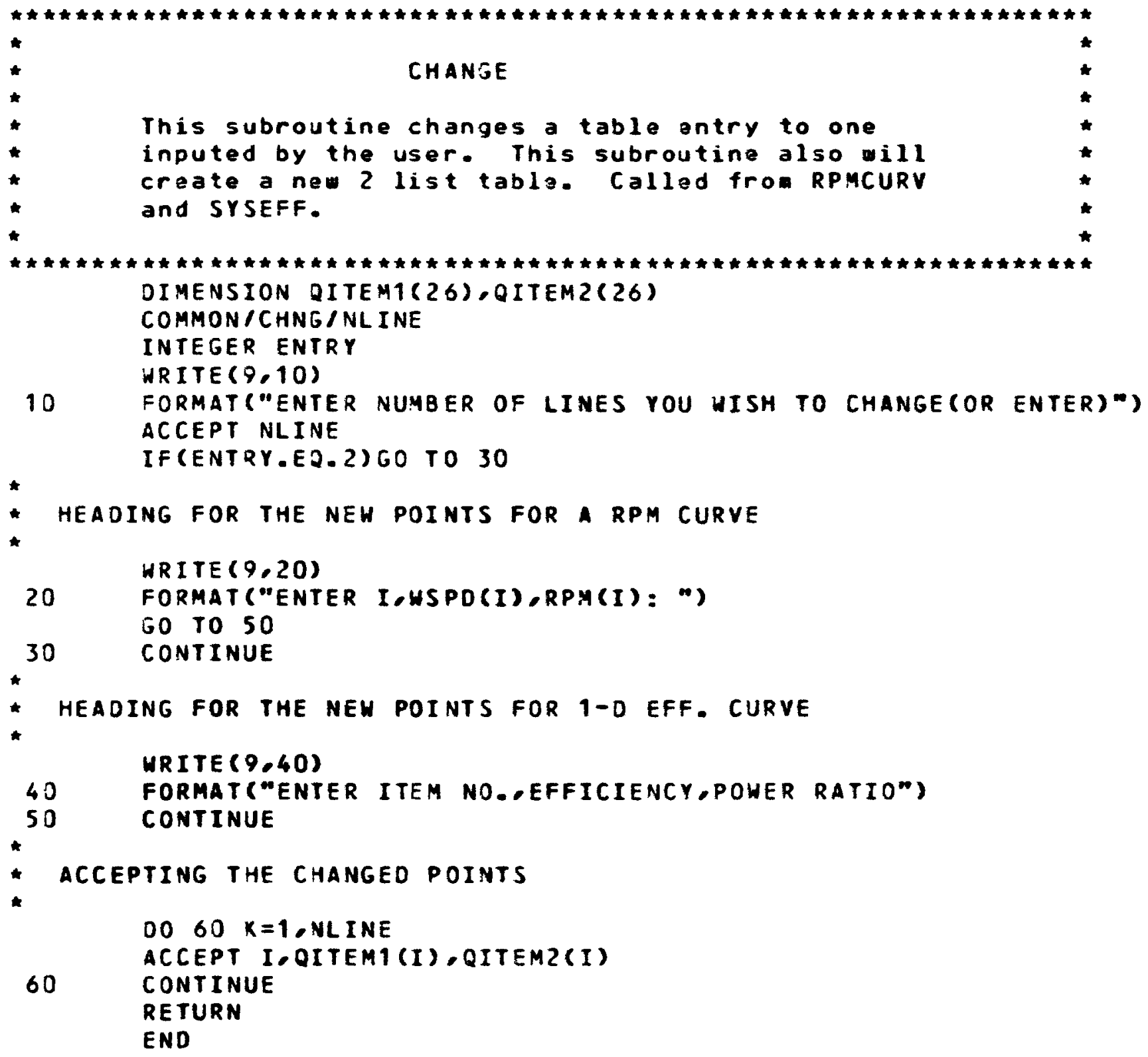


integer function $r n(i d u m)$

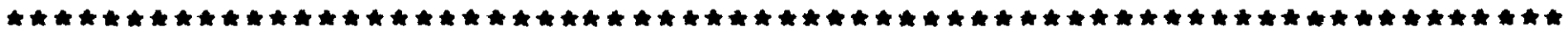

म

$\mathbf{Y N}$

This function reads in an charactor, "y" or " $n$ ", and converts it to $a$ number, $y=0$ and $n=1$. The calling routine can then use an if statement to

$+$

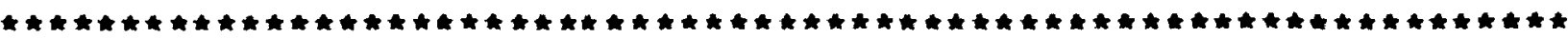
road $(11,1001)$ iflag

1001 format(a1)

$y n=0$

if(.not. ((iflag.eg."Y").or.(iflag.ea."y ")) )go to 2300 $y n=1$

2300 continue

return end 
Based on the power curve (power in KH VS. windspeed) from the POWERCV codee this program calculates the annual energy production under a Weibell * wind distribution. requiring the input of the $k$ * and $C$ values. If a Rayleigh wind distribution is used. when $k=2$, the annual energy production will be expressed as a function of annual average wind- * speed ranging from 5 to $18 \mathrm{mph}$.

An option is givan for a user's diurnal energy supplyldemand match (or mismatch). The local wind characteristics and load profile nust be known and provided in the files WINDDI and LOADDI.

Developed by: Peter Tu

Written by: Peter Tu Veronica Kertesz

NTESTC - Number of data points

VV - Free stream wind speed [mph]

$X X$ - Rotor blade tip speed to vind speed ratio

IP - Rotor power [KW]

CPAV - Average rotor power coefficient

HUS - Entered hub height [ft]

NOIST - Choice of distribution

RK - Weibell K value

NDEC - Choice of output format

INTERMEDIATE VALUES

WK - Inverse of RK

GK - Wind distribution equation constant

GARMA - ditto

GAR - ditto

VBAR - Average windspeed [mph]

HVBAR - VBAR at hub height

C - HVBAR/GAR

DATA FILES

WFILE - New WINDDI file if WINDDI changed

OUTPUT - OUtPUt onto CRT

ENGDAT - Input file from POWERCV containing NTESTC,VV,TP, $X X, C P A V$

WINDOI - Diurnal oindspeed distribution file 
ENERGI - Calculates the energy yield for a given windspeed, Calls INTERPT

MISMAT - Calculates the energy supplyldenand match Reads WINDOI, LOADDI, calls INTERPT, MATOUT. HCHANGE

MATOUT - Prints the energy yield tablee the windspeede load distributions and the supply/ demand match onto UINDOUT and the CRT

HCHANGE - Option for changing HINDDI (a 2-D array)

INTERPT - Interpolates a 2-D table called from ENERGI

DIMENSION VV(26),XX(26),TP(26), CPAV(26),DAYHR (26), HNDSP $(4,26)$

DIMENSION WTKWH(26), LDKWH (26), NTKWH(26),WTKH $(4,26), \operatorname{LDKH}(4,26)$

OIMENSION NTKH $(4,26), X C(26), Y C(26)$

COMMON/ENRGI/C, RK, VBAR - NDIST, NOEC

COMMON/INTID/XC,YC,NPOINT

COMMON/INTPT/X,Y,Z

COMMONIMISHTIHUB, VV,TP . NTESTC

INTEGER YN

REAL LOKWH,LOKH,NTKWH,NTKW, MTRHT

OPEN 3,"WINDOI"

OPEN 6."OUTPUT"

OPEN 15,"LOADDI"

OPEN 16,"HFILE"

OPEN $25, "$ "WINDOUT", ATT $=$ "A"

OPEN 30,"ENGDAT"

OPEN 32,"PLTDAT2", ATT="A"

REHIND 30

READ $(30,24)$ NTESTC,VV(1),TP(1),XX(1),CPAV(1)

24 FORMAT $(1 X, I 4,4 X, F 8.3,3 x, F 8,3,2 X, F 7,3,3 x, F 6,3)$

READ $(30,25)$ ( VV (J),TP(J),XX(J),CPAV(J), J=2,NTESTC)

25 FORMAT $(9 X, F 8,3,3 X, F 8,3,2 X, F 7,3,3 X, F 6.3)$

27 CONTINUE

ACCEPT "ENTER HUB HEIGHT, IN FT. ",HUB

ACCEPT "ENTER 1 FOR NEIBULL, 2 FOR NASA DISTRIBUTION "NNIST IF (NDIST.EQ. 2 ) GO TO 35

ACCEPT "ENTER HEIBULL OISTRIBUTION'S K VALUE ",RK

35 GO TO 60

RK $=2.27$

60 CONTINUE

WRITE $(6,33)$

33 FORMATC"FOR ENERGY OUTPUT ENTER 1 FOR A OUICK SUMMARY,"

$+24 \times, 02$ FOR A DETAILED REPORT ')

ACCEPT NDEC

$M K=1.0 / R K$

$G K=1.0+(1.0 /(12.0 * W K))+(1.0 /(288.0 *(W K * 2)))$

$+-(139.0 /(51840.0 *(H K * * 3)))$

GARMA $=(W K * W K) *(E X P(-W K)) *((2.0 * P I / W K) * * 0.5) \star G K$ 


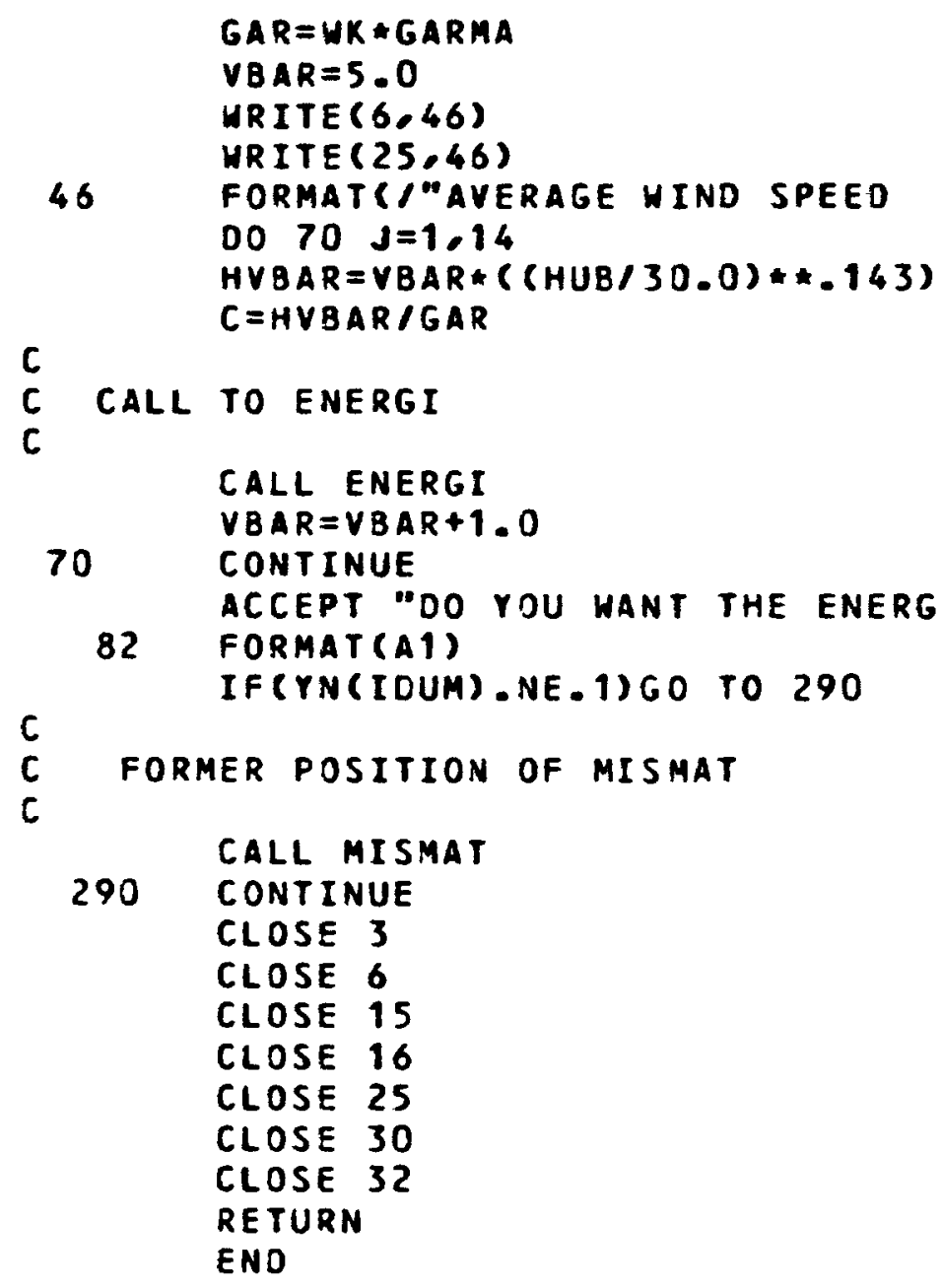


SUBROUTINE ENERGI

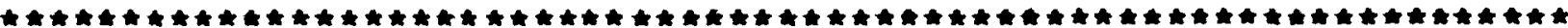

This subroutine calculates the annual hours of operation and energy production of a SHECS under The specified Weibull ind distribution and the annual average windspeed. The windspeed used in the calculatons increases from the cut-in to the cut-out windspeed at an increment of $0.05 \mathrm{mph}$. The max. hours, max. rotor power and the max. energy output for the interval of $V$ to $V+D V$ mp are found and the integrated value of these energies is printed out.

Subroutines called - INTERPT MATOUT

Setting the constants

CONST $=1.0$

ENERGY $=0.0$

EMAX $=0.0$

$\operatorname{HMAX}=0.0$

$V=V v(1)$

DV $=0.05$

CONTINUE

Checking if $V$ is aithin the vindspeed vs pover table IF(V. GT. VV(NTESTC) GO TO 50 
* Setting the table into INTERPT's arrays

* Calling INTERPT to interpolate a pouer

$+$

DO $41 I=1$ - NTESTC

$X C(I)=V V(I)$

$\begin{array}{ll} & Y C(I)=T P(I) \\ \text { CONTINUE }\end{array}$

$X=V$

NPOINT $=$ NTESTC

CALL INTERPT

$\star$

* Calulations of power dependant variables

$*$

HOURS $=8766.0 *(\operatorname{EXP}(-\operatorname{CONST} *(V / C) * * R K)-$

$+\operatorname{EXP}(-C O N S T *((V+D V) / C) \star * R K))$

OELEN $=Y * H O U R S$

$\star$

* Searching for the max. energies and hours

$\star$

IF (OELEN - LT. EMAX) GO TO 42

EMAX $=$ DELEN

42 VMAXE=V

42 CONTINUE

IF( HOURS -LT. HAAX) 60 TO 44 HMAX $=$ HOURS

$\checkmark \operatorname{MAX}=V$

PMAX $=Y$

44 CONTINUE

a

* Integration for ENERGY

$+$

ENERGY = ENERGY + DELE A

$V=V+D V$

GO TO 40

SO CONTINUE

$+$

*Call to matout

$+$

CALL MATOUT(1)

RETURN

END 


\section{YI SMAT}

This subroutine calculates the energy supply/demand match(or mismatch). Using a user supplied wind distribution to calculate the SWECS power output and comparing this to a user supplied load distribution. WINDOI and LOADDI respactively, the watch between thase two is printed out.

Subroutines called - HCHANGE MATOUT

\section{SUBROUTINE VARIABLES}

MTRHT - Anamometer height, from WINDDI

WNDAVE - Average windspeed, from WINDDI

DAYHR - Time of daye $24 \mathrm{hr}$. clock. NINDDI \& LOADOI

WNDSPD - Windspeed for a certain time and season

FACT - Correction factor for the hub height

LDKW - Load for a certain time and season,LOADDI

TOTKWH - Yearly total of energy summation

TOTWT - Yaarly total of SWECS pousr summation

TOTLOAD- Yearly total of load summation

WTKWH - Seasonal total of SWECS energy summation

LDKWH - Seasonal total of load energy sumnation

NIXWH - Seasonal net energy(SWECS-load) sumnation

AVEKWH - Annual average energy (net)

AVEWT - Annual average SHECS power

AVELOAD- Annual average load power

DIMENSION VV(26), XX(26),TP(26),CPAV (26), DAYHR (26), WNDSP $(4,26)$

DIMENSION HTKWH(26),LDXWH(26), NTKWH(26),WTKW(4,26), LDKW(4,26)

DIMENSION NTKH $(4,26), X C(26), Y C(26)$

INTEGER YN

REAL LDKHH,LDKH,NTKWH,NTKW,MTRHT

COMMON/INTIO/XC,YC,NPOINT

COMMON/INTPT/X,Y,Z

COMMON/MISMT/HUB,VV,TP,NTESTC

COMMON/MSOUT / AVEWT, TOTHT, AVELOAD, T JTLOAD, AVEKWH, TOTKWH

COMMON/MOUT/WTKHH, LOKWH,NTKWH

NFLAG $=0$

WRITE $(6,83)$

Selecting the type of table desired

83 FORMATC/" $/$ SELECT THE FOLLOWING OPTIONS FOR"/

+ "DETERMINING THE hIND SPEED DISTRIBUTION "/

+ "1- FOR ENTERING A NEW OISTRIBUTION BY THE USER"I

+ "2- FOR USING THE EXISTING DISTRIBUTION" $)$

+ "3- FOR USING A STANDARDIZED DISTRIBUTION"/)

ACCEPT SELECTW

IF (SELECTW-2.0)145,90,200 
* Option for using the existing distribution

- i.e. WINDDI

- Reading in HINDDI

$\star$

90 READ(3.95) MTRHT,WNDAVE

95 FORMAT $(16 X, F 6.1,23 X, F 6.1)$

DO $100 \mathrm{~J}=1.25$

110 FORMAT (SF10.2)

100 CONTINUE

FACT $=($ HUS/MTRHT $) * *(1.0 / 7.0)$

JO $117 \quad I=1.4$

DO $115 \mathrm{~J}=1,25$

115 CONTINUE

117 CONTINUE

WRITE $(6,120)$

120 FORMATC" "THE FOLLOWING IS THE 4 SEASONS DIURNAL WIND SPEED"1X, + "DISTRISUTION TABLE"//5X"JAYHR",6X"WINDSPEED IN MPH"/15X"SPRING"

$+4 X "$ "SUYMER" 4 X"FALL" 4 X"NINTER" /)

JO $130 \mathrm{~J}=1.25$

WRITE $(5,140)$ DAYHR $(J), W N D S P(1, J), W N D S P(2, J), W N D S P(3, J), W N O S P(4, J)$

130 CONTINUE

140 FORMAT (5 (F10.3))

$\star$

- Option to change dINDJI. WCHANGE

$*$

a

or to input a wind sistribution from the CRT

WRIT $\equiv(6,153)$

150 FORMAT(/"DO YOU NISH TO CHANGE THE TABLE?")

IF (YN (IDUM). VE. O)GO TO 145

NFLAS $=1$

GO TO 205

145 CONTINUE

CALL WCHANSE (WNOSP)

200 WRITE $(3.21)$

205 HRITE(25,120)

210 FORMATR"THIS IS THE FIYAL OIURNAL WINOSPEED DISTRIBUTION"/1

+8 "JAYHR" $^{\circ}$ "WINDSPEED IN MPH"/21X"SPRING SUMMER FALL HINTER"/)

DO $220 \mathrm{~J}=1.25$

IF (NFLAG.52.1)GO TC 215

WRITE $(6,143)$ JAYHR (J),WNDSP $(1, J), W N O S P(2, J), W N D S P(3, J), W N D S P(4, J)$

215 HRITE $(25,1 \div 0) 0 A Y H R(J), W N D S \supset(1, J), W N D S P(2, J), W N D S P(3, J), W N D S P(4, J)$

220 WRITE

*

* Reading in and printing out the load distribution, LOAODI

-

WRITE $(6,303)$

WRITE $(25,330)$

300 FORMAT(//5X,"THE LOAD OISTRI3UTION TABLE"1/2X,"DAYHOUR"5X,"SPRING".

+ 5X,"SUMMER", SX, "FALL",5X,"WINTER"/1)

$00330 \mathrm{~J}=1.25$

READ $(15,310)$ DAYAR $(J), \operatorname{LDKW}(1, J), \operatorname{LDKK}(2, J), \operatorname{LDKH}(3, J), \operatorname{LDKW}(4, J)$

310 FORMAT $(5 F 13.2)$

WRITE $(6,313)$ DAYHR $(J), \operatorname{LDKW}(1, J), \operatorname{LDKW}(2, J), \operatorname{LOKH}(3, J), \operatorname{LDKW}(4, J)$

WRITE $(25,310)$ JAYHR(J),LDKH $(1, J), \operatorname{LOKW}(2, J), \operatorname{LOKH}(3, J), \operatorname{LOKW}(4, J)$

330 CONTINUE

*

* Intializing the match varlables 
TOTKUH=0.

TOTHT $=0$.

TOTLOAD $=0$.

DO $240 \quad I=1.4$

WTKHH (I) $=0$.

$\operatorname{LDKHH}(I)=0$.

NTKWH $(I)=0$.

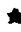

* Interpolating a power for each windspeed

$\star$

DO $230 \mathrm{~J}=1.25$

$X=$ HNDSP $(I, J)$

DO $225 K=1$, NTESTC

$X C(K)=V V(K)$

225 CONTINUE

CALL INTERPT

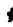

* Calculate the match variables

$\star$

$W T K H(I, J)=Y$

$W T K W H(I)=W T K W H(I)+W T K W(I, J)$

$\operatorname{LDKWH}(I)=\operatorname{LOKWH}(I)+\operatorname{LDKW}(I, J)$

$N T K W(I, J)=W T K W(I, J)-\operatorname{LOKW}(I, J)$

230 CONTINUE

TOTKWH = TOTKWH+NTKWH(I)

TOTHT = TOTWT + WT KWH (I)

240 CONTINUE

AVEKWH=TOTKWH/ 4 .

AVEWT = TOTWT $/ 4$.

AVELOAD $=$ TOTLOAD/4.

$\star$

* Printing of the match table

CALL MATOUT(2)

RETURN

END 
SUBROUTINE WCHANGE (OITEM)

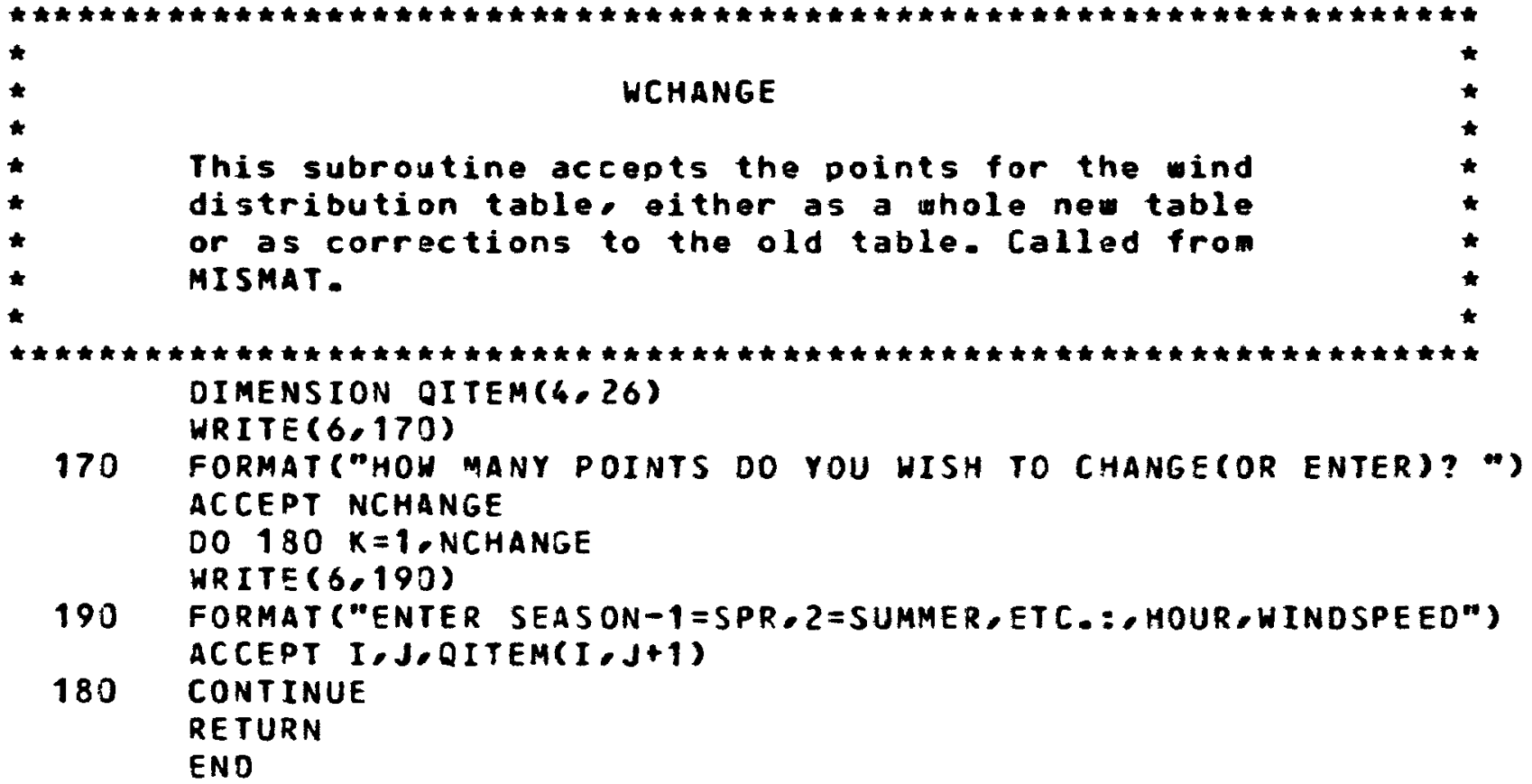




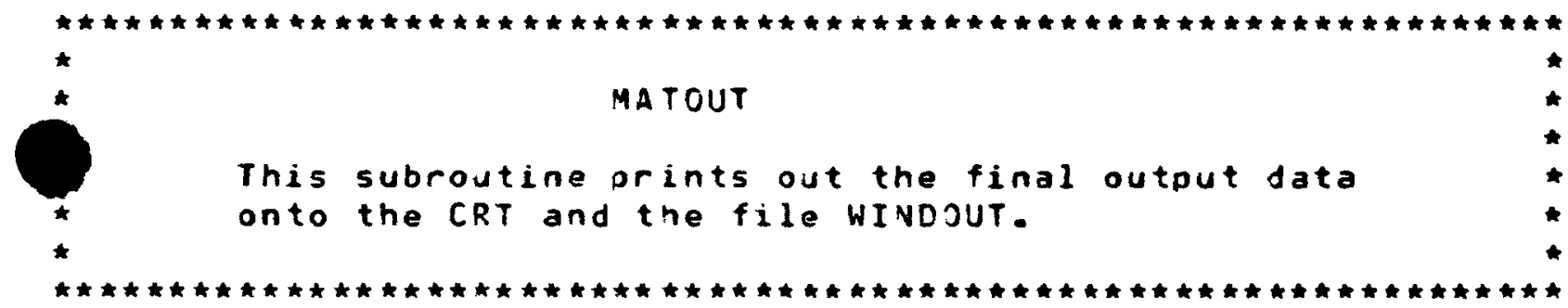

DIMENSION WTKWH(26), LDKWH(26), NTKHH(26)

COYMON/ENRGI/C,RK, VBAR,NOIST,NOEC

COMMON/MTO'JT /ENERG Y, VMAX , PMAX, VMAXE

COMMON/MSOUT / AVEWT, TOTWT , AVELOAD, TOTLOAD, AVEXWH, TOTKWH

COMMON / MOUT / WTKWH, LDKWH, NTKWH

REAL LDKWH,NTKHH

IF (I SNTRY.EQ.2)GO TO 80

IF (NDEC. EQ. 2) 50 TO 48

*

* Print out the quick summary of the energy table

$\star$

WRITEFREE (32) VRAR, ENERGY

WRITE $(6.47)$ VBAR,ENERGY

WRITE $(25,47)$ VBAR, ENERGY

47 FORMAT $(5 X, F 5.2,9 X, F 10.0)$

GO TO $50 J$

48 CONTINUE

$+$

* Print out the Weibull distribution paraneters

$+$

IF( NOIST. EQ. 2) GO TO 52

WRITE (S.51) RK, C, VBAR

WRITE $(25.51)$ RK, C, VSAR

GO TO 55

52 CONTINUE

* Print out of tha detailed report of the energy table

$+$

WRITE $(6.53)$ VBAR

WRITE $(25.53)$ VSAR

55 CONTINUE

WRITE $(5,56)$ ENERTY

WRITE $(25,56)$ ENERGY

WRITEFREE (32) VBAR, ENERGY

PBAR =ENERGY/3706.0

WRITE $(5,57)$ PEAR

WRITE $(25,57)$ PSAR

WRITE $(3,58)$ VMAX,PMAX, VMAXE
WRITE $(25,53)$ VMAX, PMAX, VMAXE

51 FORMAT ( 1 "WEIBULL DISTRIBUTION PARAMETERS: $K=" F 4.2$ " $\mathrm{C}=$ "F4.1/5X,

- "ANNUAL aVERAGE WIND 5PEED = "F5.2)

53 FORMATC//"NASA VELOCITY DISTRI3UTION"/5X,"MEAN SPEED = "

+ F5.2)

56 FORMAT $\left(18 \times\right.$. ANNUAL ENERGY YIELD $\left.={ }^{\circ} F 10.0,0 \mathrm{KWH}{ }^{\circ}\right)$

57 FORMAT ( $8 \times$, "ANNUAL AVERAGE POUER OUTPUT = "F10.?, $\mathrm{KW}$ ")

58 FORMAT (/5X,"MOST PROBABLE WINO SPEED = "F5.1.

+ $15 X$, "MOST PROBARLE PONER OUTPUT = "F6.2,

$+15 X, "$ "WIND SPEED FOR MAXIMUM ENERGY DENSITY = "F5.1) FORMAT (F10.2)

GO TO 500 


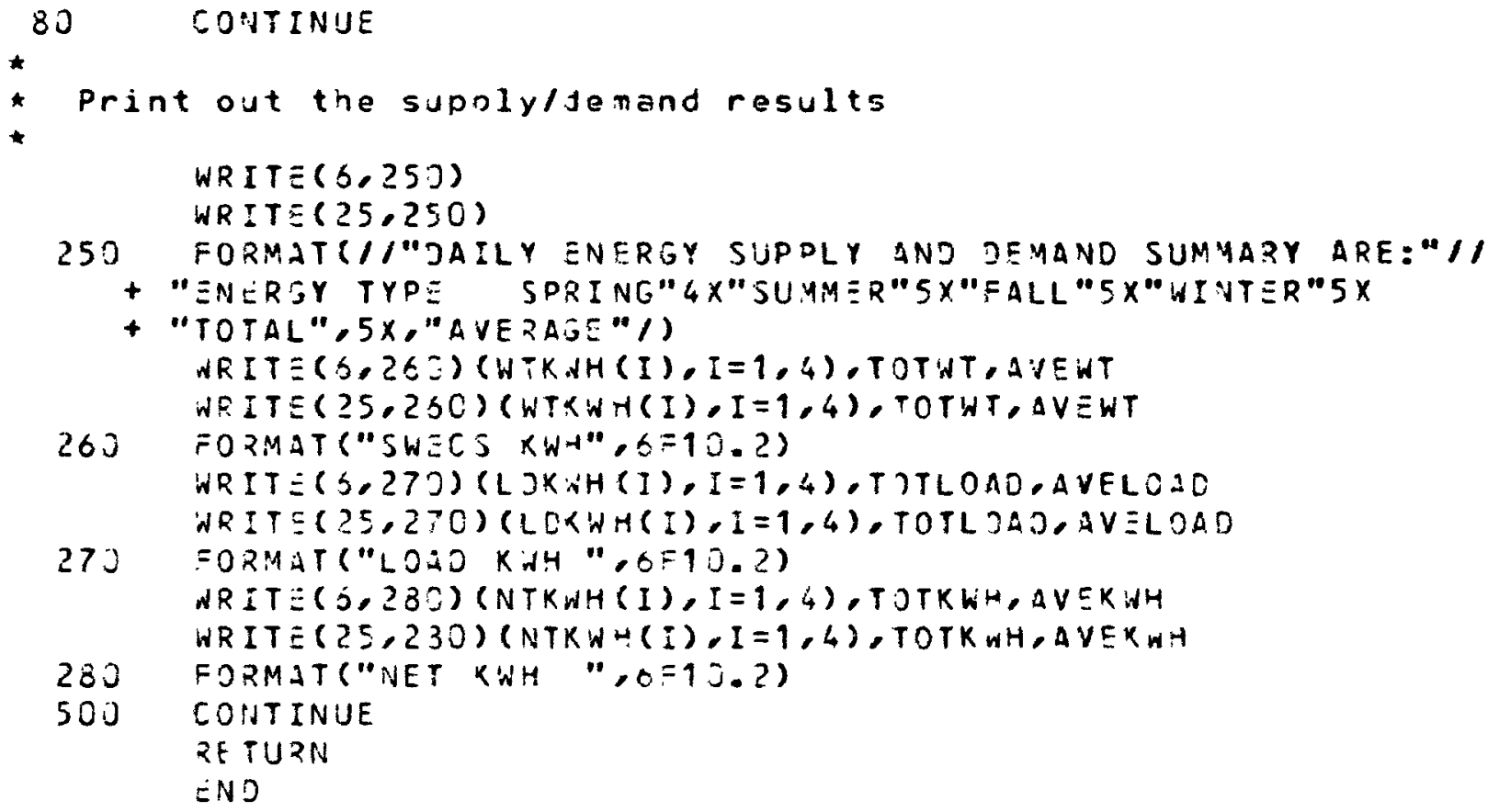

\U.S. GOVERNMENT PRINTING OFFICE: 1983-679-553/310 